\title{
Analysis of Mouse Growth Plate Development
}

\author{
Laura Mangiavini, ${ }^{1}$ Christophe Merceron, ${ }^{1,2,3}$ and Ernestina Schipani ${ }^{1}$ \\ ${ }^{1}$ Department of Orthopaedic Surgery, Department of Medicine, Division of Endocrinology \\ and Department of Cell and Developmental Biology, University of Michigan Medical \\ School, Ann Arbor, Michigan \\ ${ }^{2}$ Inserm, UMRS 791-LIOAD, Centre for Osteoarticular and Dental Tissue Engineering, \\ Group STEP 'Skeletal Tissue Engineering and Physiopathology', Nantes, France \\ ${ }^{3}$ Faculty of Dental Surgery, LUNAM, Nantes University, Nantes, France
}

\begin{abstract}
To investigate skeletal development, pathophysiological mechanisms of cartilage and bone disease, and eventually assess innovative treatments, the mouse is a very important resource. During embryonic development, mesenchymal condensations are formed, and cells within these mesenchymal condensations either directly differentiate into osteoblasts and give origin to intramembranous bone, or differentiate into chondrocytes and form a cartilaginous anlage. The cartilaginous anlage or fetal growth plate is then replaced with bone. This process is also called endochondral bone development, and it is responsible for the generation of most of our skeleton. Here we discuss in detail the most common in vivo and in vitro techniques our laboratory is currently using for the analysis of the mouse fetal growth plate during development. @ 2016 by John Wiley \& Sons, Inc.
\end{abstract}

Keywords: endochondral bone development $\bullet$ cartilage $\bullet$ mouse $\bullet$ cell culture - staining

\begin{tabular}{c} 
How to cite this article: \\
Mangiavini, L., Merceron, C., and Schipani, E. 2016. Analysis of \\
mouse growth plate development. Curr. Protoc. Mouse Biol. \\
6:67-130. \\
doi: $10.1002 / 9780470942390 . \operatorname{mo} 150094$ \\
\hline
\end{tabular}

\section{INTRODUCTION}

To investigate skeletal development, pathophysiological mechanisms of cartilage and bone disease, and eventually assess innovative treatments, animal models are an essential resource. Mouse is the most widely used animal model to study skeletal development for several reasons. Mouse models share many developmental and physiological features with humans (Mouse Genome Sequencing, 2002; Nguyen and $\mathrm{Xu}, 2008$; Piret and Thakker, 2011; Karsenty and Ferron, 2012). In addition, its relatively small size coupled with its reproductive abilities makes it an ideal species to study development. Lastly, mice can be genetically manipulated. During recent decades, analysis of genetically modified mice has led to numerous and major breakthroughs in the understanding of the genetic, cellular, and molecular mechanisms of cartilage and bone development and homeostasis.

Development of bone is a finely orchestrated process both spatially and temporally, requiring careful coordination of multiple steps, which are controlled by a variety of molecular mechanisms and signaling pathways. Bones are formed mainly through two distinct processes. During embryonic development, mesenchymal condensations are formed, and cells within these mesenchymal condensations either directly differentiate into 


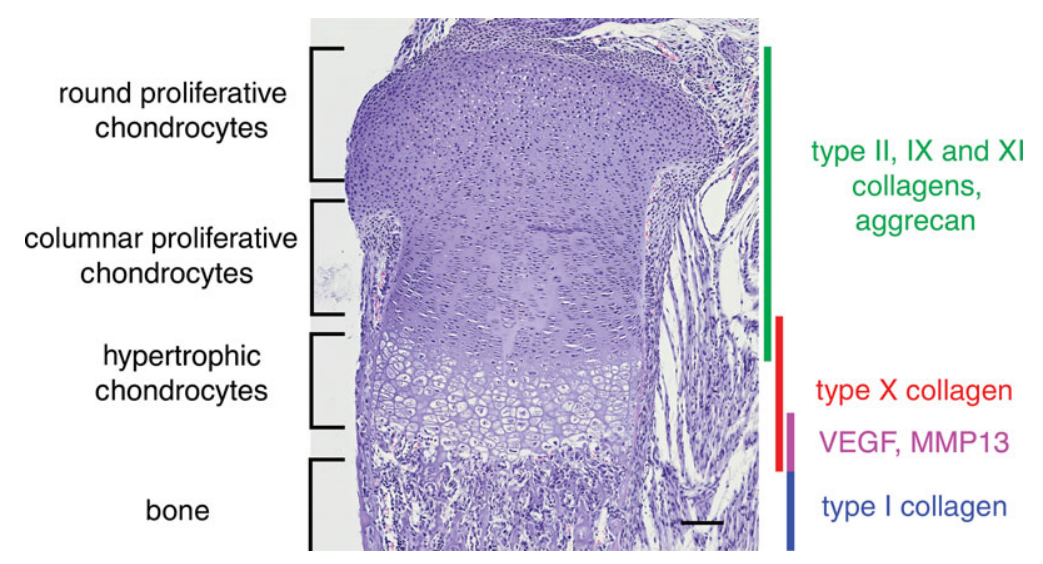

Figure 1 Cartilage growth plate histology of a newborn mouse after H\&E staining (bar $=100 \mu \mathrm{m})$.

osteoblasts and give origin to intramembranous bone, which forms the flat bones of the skull, or differentiate into chondrocytes and generate a cartilaginous anlage. The cartilaginous anlage or fetal growth plate is then replaced with bone. This process is also called endochondral bone development, and is responsible for the generation of most of the human skeleton (Karsenty, 2003; Kronenberg, 2003; Zelzer and Olsen, 2003; Michigami, 2013). Within the cartilaginous template, chondrocytes proliferate and produce a matrix enriched in type II, IX and XI collagens and in specific proteoglycans, mainly aggrecan (Aigner and Stove, 2003; Heinegard, 2009). Chondrocytes eventually form a columnar structure before exiting the cell cycle. They next undergo hypertrophy and start producing a matrix enriched in type $\mathrm{X}$ collagen. Terminally differentiated hypertrophic chondrocytes either die or transdifferentiate into cells of the osteoblastic lineage. Hypertrophic chondrocytes also express markers such as matrix metalloproteinase 13 (MMP-13) and vascular endothelial growth factor (VEGF) (Zelzer et al., 2004; Maes et al., 2012b) that are critically important to promote degradation of the cartilaginous matrix and its invasion by blood vessels, and thus pave the way to the replacement of the cartilaginous anlage with bone. Histological description of the cartilage growth plate is shown in Figure 1.

Presented here are the most common in vivo and in vitro techniques our laboratory is currently using to analyze the fetal growth plate during development. Basic Protocol 1 describes how to generate paraffin-embedded tissue sections; Support Protocol 1 provides details on how to properly orient samples in paraffin blocks. Basic Protocol 2 illustrates how to generate freshly frozen sections. Alternate Protocol 1 describes the preparation of frozen sections from formalin-fixed specimens. Basic Protocol 3 discusses the Alizarin Red/Alcian Blue whole-mount staining, which allows the evaluation of the shape and size of the skeleton. Basic Protocols 4 to 10 describe the most common stainings we routinely perform on paraffin-embedded tissue sections. In particular, Basic Protocols 4 and 5 describe H\&E and Safranin O stainings, which allow morphological examination of the growth plate and analysis of glycosaminoglycans (GAGs) accumulation, respectively. Basic Protocol 6 discusses in situ hybridization, a powerful technique for the identification of specific mRNA species within individual cells in tissue sections. Basic Protocol 7 describes how to perform in situ cell death detection (TUNEL assay), an established method that detects DNA fragments and thus cell death. Basic Protocol 8 gives a brief overview of a standard immunohistochemistry technique, which allows for the detection of antigens in tissue sections. Basic Protocol 9 provides a description of BrdU proliferation assay, which allows cell proliferation evaluation by directly measuring DNA synthesis through an antibody-based detection of the nucleoside analog 
bromo-deoxyuridine (BrdU); Support Protocol 2 provides details on how to detect BrdU with a fluorescent dye. Alternate Protocol 2 illustrates the EdU proliferation assay, which represents a quicker and easier alternative to BrdU staining. PCNA staining, a third procedure to estimate cell proliferation, is presented in Basic Protocol 10, and Support Protocol 3 provides details on how to detect PCNA with a fluorescent dye. Basic Protocol 11 provides a description of EF5 staining, which detects levels of hypoxia in the growth plate by immunofluorescence. Basic Protocol 12 and Alternate Protocol 3 detail a simple and standardized method to quantify signals on histological sections. Lastly, Basic Protocol 13 and Support Protocol 4 give a brief overview on chondrocyte isolation and adenovirus transduction for in vitro studies.

NOTE: All protocols using live animals must first be reviewed and approved by an Institutional Animal Care and Use Committee (IACUC) or must conform to governmental regulations regarding the care and use of laboratory animals.

\section{MOUSE EMBRYO HARVESTING FOR PARAFFIN SECTIONS}

The analysis of endochondral bone development can start as early as E11.5 when formation of mesenchymal condensation occurs. This protocol describes how to isolate, fix, dissect and process tissues from mouse embryos. In addition, provided here are the essential steps to obtain paraffin-embedded tissue sections of fetal growth plates. Paraffin sections are suitable for a variety of stainings, such as in situ hybridization analysis, immunohistochemistry with selected antibodies, BrdU and EdU labeling and TUNEL assay.

\section{Materials}

Pregnant female mouse

Isoflurane or $\mathrm{CO}_{2}$ chamber

Ice

Phosphate-buffered saline (PBS), $1 \times$, sterile (see recipe)

$70 \%$ (v/v) ethanol (EtOH; see recipe)

$4 \%$ paraformaldehyde (PFA; see recipe)

$80 \%(\mathrm{v} / \mathrm{v}) \mathrm{EtOH}$ (see recipe)

$95 \%(\mathrm{v} / \mathrm{v}) \mathrm{EtOH}$ (see recipe)

$100 \%(\mathrm{v} / \mathrm{v}) \mathrm{EtOH}$

Xylene

Paraffin (Fisherbrand Paraplast X-Tra Tissue Embedding Medium; Fisher

Scientific, cat. no. 23-021-401)

Surgical instruments including:

Sterile scalpels

Scissors

Forceps

Microdissecting forceps and scissors

100-mm petri dishes

25-ml glass scintillation vials

Stereomicroscope

Microsette biopsy cassettes

Automated processor

Embedding station

Molds (plastic or metallic)

Microtome

Paraffin blocks

Disposable low profile blades

BASIC

PROTOCOL 1
Mouse Growth

Plate Development 
Flat ice block

Paintbrush

Water bath

Superfrost Plus slides

Paper towels

Slide boxes

Magnifying glass

Plastic or glass containers

\section{Isolate embryos}

1. Sacrifice the pregnant female mouse with isoflurane or $\mathrm{CO}_{2}$.

2. Immediately after sacrifice, pinch the abdominal skin and make a longitudinal incision $(1 \mathrm{~cm})$ with surgical scissors. Pull the skin apart to expose the abdominal cavity.

3. Using scissors, carefully cut the peritoneum and move the intestine to better locate the uterus.

4. Remove the uterus.

5. Immediately place the uterus on ice.

6. Prepare the stereo microscope and place a $100-\mathrm{mm}$ petri dish with $10 \mathrm{ml} 1 \times$ sterile PBS on the stage.

7. Quickly rinse the uterus with $10 \mathrm{ml}$ sterile $1 \times$ PBS.

8. Peel the soft tissue with sterile forceps and quickly remove each embryo from its amniotic sac.

9. Place the embryos in $10 \mathrm{ml} 1 \times$ sterile PBS.

10. Rinse each embryo three times, each time with $10 \mathrm{ml}$ sterile $1 \times$ PBS in clean petri dishes.

11. Fill a glass or plastic container with $20 \mathrm{ml} 70 \% \mathrm{EtOH}$ and clean the instruments with $70 \%$ EtOH between different embryos.

\section{Fixation}

After isolation, the embryos need to be fixed in $4 \%$ paraformaldehyde (PFA) at $4^{\circ} \mathrm{C}$. This cross-linked fixative provides good accessibility and retention of mRNAs.

12. Fill $25-\mathrm{ml}$ glass scintillation vials with 20 to $25 \mathrm{ml}$ of $4 \%$ PFA.

13. Rinse each embryo with $5 \mathrm{ml} 1 \times$ PBS in a clean petri dish.

14. Open the embryo's abdomen with scissors to facilitate rapid fixation, taking care not to nick the organs or ribs.

15. Place each embryo in a $25-\mathrm{ml}$ glass scintillation vial.

16. Store the vials for $48 \mathrm{hr}$ at $4^{\circ} \mathrm{C}$.

17. Replace $4 \%$ PFA with fresh $4 \%$ PFA after $24 \mathrm{hr}$ and store the vials at $4{ }^{\circ} \mathrm{C}$.

18. Replace 4\% PFA with 20 to $25 \mathrm{ml} 70 \% \mathrm{EtOH}$ the following day.

19. Store the specimens at $4^{\circ} \mathrm{C}$ until dissection. 


\section{Dissection}

Mouse embryos can be dissected before or after fixation. However, fixation preserves tissues and gives the investigator time to properly dissect the specimens.

20. Place a clean $100-\mathrm{mm}$ petri dish with a small amount $(5 \mathrm{ml})$ of $1 \times \mathrm{PBS}$ on the stage of the stereomicroscope.

21. Remove the embryo from the glass scintillation vial and place it in the petri dish.

22. Select the forelimb or hindlimb to dissect and carefully remove it by cutting the proximal end with microdissecting scissors.

23. Peel off the thin skin layer from the limb with microdissecting forceps.

24. Carefully remove the soft tissues surrounding bone and cartilage with the forceps without smashing the growth plate or the bone.

25. Place the dissected specimen in a microsette biopsy cassette and store it in $25 \mathrm{ml}$ of $70 \% \mathrm{EtOH}$ at $4^{\circ} \mathrm{C}$ until processing.

For optimal results, processing should be performed within 1 to 2 weeks.

\section{Processing}

Processing includes the stepwise dehydration of the samples with increasing concentrations of ethanol, followed by clearing with xylene and impregnation with paraffin. Because melted paraffin wax is hydrophobic, most of the water in a specimen must be removed before it can be infiltrated with wax. This process is commonly carried out by immersing specimens in a series of ethanol solutions of increasing concentration until pure, water-free alcohol is reached. A series of increasing concentrations is used to avoid excessive distortion of the tissue. Xylene is then used to "clear" the tissue and to allow wax infiltration. Xylene is miscible both with ethanol and wax, and therefore represents an ideal intermediate solvent. After treatment with xylene, the tissue can then be infiltrated with paraffin wax. The appropriate temperature for the paraffin wax depends on the formulation used. We typically use paraffin with "low" melting temperature, below $60^{\circ} \mathrm{C}$, because it better preserves epitope and mRNA integrity for immunohistochemistry and in situ hybridization, respectively.

\section{Using an automated processor}

26. Place the cassettes in the processor.

27. Add $70 \%$ EtOH $1 \mathrm{hr}$.

28. Add $80 \%$ EtOH $1 \mathrm{hr}$.

29. Add 95\% EtOH $1 \mathrm{hr}$.

30. Add 95\% EtOH $1 \mathrm{hr}$.

31. Add $100 \%$ EtOH 1 hr.

32. Add $100 \% \mathrm{EtOH} 1 \mathrm{hr}$.

33. Add xylene $1 \mathrm{hr}$.

34. Add xylene $1 \mathrm{hr}$.

The amount of EtOH and xylene depend on the type of automated processor used.

35. Add paraffin wax at $58^{\circ} \mathrm{C}$ under vacuum $1 \mathrm{hr}$.

36. Add paraffin wax at $58^{\circ} \mathrm{C}$ under vacuum $1 \mathrm{hr}$. 
37. Add paraffin wax at $58^{\circ} \mathrm{C}$ under vacuum $1 \mathrm{hr}$.

All these steps (26 to 37) are performed in the automated processor. Thus, the amount of ethanol, xylene and paraffin wax may vary based on the machine used.

\section{Embedding}

After processing, the specimen needs to be inserted into a paraffin "block" that can be clamped onto a microtome for section cutting. The proper orientation of the specimen is the critical step during embedding.

38. Place cassettes in the paraffin reservoir of the embedding station to equilibrate specimen to optimal embedding temperature ( $\sim 20 \mathrm{~min})$.

39. Fill the mold with paraffin.

40. Using a magnifying glass, orient specimen in the mold (see Support Protocol 1).

41. Hold the specimen in place with forceps, carefully move the mold over the cold plate.

42. Hold the specimen in place until the bottom part of the paraffin hardens.

43. Place bottom of the cassette on top of the mold, and add some wax on the top.

44. Leave the block on cold plate ( $\sim 20 \mathrm{~min})$ to completely harden.

45. Remove the block from the mold and remove the excess wax around the cassette with a scalpel.

\section{Sectioning}

46. Orient the blade on the microtome (angle $\sim 5^{\circ}$ ).

47. Set the microtome to $5 \mu \mathrm{m}$ of thickness.

48. Cool the paraffin block face down on the ice block.

Frequently cool the block on ice during sectioning (up to 15 to $20 \mathrm{~min}$ ).

49. Place cooled block in microtome chuck.

50. Orient the block for optimal cutting.

Orient the block in the microtome chuck to have the proximal and the distal growth plates at the same level (parallel section).

Always place block back in the chuck in the same direction.

51. Gently pull paraffin ribbon from cutting surface.

52. Gently detach ribbon from cutting surface with a fine paintbrush.

53. Float cut ribbon on water bath at $50^{\circ}$ to $55^{\circ} \mathrm{C}$.

54. Using positively charged $(+)$ slides, pick up sections by gently placing the slides underneath the sections.

55. Remove the excess of water by gently tapping the slides onto some paper towels.

56. Place the slides into the slide box.

57. Store the slides up to 1 year at $4^{\circ} \mathrm{C}$ until use. 
Specimen orientation, as described below, has been specifically designed to obtain complete and comparable longitudinal sections of the limbs. Physiological curvature of bony parts may interfere with the cutting and may lead to misinterpretation of the growth plate analysis.

\section{Forelimb}

Embed forelimbs, dorsal side down, and pads facing up.

\section{Right forelimb}

Orient the scapula (or the humerus) to point to the right and the distal end of the radius and ulna to the left of the mold.

\section{Left forelimb}

Orient the scapula (or the humerus) to point to the left and the distal end of the radius and ulna to the right of the mold.

\section{Hindlimb}

Embed hindlimbs with the inner thigh downwards.

\section{Right hindlimb}

Orient the femur to point to the right and the paw to the left of the mold.

\section{Left hindlimb}

Orient the femur to point to the left and the paw to the right of the mold.

\section{Spine}

Embed spine with the dorsal side facing down.

\section{MOUSE EMBRYO HARVESTING FOR FRESHLY FROZEN SECTIONS}

Frozen sections of OCT- (Optimal Cutting Temperature) embedded specimens have inherent disadvantages compared to their paraffin counterparts, such as poor morphology and poor resolution at higher magnifications. They are also technically more difficult to cut. Still, the use of frozen sections remains essential for the demonstration of many antigens by immunohistochemistry, for more sensitive detection of poorly expressed mRNAs by in situ hybridization analysis, and for detection of temperature-sensitive enzymatic activities such as alkaline phosphatase. This protocol describes all the necessary steps to obtain good quality freshly frozen sections.

\section{Additional Materials (also see Basic Protocol 1)}

OCT Compound (Fisher Healthcare Tissue-Plus; Fisher Scientific, cat. no. 4585)

Flat block of dry ice

Sample holder
Forceps
Cryostat
High profile blade
$-80^{\circ} \mathrm{C}$ freezer


Paintbrush

Superfrost Plus slides

Slide box

\section{Isolation and dissection}

1. Isolate embryos as described in Basic Protocol 1 (see steps 1 to 11).

2. Dissect embryos immediately after isolation to obtain freshly frozen sections. Proceed as described in Basic Protocol 1 (see steps 20 to 24). Immediately proceed with tissue embedding after dissection to obtain freshly frozen sections.

\section{Embedding}

3. Label the base mold and partially fill the mold with OCT.

4. Place the dissected tissue in the prelabeled base molds.

5. Flatten the tissue at the bottom of the mold with forceps.

6. Let the specimen equilibrate in the liquid OCT for 1 to $2 \mathrm{~min}$ at room temperature.

7. Put the mold on a flat block of dry ice.

Isopentane chilled with dry ice can also be used to freeze the OCT block.

8. Hold the tissue with forceps until the OCT on the bottom part of the mold solidifies.

9. Store the frozen block at $-80^{\circ} \mathrm{C}$ until use.

Immediately store the frozen block at $-80^{\circ} \mathrm{C}$. Frozen blocks can be stored up to 1 year at $-80^{\circ} \mathrm{C}$.

\section{Sectioning}

10. Equilibrate the frozen blocks in the cryostat for $15 \mathrm{~min}$ at $-20^{\circ} \mathrm{C}$.

11. Orient the blade on the cryostat (angle $\sim 30^{\circ}$ ).

12. Select $10 \mu \mathrm{m}$ as thickness.

13. Apply approximately $0.5 \mathrm{ml}$ of OCT on the back of the frozen block.

14. Attach the cooled block to a sample holder.

15. Place the sample holder in the cryostat chuck.

16. Orient the block for optimal cutting.

Orient the specimen in the plastic mold as described in Support Protocol 1.

Orient the block in the cryostat chuck so the proximal and the distal growth plates are at the same level.

17. Using a paintbrush, pick up one or two sections per slide.

18. Collect the slides in a slide box.

19. Store the slide box at $-80^{\circ} \mathrm{C}$ for long-term storage or $-20^{\circ} \mathrm{C}$ for short-term storage.

Frozen slides can be stored up to 1 to 2 weeks at $-20^{\circ} \mathrm{C}$ and up to 6 months at $-80^{\circ} \mathrm{C}$.

ALTERNATE PROTOCOL 1

Mouse Growth Plate Development

\section{MOUSE EMBRYOS HARVESTING FOR FIXED FROZEN SECTIONS}

Formalin-fixed specimens can be also used to generate frozen sections. In this case the morphology of the tissue is better maintained than in the freshly frozen tissue. 
$30 \%$ sucrose/PBS (see recipe)

$1 \times$ phosphate-buffered saline (PBS; see recipe)

Glass or plastic container

Rocking platform

\section{Isolation, fixation, and dissection}

1. Follow the first three sections as described in Basic Protocol 1 (steps 1 to 25).

\section{Embedding}

2. Soak the fixed tissues in $50 \mathrm{ml} 30 \%$ sucrose/PBS on a rocking platform in a glass or plastic container overnight at $4^{\circ} \mathrm{C}$.

The indicated amount of 30\% sucrose/PBS is sufficient for 3 samples of fixed tissues.

3. Quickly rinse the sample in $50 \mathrm{ml} \mathrm{1 \times PBS}$.

The indicated amount of $1 \times P B S$ is sufficient for 3 samples of fixed tissues.

4. Proceed as described in Basic Protocol 2 (steps 3 to 9).

\section{Sectioning}

5. Follow steps 10 to 19 of Basic Protocol 2.

\section{ALIZARIN RED/ALCIAN BLUE WHOLE-MOUNT STAINING}

Whole-mount skeletal staining permits the evaluation of the shape and size of the skeleton. Alizarin Red/Alcian Blue staining distinguishes bone, which contains calcium, and cartilage, which is enriched in glycosaminoglycans (GAGs) (McLeod, 1980). GAGs or mucopolysaccharides are homo- or heteropolymers consisting of a repeating disaccharide unit, which in turn consists of an amino sugar [ $\mathrm{N}$-acetylglucosamine or $\mathrm{N}$ acetylgalactosamine and a uronic sugar (glucuronic acid or iduronic acid) or galactose (Esko et al., 2009)]. GAGs are negatively charged and therefore attract water. Alizarin Red is an anionic dye, it thus binds to calcium (Horobin, 2010); Alcian Blue on the other hand, is a cationic dye that strongly binds to the negatively charged GAGs (Schenk, 1981). This technique is thus widely used to analyze skeletal maturation and to detect defects in endochondral bone development, in mineralization and in skeletal patterning (Schipani et al., 2001; Pfander et al., 2004; Provot et al., 2007; Mangiavini et al., 2014). An example of Alizarin Red/Alcian Blue staining of a newborn mouse is shown in Figure 2.

\section{Materials}

Pregnant female mouse

$1 \times$ phosphate-buffered saline (PBS; see recipe)

$95 \% \mathrm{EtOH}$ (see recipe)

$100 \%$ acetone

Alizarin Red/Alcian Blue staining working solution (see recipe)

Distilled water

$1 \% \mathrm{KOH}$ working solution (see recipe)

$20 \%$ glycerol $/ 1 \% \mathrm{KOH}$ (see recipe)

$50 \%$ glycerol $/ 1 \% \mathrm{KOH}$ (see recipe)

$80 \%$ glycerol $/ 1 \% \mathrm{KOH}$ (see recipe)

$100 \%$ glycerol

100-mm petri dishes

Scissors and forceps 


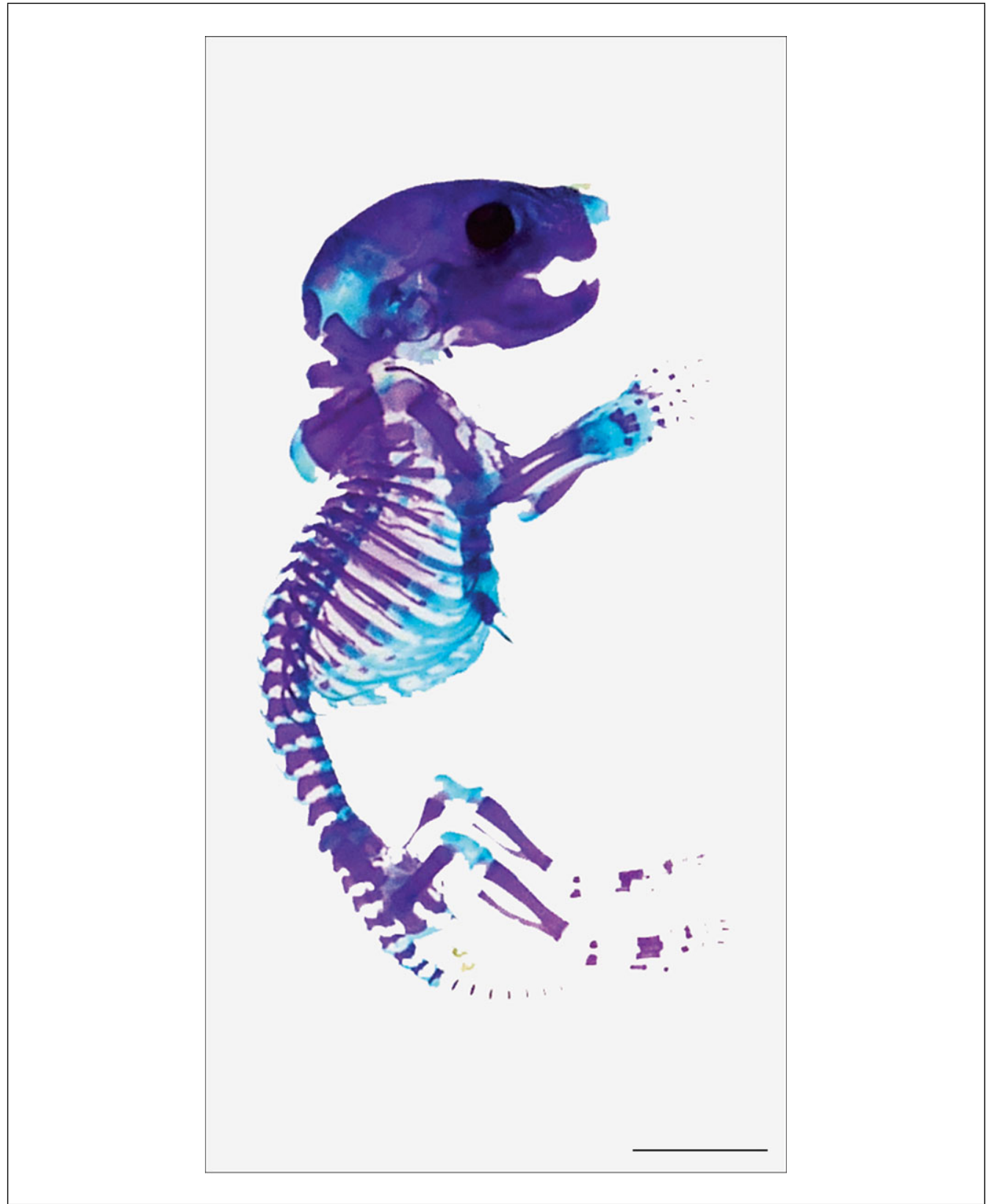

Figure 2 Whole mount Alizarin Red S/Alcian blue staining of newborn mouse (bar $=5 \mathrm{~mm}$ ).

25-ml glass scintillation vials

$37^{\circ} \mathrm{C}$ incubator

\section{Isolate embryos}

1. Sacrifice the pregnant female and isolate the embryos as described in Basic Protocol 1 (see steps 1 to 11).

2. Rinse each embryo with $5 \mathrm{ml} 1 \times \mathrm{PBS}$ in a clean 100 -mm petri dish.

3. Remove skin and viscera from the embryos with microdissecting forceps.

\section{Fixation}

Mouse Growth Plate Development

4. Place each embryo in a $25-\mathrm{ml}$ glass scintillation vial filled with $95 \%$ ethanol for 5 days at room temperature.

Incubation time in the solutions may vary based on the age of the specimens. 
5. Occasionally agitate the vials by hand.

6. Transfer the specimens in 20 to $25 \mathrm{ml}$ of $100 \%$ acetone for 2 days at room temperature to remove fat.

\section{Staining}

7. Place specimen in 20 to $25 \mathrm{ml}$ Alizarin Red/Alcian Blue staining working solution for up to 5 days at $37^{\circ} \mathrm{C}$ in the incubator.

8. Briefly wash specimen in 20 to $25 \mathrm{ml}$ distilled water $\left(\mathrm{dH}_{2} \mathrm{O}\right)$.

9. Clear the specimen in 20 to $25 \mathrm{ml} 1 \% \mathrm{KOH}$ working solution for at least 12 to $48 \mathrm{hr}$ at room temperature (up to 4 days).

Change 1\% $\mathrm{KOH}$ working solution every day.

10. Continue clearing the specimen through 20 to $25 \mathrm{ml}$ of $20 \%$ glycerol/1\% $\mathrm{KOH}$ for $\sim 5$ to 7 days.

Change $20 \%$ glycerol/1\% KOH every 2 days.

Incubation time in $20 \%$ glycerol/1\% KOH may vary based on the age of the specimen.

11. Continue clearing the specimen through 20 to $25 \mathrm{ml}$ of $50 \%$ glycerol/1\% $\mathrm{KOH}$ for $\sim 5$ to 7 days.

Before proceeding to $50 \%$ glycerol/1\% $\mathrm{KOH}$, status of the specimen can be assessed by transferring the specimen into a petri dish containing $20 \%$ glycerol/1\% $\mathrm{KOH}$ and quickly examining it under a stereomicroscope. However, prolonged exposure to this concentration of $\mathrm{KOH}$ in conjunction with the heat originating from the microscope bulb may cause disintegration of the specimen.

Change 50\% glycerol/1\% KOH every 2 days.

Incubation time in 50\% glycerol/1\% KOH may vary based on the age of the specimen.

12. Complete clearing of the specimen in 20 to $25 \mathrm{ml}$ of $80 \%$ glycerol $/ 1 \% \mathrm{KOH}$ for $\sim 1$ to 2 weeks.

Change $80 \%$ glycerol/1\% KOH every 4 days.

Incubation time in $80 \%$ glycerol/1\% KOH may vary based on the age of the specimen.

13. Store the specimen in $100 \%$ glycerol up to 8 weeks at $4^{\circ} \mathrm{C}$.

\section{HEMATOXYLIN AND EOSIN STAINING ON THE FETAL GROWTH PLATE}

Paraffin-embedded tissue sections are suitable for a variety of stains. A deparaffinization step and a rehydration step are necessary to remove the paraffin and to allow the stain to penetrate into the tissue. Hematoxylin and eosin $(\mathrm{H} \& \mathrm{E})$ is one of the basic stains in histology and is used to evaluate tissue morphology (Titford, 2005). Hematoxylin is a basic/positive stain and it binds to acidic and negatively charged substances such DNA and RNA. Hematoxylin generates a violet/blue nuclear staining. Eosin is acidic/negative stain and it binds to basic and positively charged substances such as proteins. Eosin generates a pink cytoplasmic staining. There are different kinds of hematoxylin, but Harris Hematoxylin is the most commonly used because its dark blue color provides a good contrast with the pink eosin (Levdik, 1989). H\&E stain is a valuable tool to evaluate the morphology of the developing growth plate (Schipani et al., 2001; Pfander et al., 2004; Provot and Schipani, 2007; Mangiavini et al., 2014). A representative image of $\mathrm{H} \& \mathrm{E}$ staining of a mouse forelimb is displayed in Figure 3.

BASIC PROTOCOL 4

Mouse Growth Plate Development 




Figure 3 H\&E staining of E15.5 mouse forelimb (bar $=100 \mu \mathrm{m})$.

\section{Materials}

5- $\mu$ m paraffin-embedded tissue sections on Superfrost Plus slides (see Basic Protocol 1)

Xylene in Coplin jars

$100 \%$ EtOH in Coplin jars

95\% EtOH in Coplin jars (see recipe)

$\mathrm{dH}_{2} \mathrm{O}$ in Coplin jars

Harris Hematoxylin in Coplin jars

Eosin Y in Coplin jars

Cold tap water

Xylene-based mounting medium

Slide warmer

Glass coverslips

Slide racks

Slide tray

\section{Slide preparation}

1. Dry paraffin-embedded tissue sections on the slide warmer at $60^{\circ} \mathrm{C}$ for at least 2 to $4 \mathrm{hr}$.

\section{Deparaffinization and rehydration}

2. Place the slides in a slide rack; deparaffinize, clear, and rehydrate the tissue sections in Coplin jars as follows:

- Xylene, 3 times for 2 min each.

- $100 \% \mathrm{EtOH}, 2$ times for 1 min each.

- $95 \% \mathrm{EtOH}, 1$ time for $1 \mathrm{~min}$.

- $\mathrm{dH}_{2} \mathrm{O}, 2$ times for 1 min each.

$H \& E$ staining can also be performed on frozen sections thereby avoiding the deparaffinization and dehydration steps. 


\section{Staining}

3. Stain slides with 200 to $250 \mathrm{ml}$ Harris Hematoxylin for $75 \mathrm{sec}$.

Xylene, 100\% EtOH, 95\% EtOH, Harris Hematoxylin, and Eosin Y solutions may be re-used for three to four $H \& E$ stains.

Harris Hematoxylin must be re-filtered before each use.

4. Gently rinse slides in cold tap water for 2 min.

Let the tap water run a few minutes in advance to cool it down.

The tap water flush must be gentle.

5. Incubate the slides twice, each time in 200 to $250 \mathrm{ml} \mathrm{dH_{2 }} \mathrm{O}$ for $1 \mathrm{~min}$ each at room temperature.

6. Incubate the slides in 200 to $250 \mathrm{ml} \mathrm{95 \%} \mathrm{EtOH}$ for $2 \mathrm{~min}$ at room temperature.

7. Stain the slides with 200 to $250 \mathrm{ml}$ Eosin $\mathrm{Y}$ for $15 \mathrm{sec}$ at room temperature.

8. Incubate the slides twice, each time in 200 to $250 \mathrm{ml} 95 \% \mathrm{EtOH}$ for $30 \mathrm{sec}$ each at room temperature.

9. Incubate the slides four times, each time in 200 to $250 \mathrm{ml} 100 \% \mathrm{EtOH}$ for $1 \mathrm{~min}$ each at room temperature.

10. Incubate the slides three times, each time in 200 to $250 \mathrm{ml}$ xylene for $2 \mathrm{~min}$ at room temperature.

Completely submerge the slides in the solutions.

\section{Coverslipping}

11. Coverslip with xylene-based mounting medium.

If bubbles form during coverslipping, gently press on the glass cover slip with forceps to remove them.

12. Dry the slides on a slide tray overnight at room temperature.

\section{SAFRANIN O STAINING TO EVALUATE GAGS IN MOUSE GROWTH PLATE}

GAGs represent an essential component of the chondrocyte matrix (see Basic Protocol 3) for details on GAGs structure). Safranin O is a red metachromatic cationic dye, which binds the negatively charged groups (polyanions) of the GAGs in a pH-dependent manner. Safranin O thus permits in vivo evaluation of the presence of GAGs in the growth plate (Mangiavini et al., 2014). Figure 4 illustrates an example of Safranin O staining in a mouse forelimb.

\section{Materials}

5- $\mu$ m paraffin-embedded tissue sections on Superfrost Plus slides (see Basic Protocol 1)

Xylene in Coplin jars

$100 \%$ ethanol in Coplin jars

95\% ethanol in Coplin jars (see recipe)

$\mathrm{dH}_{2} \mathrm{O}$ in Coplin jars

Weigert's Iron Hematoxylin working solution (see recipe)

$0.1 \%$ Fast Green solution (see recipe)

$1 \%$ acetic water (see recipe \#18)

$0.08 \%$ Safranin O solution (see recipe)

Xylene-based mounting medium 


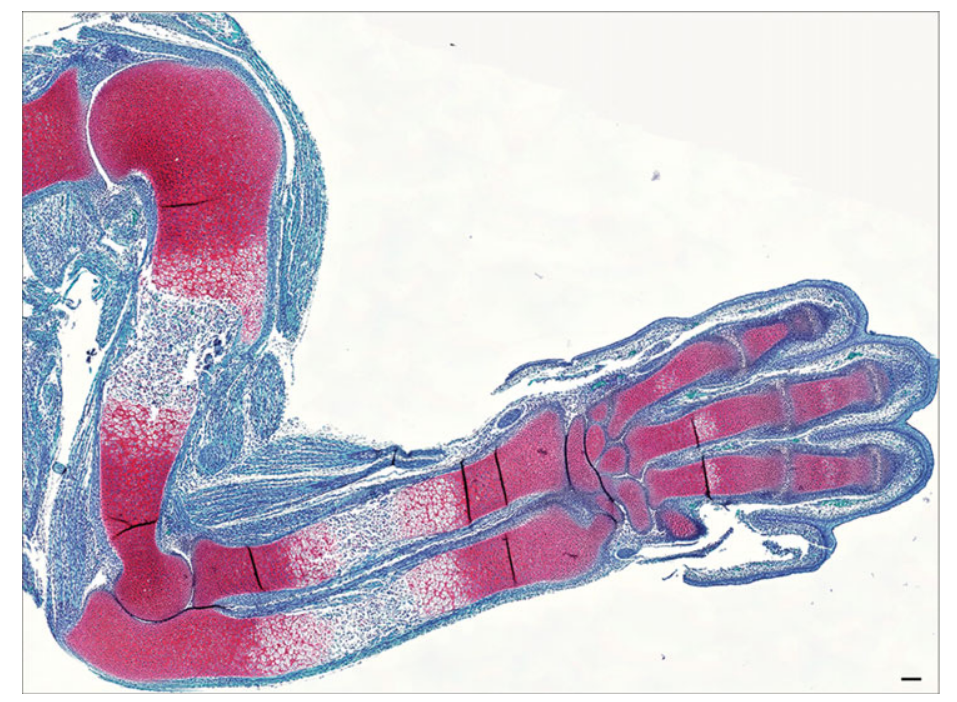

Figure 4 Safranin O staining of E15.5 mouse forelimb (bar $=100 \mu \mathrm{m})$. The accumulation of GAGs is shown in red.

Slide warmer

Wheaton glass staining dishes or Coplin jars

Transfer pipets

Paper filters

Glass coverslips

Slide racks

Slide tray

\section{Slide preparation}

1. Dry the paraffin-embedded tissue sections on the slide warmer overnight at $60^{\circ} \mathrm{C}$.

\section{Deparaffinization and rehydration}

2. Place the slides in a slide rack; deparaffinize, clear, and rehydrate the tissue sections in Coplin jars as follows:

- Xylene, 3 times for 2 min each.

- $100 \% \mathrm{EtOH}, 2$ times for 1 min each.

- $95 \% \mathrm{EtOH}, 1$ time for $1 \mathrm{~min}$.

- $\mathrm{dH}_{2} \mathrm{O}, 2$ times for 1 min each.

Use fresh xylene and $\mathrm{EtOH}$.

\section{Staining}

3. Apply working Weigert's Iron Hematoxylin on each section with the transfer pipet $(\sim 1 \mathrm{ml}$ per slide) and incubate for $10 \mathrm{~min}$ at room temperature.

Filter the solutions immediately before use.

4. Rinse the sections in 200 to $250 \mathrm{ml} \mathrm{dH_{2 }} \mathrm{O}$ for $1 \mathrm{~min}$ at room temperature.

5. Wash the sections in cold tap water for $10 \mathrm{~min}$.

6. Rinse the slides in 200 to $250 \mathrm{ml} \mathrm{dH_{2 }} \mathrm{O}$ for $1 \mathrm{~min}$ at room temperature.

7. Incubate the sections in 200 to $250 \mathrm{ml} 0.1 \%$ Fast Green working solution for $10 \mathrm{~min}$ at room temperature.

Filter the solutions immediately before use. 
8. Rinse the slides in 200 to $250 \mathrm{ml} 1 \%$ acetic water for 10 to $15 \mathrm{sec}$.

9. Incubate the sections in 200 to $250 \mathrm{ml} 0.08 \%$ Safranin O working solution for $5 \mathrm{~min}$ at room temperature.

Filter the solutions immediately before use.

10. Dehydrate the slides as follows:

95\% EtOH, 2 times for 1 min each.

$100 \% \mathrm{EtOH}, 3$ times for $1 \mathrm{~min}$ each.

Xylene, 3 times for 2 min each.

\section{Coverslipping}

11. Coverslip with xylene-based mounting medium.

12. Dry the slides on a slide tray overnight at room temperature.

\section{IN SITU HYBRIDIZATION: A METHOD TO DETECT mRNA IN VIVO}

In situ hybridization is a powerful technique for identifying specific mRNA species within individual cells in tissue sections (Wilkinson and Nieto, 1993). In this protocol, we describe a specific in situ hybridization technique in which the complementary RNA probes (riboprobes) are labeled with radioactive bases ( ${ }^{35}$ S-UTP). During in situ hybridization, the riboprobe hybridizes to the target sequence; next, the probe excess is washed away after prior hydrolysis using RNase A. Parameters such as temperature and salt detergent concentration can be manipulated to eliminate any nonspecific interaction (i.e., only exact sequence matches will remain bound). The bound probe is visualized using autoradiography and photographic emulsion (Schipani et al., 2001; Pfander et al., 2004; Provot et al., 2007; Mangiavini et al., 2014). Riboprobes can also be fluorescent- or antigen-labeled (digoxigenin or biotin) (Wilkinson, 1995). However, radioactive-in situ hybridization is very sensitive, and it allows detection of low abundance mRNAs. Representative pictures of in situ hybridization are shown in Figure 5.

In situ hybridization requires different steps:

- Labeling riboprobes

- Prehybridization treatment

- Hybridization

- Post-hybridization washing

- Dipping

- Developing and counterstaining

\section{Materials}

$5 \times$ transcription buffer (Promega, cat. no. P118B)

$100 \mathrm{mM}$ dithiothreitol (DTT; Promega, cat. no. P117B)

rATP (Promega, cat. no. P113B)

rCTP (Promega, cat. no. P114B)

rGTP (Promega, cat. no.P115B)

${ }^{35}$ S-UTP (Perkin Elmer, cat. no. NEG739H001MC)

RNase inhibitor (Promega, cat. no. N211A)

Linear DNA template of target gene

RNA polymerase (T3, T7 or Sp6; Fisher, cat. no. BP3206-1; Promega, cat. no. P207B- P108B)

Ice 
DNase I (Promega, cat. no. M610A)

0.5 M EDTA, pH 8.0

$5 \times$ NTE (see recipe)

DEPC-treated water

Scintillation fluid (e.g, Scintiverse)

4\% paraformaldehyde (PFA; see recipe)

RNase away

Xylene

$100 \% \mathrm{EtOH}$

95\% EtOH (see recipe)

$1 \times$ phosphate-buffered saline (PBS; see recipe)

$10 \mu \mathrm{g} / \mathrm{ml}$ proteinase $\mathrm{K}$ working solution (see recipe)

$0.2 \mathrm{~N}$ hydrochloric acid ( $\mathrm{HCl}$; see recipe)

$\mathrm{dH}_{2} \mathrm{O}$

$0.1 \mathrm{M}$ triethanolamine $/ 30 \mathrm{mM}$ acetic anhydride (TEA/AA), $\mathrm{pH} 7.5$ (see recipe)

$70 \% \mathrm{EtOH}$ (see recipe)

UltraPure formamide (Sigma, cat. no. 47671)

Hybridization solution (see recipe)

$1 \mathrm{M}$ dithiothreitol (DTT; see recipe)

$2 \times \operatorname{SSC}$ (see recipe)

$1 \times$ saline-sodium citrate (SSC; see recipe)

$4 \times \mathrm{SSC} /$ formamide (see recipe)

$20 \mathrm{mg} / \mathrm{ml} \mathrm{RNase}$ A (see recipe)

$70 \% \mathrm{EtOH} / 0.1 \times \mathrm{SSC}$ (see recipe)

$80 \% \mathrm{EtOH} / 0.1 \times \mathrm{SSC}$ (see recipe)

$95 \% \mathrm{EtOH} / 0.1 \times \mathrm{SSC}$ (see recipe)

Kodak Autoradiography Emulsion NTB 2 (VWR Scientific, cat. no. IB8895666)

$2 \%$ glycerol working solution (see recipe)

Silica Gel Tel-Tale (desiccant; Fisher Scientific, cat. no. S161)

Kodak developer solution (see recipe)

Kodak fixer solution (see recipe)

Harris Hematoxylin in Coplin jars

Tap water

$\mathrm{dH}_{2} \mathrm{O}$ in Coplin jars

95\% EtOH in Coplin jars (see recipe)

Eosin Y in Coplin jars

$100 \%$ EtOH in Coplin jars

Xylene in Coplin jars

Windex

Geiger counter

Water baths at $37^{\circ}, 52^{\circ}, 85^{\circ}$, and $45^{\circ} \mathrm{C}$

Vortex mixer

Probequant G-50 columns (GE, cat. no. 28-9034-08)

Benchtop centrifuge

RNase-free microcentrifuge tubes

25-ml glass scintillation vials

Liquid scintillation counter (LSC)

Slide warmer

600-ml Wheaton glass staining dishes (at least five to six)

Stainless steel slide racks

Humidified hybridization chamber

Mouse Growth

Absorbent underpads 
Whatman paper

Parafilm

Hybridization oven at $55^{\circ} \mathrm{C}$

Sterile-filtered tips

600-ml Wheaton glass staining dishes with lids (at least 10; use different dishes from the prehybridization treatment)

Microwave

Autoradiography cassettes

Clear tape

Kodak Biomax MR single emulsion films (Kodak, cat. no. 870 1302)

Darkroom

Blade

Opaque plastic bottles

Heavy-duty aluminum foil

1-liter glass beakers

Dip miser (Electron Microscopy Science, cat. no. 70520) - cleaned before use

Metal stand for the dip miser (Electron Microscopy Science)

35-mm petri dishes

Tape

Slides boxes (for 25 slides)

50-ml Falcon tubes

Paper towels

Slide draining rack

Glass coverslips

Kimwipes

Slide tray

Microscope with darkfield capacity

NOTE: Clean all work surfaces with RNase Away.

\section{Labeling riboprobes}

1. Prepare the riboprobe in RNase-free microcentrifuge tubes by combining the following items in the order shown:

$4 \mu 15 \times$ transcription buffer

$2 \mu \mathrm{l}$ of $100 \mathrm{mM}$ dithiothreitol (DTT)

$1 \mu \mathrm{rATP}$

$1 \mu 1 \mathrm{rCTP}$

$1 \mu 1 \mathrm{rGTP}$

$6 \mu \mathrm{l}^{35} \mathrm{~S}$-UTP

$1.5 \mu 1$ RNase inhibitor

$1.5 \mu \mathrm{l}(1 \mu \mathrm{g})$ linear DNA template of target gene

$2 \mu 1$ RNA polymerase (T3, T7, or Sp6)

Keep all the reagents on ice.

If more than one riboprobe is labeled, prepare a master mix of $5 \times$ transcription buffer, $100 \mathrm{mM}$ DTT, rATP, $r C T P$, and $r G T P$.

Survey all the work surfaces, the supplies and yourself with the Geiger counter during the procedure.

2. Incubate the tubes in the water bath for $1 \mathrm{hr}$ at $37^{\circ} \mathrm{C}$.

3. Remove the tubes from the water bath and add $1 \mu 1 \mathrm{RNA}$ polymerase (T3, T7, or Sp6). 


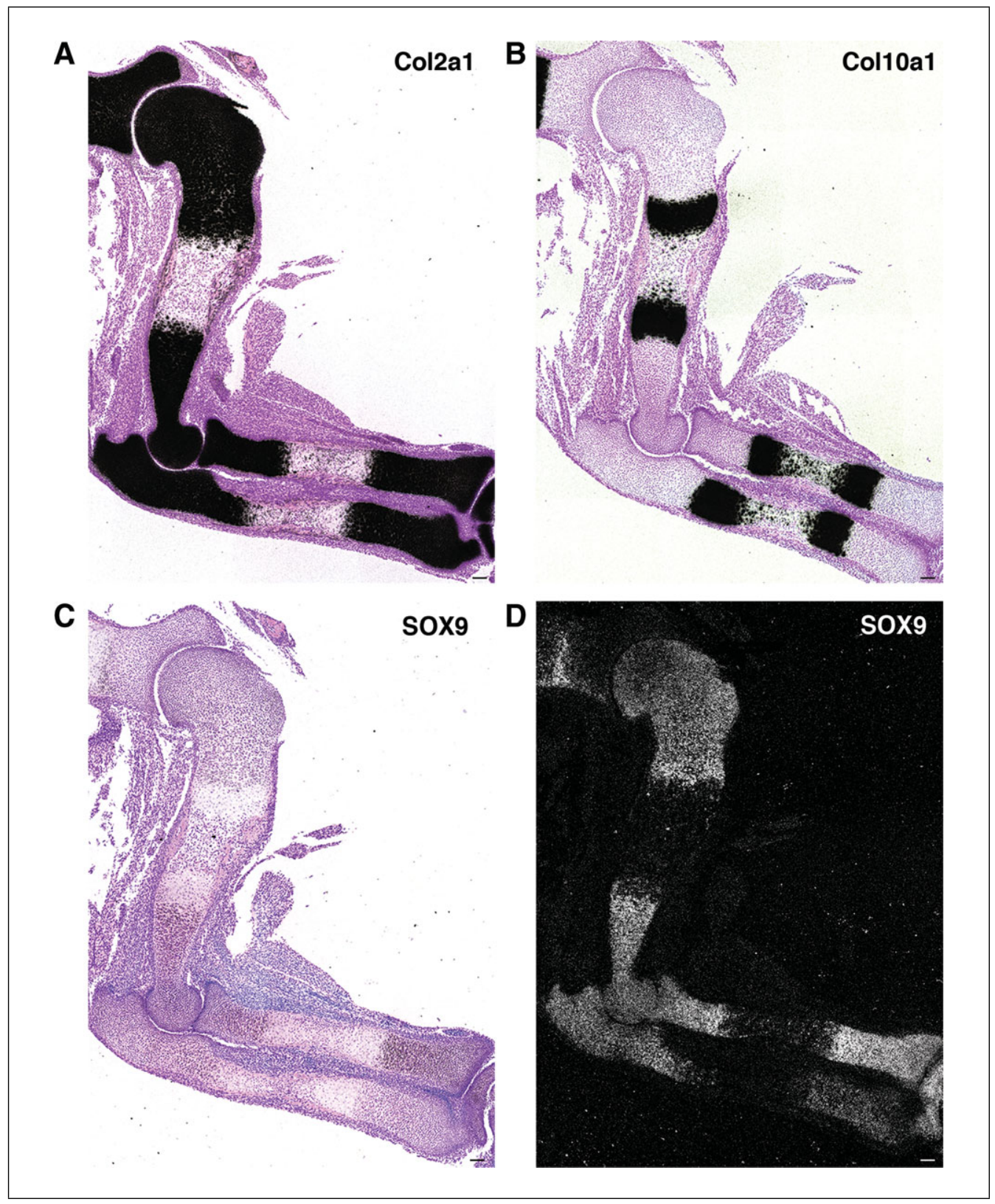

Figure 5 (A) In situ hybridization for detection of type II Collagen (Col2a1), (B) type X Collagen (Col10a1) and (C,D) SOX9) mRNAs in E15.5 mouse forelimbs. Bright-field images (black signal) are shown in (A-C). Darkfield image (silver/white signal) is shown in (D) (bar $=100 \mu \mathrm{m})$.

4. Incubate the tubes in the water bath for an additional $1 \mathrm{hr}$ at $37^{\circ} \mathrm{C}$.

5. Remove the tubes from the water bath and add $1 \mu l$ RNase inhibitor and $1 \mu l$ DNase I.

6. Incubate the tubes in the water bath for $15 \mathrm{~min}$ at $37^{\circ} \mathrm{C}$.

7. Prepare the following mix in a RNase-free microcentrifuge tube:

$$
\begin{aligned}
& 7 \mu 1 \text { of } 0.5 \mathrm{M} \text { EDTA } \\
& 14 \mu \mathrm{l} \text { of } 5 \times \text { NTE } \\
& 38 \mu \mathrm{l} \text { DEPC-treated water }
\end{aligned}
$$

8. Remove the tubes from the water bath (see step 6) and add the mix to the riboprobe. 


\section{Purify probes using mini Probequant G-50 columns}

9. Thoroughly vortex the Probequant G-50 column to fully suspend the Sephadex.

10. Remove the bottom from column and loosen the cap a quarter turn. Place it in the sterile $2-\mathrm{ml}$ collection tube provided by the kit.

11. Centrifuge for $1 \mathrm{~min}$ at $735 \times g$, at room temperature.

12. Discard the collection tube with the eluted buffer.

13. Place the columns in fresh, sterile, RNase-free labeled microcentrifuge tubes.

14. Apply the riboprobe to the middle of the column bed.

15. Centrifuge for $2 \mathrm{~min}$ at $735 \times g$, at room temperature.

\section{Quantify riboprobe activity using a LSC}

16. Fill 25-ml glass scintillation vials with $5 \mathrm{ml}$ scintillation fluid.

17. Place $1 \mu 1$ of the labeled-probe in each vial.

18. Using the LSC count for $1 \mathrm{~min}$.

19. Store riboprobes up to 2 weeks at $-20^{\circ} \mathrm{C}$.

For each labeled probe, the counts should be between 500,000 and 2 million counts per minute (CPM).

\section{Prehybridization treatment (first day) (for up to 50 slides)}

20. Dry the selected slides on the slide warmer overnight at $60^{\circ} \mathrm{C}$.

21. Prepare $600 \mathrm{ml} 4 \%$ PFA 1 to $2 \mathrm{hr}$ before starting the experiment.

22. Clean all the work surfaces and all the supplies with RNase Away and then rinse them 3 times with $500 \mathrm{ml} \mathrm{dH}_{2} \mathrm{O}$.

23. Deparaffinize, clear, and rehydrate the tissue sections as follows (use fresh xylene and ethanol):

Xylene, 3 times for 5 min each.

$100 \%$ ethanol, 2 times for 1 min each.

95\% ethanol, 1 time for $1 \mathrm{~min}$.

$1 \times$ PBS, 1 time for $1 \mathrm{~min}$.

24. Transfer the slides to a stainless steel slide rack in a Wheaton glass dish containing $600 \mathrm{ml} \mathrm{1 \times}$ PBS.

Avoid drying the sections during this step.

25. Wash the slides in $1 \times$ PBS for 5 min at room temperature.

26. Submerge the slides in 4\% PFA (prepared in step 21) for $15 \mathrm{~min}$ at room temperature. Do not discard the solution after use.

27. Wash the slides in $600 \mathrm{ml} 1 \times$ PBS for $5 \mathrm{~min}$ at room temperature.

28. Submerge the slides in $600 \mathrm{ml} 10 \mu \mathrm{g} / \mathrm{ml}$ proteinase $\mathrm{K}$ for $15 \mathrm{~min}$ at room temperature. Carefully shake the slide rack at each passage to properly mix the solutions.

29. Submerge the slides in $4 \%$ PFA for 10 min (re-use solution from step 26) at room temperature.

30. Wash the slides in $600 \mathrm{ml} 1 \times$ PBS for $5 \mathrm{~min}$ at room temperature.

Mouse Growth

Plate Development 
31. Submerge the slides in $600 \mathrm{ml} 0.2 \mathrm{~N} \mathrm{HCl}$ for $10 \mathrm{~min}$ at room temperature.

32. Wash the slides in $600 \mathrm{ml} 1 \times \mathrm{PBS}$ for $5 \mathrm{~min}$ at room temperature.

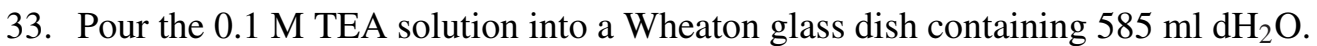

34. Transfer the slides into the dish.

35. Directly pour the AA solution onto the slides.

36. Gently shake the slide rack, and start the timer for $10 \mathrm{~min}$.

37. Wash the slides in $600 \mathrm{ml} 1 \times \mathrm{PBS}$ for $5 \mathrm{~min}$ at room temperature.

38. Submerge the slides in $600 \mathrm{ml} 70 \%$ ethanol for $5 \mathrm{~min}$ at room temperature.

39. Submerge the slides in $600 \mathrm{ml} 95 \%$ ethanol for $5 \mathrm{~min}$ at room temperature.

40. Dry the slides on a clean absorbent underpad.

After the procedure, leave the slides on a clean absorbent underpad for approximately $1 \mathrm{hr}$.

\section{Hybridization (first day)}

41. Prepare humidified hybridization chambers (cover the bottom of the chamber with Whatman paper, mix $50 \%$ formamide with $50 \% \mathrm{ddH}_{2} \mathrm{O}$ and distribute the solution on the paper).

42. Prepare coverslips by cutting small pieces of Parafilm. The size of the cover slips should match the size of the tissue sections.

43. Warm an aliquot of hybridization solution to room temperature.

44. Defrost an aliquot of $1 \mathrm{M}$ DTT and vortex it to mix well.

45. Check the temperatures of the water bath and of the hybridization oven $\left(85^{\circ} \mathrm{C}\right.$ and $\left.55^{\circ} \mathrm{C}\right)$.

46. Lay the slides flat in the humidified hybridization chamber.

47. Dilute the riboprobe (see steps 1 to 19) using these proportions:

$900 \mu 1$ hybridization solution

$50 \mu 11$ M DTT

$50 \mu 1{ }^{35}$ S-labeled riboprobe

This amount of diluted riboprobe is sufficient for 10 to 12 small tissue sections.

Survey all the work surfaces, the supplies, and yourself with the Geiger counter during the procedure.

48. Vortex well and briefly centrifuge the solution for $15 \mathrm{sec}$ at $735 \times g$, at room temperature.

49. Denature the solution in the water bath for $3 \mathrm{~min}$ at $85^{\circ} \mathrm{C}$.

50. Add 80 to $100 \mu \mathrm{l}$ of the denatured riboprobe solution to the tissue section. Quickly apply the denatured riboprobe directly on the tissue section.

51. Place a small piece of Parafilm over each section, rolling to prevent bubbles.

If bubbles form under the Parafilm coverslip, carefully remove them by pressing on the Parafilm with a sterile tip.

Mouse Growth Plate Development 


\section{Post-hybridization washing (second day)}

53. Warm a Wheaton glass dish containing $600 \mathrm{ml}$ of $2 \times \mathrm{SSC}$ in the microwave for $\sim 45 \mathrm{sec}$.

54. Place the glass dish in the water bath at $37^{\circ} \mathrm{C}$ and allow the solution to reach the temperature.

55. Prepare all incubation solutions in advance and heat them in the water baths.

56. Make sure that all the heated Wheaton glass dishes have a lid.

57. Check that the water levels in the water baths completely surround the solutions contained in the glass dishes.

58. Do not start the procedure until all the solutions have reached the correct temperature.

59. Place the slides (from step 52) in $1 \times$ SSC until all Parafilm floats off the sections. Do not peel off the Parafilm to avoid damaging the sections.

60. Pick up all floating coverslips and discard them in the radioactive waste.

Survey all the work surfaces, the supplies, and yourself with the Geiger counter during the procedure.

61. Incubate the slides in $600 \mathrm{ml} 2 \times \mathrm{SSC} /$ formamide for $5 \mathrm{~min}$ at $52^{\circ} \mathrm{C}$ in the water bath.

62. Move the slides to the next glass dish and incubate them in $600 \mathrm{ml} 2 \times$ $\mathrm{SSC}$ /formamide for an additional $5 \mathrm{~min}$ at $52^{\circ} \mathrm{C}$ in the water bath.

63. Wash the slides twice, each time with $600 \mathrm{ml} 2 \times \mathrm{SSC}$ for $1 \mathrm{~min}$ at room temperature.

64. Add $900 \mu \mathrm{l}$ of $20 \mathrm{mg} / \mathrm{ml}$ RNase A to the warmed $2 \times$ SSC glass dish and then move the slides to the dish.

65. Incubate the slides for $30 \mathrm{~min}$ at $37^{\circ} \mathrm{C}$.

66. Wash the slides twice, each time with $600 \mathrm{ml} 2 \times \mathrm{SSC}$ for $1 \mathrm{~min}$ at room temperature.

67. Incubate the slides in $600 \mathrm{ml} 2 \times \mathrm{SSC} /$ formamide for $5 \mathrm{~min}$ at $52^{\circ} \mathrm{C}$ in the water bath.

68. Incubate the slides in $600 \mathrm{ml} 70 \% \mathrm{EtOH} / 0.1 \times \mathrm{SSC}$ for $3 \mathrm{~min}$ at room temperature.

69. Incubate the slides in $600 \mathrm{ml} 80 \% \mathrm{EtOH} / 0.1 \times \mathrm{SSC}$ for $3 \mathrm{~min}$ at room temperature.

70. Incubate the slides in $600 \mathrm{ml} 95 \% \mathrm{EtOH} / 0.1 \times \mathrm{SSC}$ for $3 \mathrm{~min}$ at room temperature.

71. Rinse the slides in $600 \mathrm{ml} \mathrm{dH_{2 }} \mathrm{O}$ for $10 \mathrm{sec}$ at room temperature.

72. Incubate the slides in $600 \mathrm{ml} 70 \% \mathrm{EtOH}$ for $1 \mathrm{~min}$ at room temperature.

73. Dry the slides in a slide rack for $\sim 1 \mathrm{hr}$ at room temperature.

74. Place the slides in an autoradiography cassette and secure their edges with clear tape.

75. In the darkroom, place a Kodak Biomax MR single emulsion film on top of the slides.

Only one side of the film has emulsion; make sure to place the film with the notched corner at the bottom right of the autoradiography cassette. 
76. Expose the slides to Kodak Biomax MR single emulsion film for a minimum of 12 hr.

The exposure time in the autoradiography cassette may vary based on the riboprobe. The signal intensity depends on the quality of the riboprobe, gene expression levels and quality of the sections. Testing signal intensity with a film is critical important to establish emulsion exposure time (see below). Exposure time in the autoradiography cassette may therefore vary between 12 and $72 \mathrm{hr}$.

77. Proceed to the next step if positive signal is detected on the film.

\section{Dipping (third day)}

78. Divide an aliquot of Kodak Autoradiography Emulsion (in the darkroom) into 5 equal parts with a blade and put into small, opaque bottles.

79. Wrap each opaque bottle with three layers of aluminum foil.

80. Warm the water bath to $45^{\circ} \mathrm{C}$ in the darkroom.

81. Warm some $\mathrm{dH}_{2} \mathrm{O}$ in the microwave; fill the water bath halfway. Place a 1-liter beaker filled with $45^{\circ} \mathrm{C} \mathrm{dH_{2 }} \mathrm{O}$ into the water bath. Leave the water bath lid open.

Before starting the procedure, check that the $\mathrm{dH}_{2} \mathrm{O}$ temperature is $45^{\circ} \mathrm{C}$ both inside the 1-liter beaker and in the water bath.

82. Place the clean, dry dip miser and metal apparatus into the beaker in the water bath. Make sure that the water level is just below the top of the dip miser.

Check that the dip miser is dry to avoid the contamination of the emulsion with water.

83. Place 1 aliquot of emulsion, and $20 \mathrm{ml}$ of $2 \%$ glycerol working solution outside the beaker in the water bath.

84. Activate the desiccant in the microwave for $30 \mathrm{sec}$.

85. Add the desiccant to a $35-\mathrm{mm}$ petri dish and secure the lid with tape.

86. Place a blank slide, covered with tape, in a slide box between the desiccant and the slide area.

87. Remove the slides from the autoradiography cassettes and place them in the slide box. Keep the same orientation for each slide (e.g., frosted side on the left).

If more riboprobes are tested, divide them accordingly into different slide boxes.

88. Write on a label tape the riboprobe name, the number of slides, the date of dipping, and the date to develop; place the label on the appropriate slide box.

89. Take aluminum foil, slide draining $\operatorname{rack}(\mathrm{s})$, and slide boxes to the darkroom.

90. Turn on red light and turn off overhead light.

91. Add the emulsion aliquot to the $2 \%$ glycerol working solution as follows:

a.Slowly pour down the edge of the 50-ml Falcon tube.

b.Gently mix by inversion to prevent bubble formation.

c.Slowly pour the emulsion mixture in the dip miser and place it in the metal apparatus.

92. Remove the label tape from the slide box; put it on the draining rack, leaving space for slides above the tape.

Mouse Growth Plate Development

93. Remove the slides from the slide box one at a time, and carefully dip each into the emulsion for $1 \mathrm{sec}$, holding the frosted end of the slide. 
94. At the end of $1 \mathrm{sec}$, partially lift the slide out of the dip miser and quickly dip it again two more times.

95. Tap the slide on some paper towel to remove the excess emulsion.

96. Place the slide frosted end down in the draining rack (above the label tape).

97. Repeat steps 93-96 until all slides are coated with emulsion.

98. After $15 \mathrm{~min}$ (or more) replace the slides in the appropriate boxes, keeping all frosted ends on the same side.

99. Replace the lid and turn the box on its side, oriented with frosted ends of the slides toward bottom.

100. Wrap each box with three layers of heavy-duty aluminum foil, maintaining the orientation of the slides in the box.

101. Remove the label tape from the draining tray and affix to the outside of the wrapped box (on the opposite side of the slides' frosted ends).

102. Store the slides for 12 to $24 \mathrm{hr}$ at room temperature away from radiation and with frosted ends side down and labeled side up.

103. Transfer the slide boxes to $4^{\circ} \mathrm{C}$ away from radiation and expose for the appropriate length of time.

Emulsion exposure time is usually 3 times longer than that of film; it can vary between 2 to 3 days and 10 days.

\section{Developing and counterstaining (fourth day)}

104. Remove the slide boxes from refrigerator and warm to room temperature for at least $30 \mathrm{~min}$.

105. Allow developer and fixer solutions to equilibrate at room temperature for $\sim 15$ min.

106. Bring the glass dishes containing the solutions (in this order: developer, fixer and $\mathrm{dH}_{2} \mathrm{O}$ ), slide boxes, and slide racks in the darkroom.

107. Unwrap the slide boxes and place the slides in the slide rack.

108. Incubate the slides in $500 \mathrm{ml}$ developer solution for $2 \mathrm{~min}$.

109. Incubate the slides in $500 \mathrm{ml}$ fixer solution for $4 \mathrm{~min}$.

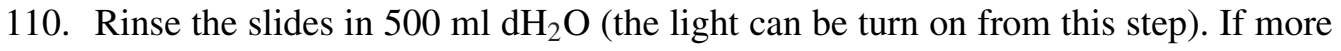

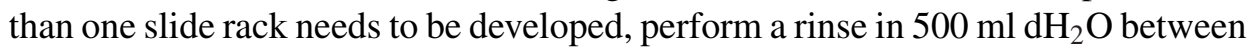
the developer and the fixer step, to keep the fixer solution clean.

After the fixer solution, slides can stay in $\mathrm{dH}_{2} \mathrm{O}$ until ready to counterstain (up to 30 min).

111. Counterstain as follows (use fresh xylene and ethanol):

- Incubate the slides in 200 to $250 \mathrm{ml}$ Harris Hematoxylin for $75 \mathrm{sec}$.

- Gently wash the slides in cold tap water for 2 min until they turn blue. Let the tap water run a few minutes in advance to have it cold. The tap water flush needs to be gentle.

- Rinse the slides in $\mathrm{dH}_{2} \mathrm{O}$ two times for 1 min each.

- Place the slides in 95\% EtOH for 2 min.

- Stain the slides with Eosin Y for15 sec. 
- Dehydrate the slides twice, each time with $95 \% \mathrm{EtOH}$ for $30 \mathrm{sec}$.

- Dehydrate the slides four times, each time with $100 \% \mathrm{EtOH}$ for $1 \mathrm{~min}$.

- Incubate the slides three times, each time in xylene for $2 \mathrm{~min}$.

112. Coverslip with xylene-based mounting medium.

113. Dry the slides on a slide tray overnight at room temperature.

114. Remove the emulsion from the back of the slides using Windex and Kimwipes.

Images can be acquired both in brightfield (the signal is black) and in darkfield (the signal is grey/white). However, the darkfield acquisition is much more sensitive and it is thus recommended for weak signals.

BASIC PROTOCOL 7

\section{.}

Mouse Growth Plate Development

\section{IN SITU CELL DEATH DETECTION (TUNEL ASSAY)}

Terminal deoxynucleotidyl transferase dUTP nick-end labeling (TUNEL) is an established method to detect DNA fragments and thus cell death. This staining relies on the ability of the enzyme terminal deoxynucleotidyl transferase (TdT) to incorporate labeled dUTP into free 3'-hydroxyl termini generated by the fragmentation of genomic DNA. TdT catalyzes the template-independent addition of deoxynucleotide triphosphates to the 3'-OH ends of DNA. When labeled nucleotides (dUTP) are incorporated by TdT, nuclei can be easily detected by standard immunohistochemical or immuno-fluorescent techniques (Gavrieli et al., 1992; Loo and Rillema, 1998). Immunohistochemical techniques can be very cumbersome and time consuming; we therefore prefer to use a direct immunofluorescent technique as described in this unit (Schipani et al., 2001; Pfander et al., 2004; Provot et al., 2007; Maes et al., 2012b; Mangiavini et al., 2014). The protocol described hereafter has been modified from the Roche "In Situ Cell Death detection Kit." Figure 6 displays a representative TUNEL assay in mouse forelimbs.

\section{Materials}

5- $\mu$ m paraffin-embedded tissue sections on Superfrost Plus slides (see Basic Protocol 1)

$1 \times$ phosphate-buffered saline (PBS; see recipe)

Permeabilization solution (see recipe)

Xylene in Coplin jars

$100 \%$ EtOH in Coplin jars

95\% EtOH in Coplin jars (see recipe)

Ice

TUNEL reaction mixture (see recipe)

In Situ Cell Death detection Kit (Roche, cat. no. 11684817 910) containing:

Enzyme solution (TdT)

Label solution (fluorescein-dUTP)

300 nM DAPI working solution (see recipe)

ProLong Gold Antifade Mountant (Life Technologies, cat. no. P36930)

Slide warmer

Humidified chamber

Whatman paper

Cold room

Rocking platform

PAP pen

Incubator at $37^{\circ} \mathrm{C}$

Glass coverslips

Aluminum foil

Microscope for fluorescence detection 


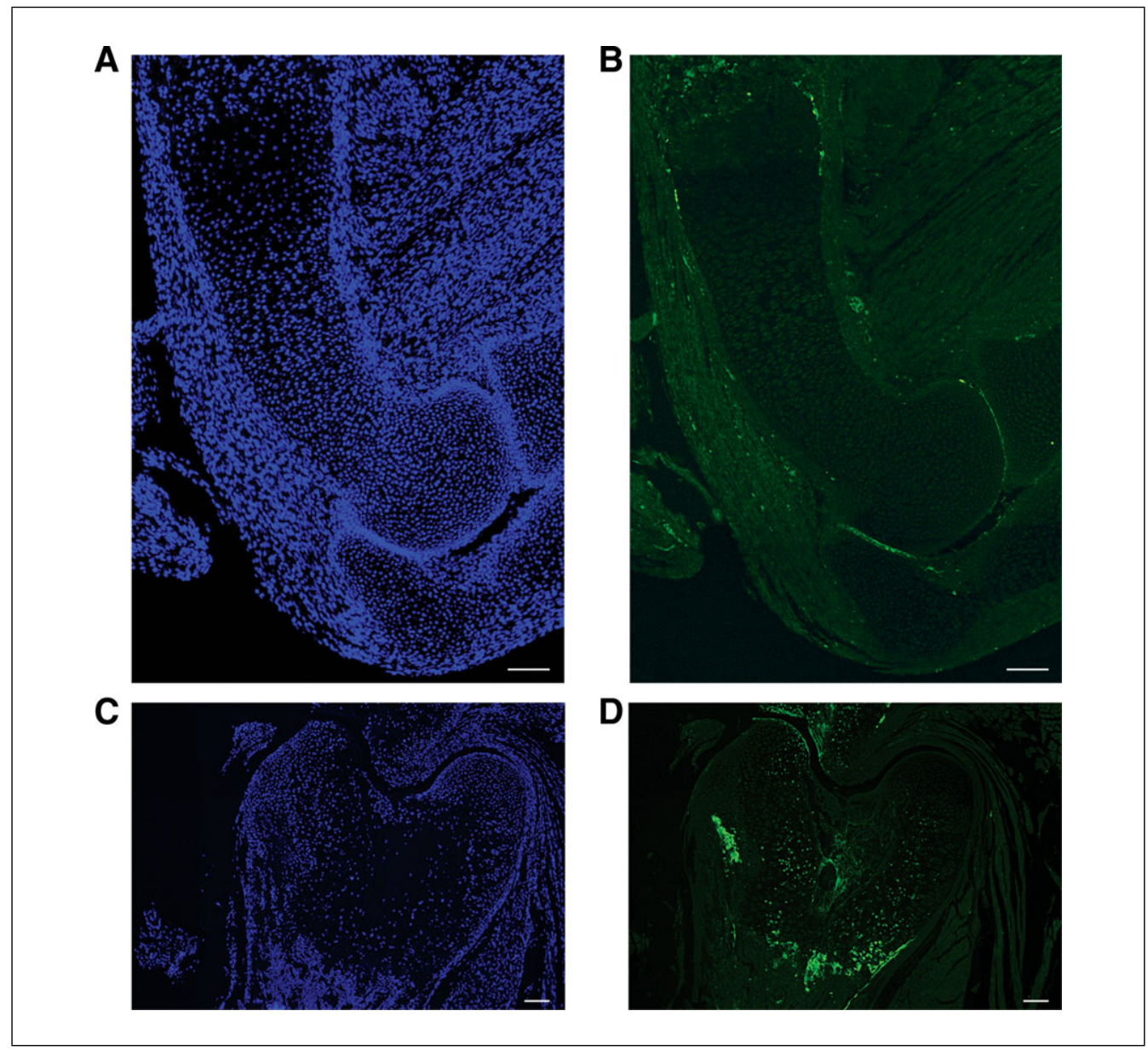

Figure 6 DAPI $(\mathbf{A}, \mathbf{C})$ and TUNEL (B,D) assay in E15.5 and P21 mouse forelimbs. Note the presence of TUNEL-positive cells in the perichondrium and primary spongiosa at E15.5 (bar = $100 \mu \mathrm{m})$.

250-ml Wheaton glass staining dishes (for $1 \times$ PBS)

Slide racks

\section{Slide preparation}

1. Dry the sections on the slide warmer overnight at $60^{\circ} \mathrm{C}$.

\section{Preparation of the permeabilization solution}

2. Prepare humidified chambers (cover the bottom of the chamber with Whatman paper and distribute $50 \mathrm{ml}$ of $1 \times$ PBS on the paper).

3. Prepare $250 \mathrm{ml}$ permeabilization solution in the cold room.

Prepare fresh permeabilization solution in the cold room $\left(a t 4^{\circ} \mathrm{C}\right)$ and do not start the procedure until the solution has reached $4^{\circ} \mathrm{C}$.

\section{Deparaffinization and rehydration}

4. Place the slides in slide rack; deparaffinize, clear, and rehydrate the tissue sections as follows (use fresh xylene and ethanol):

- Xylene, 3 times for 2 min each.

- $100 \% \mathrm{EtOH}, 2$ times for $1 \mathrm{~min}$ each.

- $95 \% \mathrm{EtOH}, 1$ time for $1 \mathrm{~min}$.

- $1 \times$ PBS, 1 time for 5 min. 


\section{Permeabilization}

5. Completely submerge the slides and incubate them in the permeabilization solution for 2 min on ice.

6. Wash the slides three times, each time with $250 \mathrm{ml} 1 \times$ PBS for $2 \mathrm{~min}$ at room temperature, on the rocking platform.

7. Dry the area around the tissue and circle it with the PAP pen.

Dry the area around the tissue before applying the PAP pen without excessively drying the tissue itself.

8. Lay the slides flat in the humidified chamber.

9. Apply $\sim 50 \mu 1$ TUNEL reaction mixture to each slide. Apply $\sim 50 \mu 1$ of the label solution on the negative control (from now on keep the slides in the dark).

Include a negative control with each staining experiment.

10. Incubate the slides in the humidified chamber for $1 \mathrm{hr}$ at $37^{\circ} \mathrm{C}$.

11. Wash the slides three times, each time with $250 \mathrm{ml} 1 \times$ PBS for $2 \mathrm{~min}$ at room temperature on the rocking platform. Carefully remove the excess of $1 \times$ PBS on the tissue sections with a laboratory tissue after every washing step.

\section{Counterstaining and coverslipping}

12. Apply $\sim 300 \mu 1$ of $300 \mathrm{nM}$ DAPI working solution to each slide.

DAPI is a potential mutagen and teratogen. Handle and dispose of it according to its biohazard nature.

13. Incubate the slides in the humidified chamber for 2 to $5 \mathrm{~min}$ at room temperature.

14. Wash the slides three times, each time with $250 \mathrm{ml} 1 \times$ PBS for $2 \mathrm{~min}$ at room temperature on the rocking platform.

15. Coverslip with 200 to $250 \mu 1$ ProLong Gold Antifade Mountant.

16. Wrap the slides in aluminum foil and store them at $4^{\circ} \mathrm{C}$.

Stained slides can be stored up to 2 weeks at $4^{\circ} \mathrm{C}$ or up to 6 months at $-20^{\circ} \mathrm{C}$ (protected from the light).

17. Observe the sections with fluorescent microscopy.

Use an excitation wavelength in the range of 350 to $400 \mathrm{~nm}$ and an emission wavelength of 450 to $500 \mathrm{~nm}$ (blue) to detect DAPI-stained nuclei and an excitation wavelength in the range of 450 to $500 \mathrm{~nm}$ and an emission wavelength in the range of 515 to $565 \mathrm{~nm}$ (green) to detect TUNEL-positive cells.

Retrieve the fluorescent signal within 7 days.

BASIC PROTOCOL 8

Mouse Growth Plate Development

\section{IMMUNOHISTOCHEMISTRY ON FORMALIN-FIXED PARAFFIN-EMBEDDED TISSUES}

Immunohistochemistry allows the detection of antigens in tissue sections by the use of specific antigen-antibody interactions that culminate in the attachment of a marker to the antigen (Ramos-Vara and Miller, 2014). For light microscopy, the marker may be a fluorescent dye (i.e., rhodamine, FITC, Hoechst) or the product of an enzyme (alkaline phosphatase, horseradish peroxidase: HRP) (Taylor et al., 2002). There are numerous immunohistochemical techniques, which may be used to localize antigens; the direct method is a one-step technique that requires a labeled antibody directly reacting with 
the antigen (Coons and Kaplan, 1950; Polak and Van Noorden, 2003). The indirect method involves an unlabeled primary antibody that binds to the target antigen in the tissue and a labeled secondary antibody that reacts with the primary antibody (Coons et al., 1955; Polak and Van Noorden, 2003). In this latter application, the secondary antibody can be labeled with an enzyme (alkaline phosphatase or HRP), a fluorescent dye or with biotin. Biotin labeling requires an additional incubation with appropriately labeled streptavidin (Guesdon et al, 1979). Formalin-fixed paraffin-embedded tissues require a series of steps to make the epitopes available for antibody binding. These steps include classic deparaffinization and antigen retrieval. Antigen retrieval is necessary to break the crosslinks created by the formalin fixative, and involves the use of heat and $\mathrm{pH}$ or proteases (i.e., hyaluronidase, chondroitinase or proteinase K) (Bogen et al., 2009). For the application of HRP-conjugated antibody it is necessary to prevent background staining caused by endogenous peroxidase, which can be blocked by treating the sections with a solution containing 3\% hydrogen peroxide/methanol. Moreover, a blocking step is also necessary to avoid nonspecific binding of the first antibody. Common blocking buffers include normal serum, non-fat dry milk or Bovine Serum Albumin (BSA). For selected antibodies, it is necessary to amplify the signal. A variety of methods have been used to amplify the signal, such as the Renaissance Tyramide Signal Amplification (TSA) system (Perkin Elmer). The TSA technology uses HRP-dependent catalysis and deposition of biotin-labeled tyramide onto tissue sections, with minimal if any loss of resolution (Gross and Sizer, 1959). Deposited biotins are detected with HRP-streptavidin. In this Protocol we describe an example of indirect immunohistochemistry involving the TSA technology (Schipani et al., 2001; Pfander et al., 2004; Provot and Schipani, 2007; Mangiavini et al., 2014). This method is particularly recommended for weak signals.

\section{Materials}

5- $\mu$ m paraffin-embedded tissue sections on Superfrost Plus slides (see Basic Protocol 1)

Xylene in Coplin jars

$100 \%$ EtOH in Coplin jars

95\% EtOH in Coplin jars (see recipe \#5)

$1 \times$ Tris-buffered saline (TBS; see recipe)

Sodium citrate solution (see recipe)

$3 \%$ hydrogen peroxide/methanol $\left(\mathrm{H}_{2} \mathrm{O}_{2} / \mathrm{MeOH}\right.$; see recipe)

$\mathrm{dH}_{2} \mathrm{O}$

TNB (see recipe)

Unconjugated primary antibody

Ice

$1 \times$ Tris/NaCl/Tween 20 (TNT; see recipe)

Biotin-conjugated secondary antibody

DAB (3, 3'-diaminobenzidine) Peroxidase (HRP) substrate kit (Vector Labs, cat. no. SK-4100; see recipe)

TSA kit (Perkin Elmer, cat. no. NEL700A) containing:

Biotynil tyramide

Amplification diluent

HRP-SA

Mayer's Hematoxylin

$1 \times$ phosphate-buffered saline (PBS; see recipe)

Xylene-based mounting medium

Slide warmer

Humidified chamber

Whatman paper 
250-ml plastic container for sodium citrate solution

Water bath at $95^{\circ} \mathrm{C}$

Kimwipes

PAP pen

Rocking platform

Glass coverslips

Slide rack

Slide tray

250-ml Wheaton glass staining dishes (for $1 \times \mathrm{PBS}, 1 \times \mathrm{TBS}, 3 \% \mathrm{H}_{2} \mathrm{O}_{2} / \mathrm{MeOH}$, $\left.\mathrm{dH}_{2} \mathrm{O}, \mathrm{TNT}\right)$

\section{Slide preparation}

1. Dry the paraffin-embedded tissue sections on the slide warmer overnight at $60^{\circ} \mathrm{C}$.

2. Prepare humidified chambers (cover the bottom of the chamber with Whatman paper and distribute $50 \mathrm{ml}$ of $1 \times$ TBS on the paper).

Do not start the procedure until the sodium citrate solution has reached $95^{\circ} \mathrm{C}$.

\section{Deparaffinization and rehydration}

3. Place the slides in slide rack; deparaffinize, clear, and rehydrate the tissue sections as follows (use fresh xylene and ethanol):

- Xylene, 3 times for 5 min each.

- $100 \% \mathrm{EtOH}, 2$ times for 1 min each.

- $95 \% \mathrm{EtOH}, 1$ time for $1 \mathrm{~min}$.

- $1 \times$ TBS, 1 time for $5 \mathrm{~min}$.

\section{Antigen retrieval}

4. Transfer the slides in the $250-\mathrm{ml}$ plastic container containing $250 \mathrm{ml}$ sodium citrate solution.

5. Incubate the slides in the sodium citrate solution for $10 \mathrm{~min}$ at $95^{\circ} \mathrm{C}$ in the water bath.

6. Remove the container from the water bath.

7. Leave the slides in the sodium citrate solution for approximately $30 \mathrm{~min}$ at room temperature.

\section{Endogenous peroxidase quenching}

8. Incubate the slides in $250 \mathrm{ml} 3 \% \mathrm{H}_{2} \mathrm{O}_{2} / \mathrm{MeOH}$ for $10 \mathrm{~min}$ at room temperature.

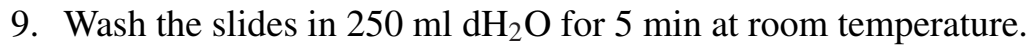

10. Wash the slides in $250 \mathrm{ml}$ of $1 \times$ TBS for $1 \mathrm{~min}$ at room temperature. Carefully remove the excess $1 \times$ TBS on the tissue sections with a Kimwipe after every washing step.

\section{Blocking of nonspecific binding}

11. Dry the area around the tissue before applying the PAP pen without drying the tissue itself. Circle the section with PAP pen.

12. Lay the slides flat in the humidified chamber.

13. Apply $\sim 100 \mu 1 \mathrm{TNB}$ onto each slide.

14. Incubate the slides in the moist chamber for $30 \mathrm{~min}$ at room temperature. 
Incubation with primary antibody

15. Pour off TNB and immediately apply $100 \mu 1$ unconjugated primary antibody (appropriately diluted in TNB). Apply only TNB on negative controls.

Keep all the reagents on ice during the procedure.

Include a negative control with each staining experiment.

16. Incubate the slides in the moist chamber overnight at $4^{\circ} \mathrm{C}$.

\section{Incubation with secondary antibody}

17. The following day, equilibrate the slides for $30 \mathrm{~min}$ at room temperature.

18. Wash the slides three times, each time with $250 \mathrm{ml} 1 \times \mathrm{TNT}$ for $2 \mathrm{~min}$ at room temperature on a rocking platform.

19. Apply $100 \mu \mathrm{l}$ of the appropriate biotinylated secondary antibody (appropriately diluted in TNB).

Keep all the reagents on ice during the procedure.

20. Incubate the slides in the moist chamber for $30 \mathrm{~min}$ at room temperature.

21. Wash the slides three times, each time with $250 \mathrm{ml} 1 \times$ TNT for $2 \mathrm{~min}$ at room temperature on a rocking platform.

\section{Signal amplification}

22. Apply $100 \mu 1$ HRP-Streptavidin (HRP-SA from TSA kit) diluted 1:100 in TNB.

23. Incubate the slides in the moist chamber for $30 \mathrm{~min}$ at room temperature.

24. Wash the slides three times, each time with $250 \mathrm{ml} 1 \times \mathrm{TNT}$ for $2 \mathrm{~min}$ at room temperature on a rocking platform.

25. Apply $100 \mu 1$ biotynil tyramide (from TSA kit) diluted 1:50 in amplification diluent (from TSA kit).

26. Incubate the slides in the moist chamber for $5 \mathrm{~min}$ at room temperature.

27. Wash the slides three times, each time with $250 \mathrm{ml} 1 \times \mathrm{TNT}$ for $2 \mathrm{~min}$ at room temperature on a rocking platform.

28. Apply $100 \mu 1$ HRP-SA (from TSA kit) diluted 1:100 in TNB.

29. Incubate the slides in the moist chamber for $30 \mathrm{~min}$ at room temperature.

30. Wash the slides three times, each time with $250 \mathrm{ml} 1 \times \mathrm{TNT}$ for $2 \mathrm{~min}$ at room temperature on a rocking platform.

\section{Signal detection}

31. Apply $100 \mu 1 \mathrm{DAB}$ solution on each section.

Protect DAB from the light and use the solution within $1 \mathrm{hr}$.

It is possible to add 2 drops of Nickel solution (from DAB HRP substrate kit) to the DAB to obtain a darker signal.

32. Incubate the slides in the moist chamber until brown color develops.

33. Rinse the slides in $\mathrm{dH}_{2} \mathrm{O}$.

\section{Counterstaining and coverslipping}

34. Counterstain the slides with two drops of Mayer's Hematoxylin. 
35. Incubate the slides in the moist chamber for $3 \mathrm{~min}$ at room temperature.

36. Wash the slides in cold tap water for $2 \mathrm{~min}$.

37. Incubate the slides in $250 \mathrm{ml}$ of $1 \times$ PBS for $30 \mathrm{sec}$.

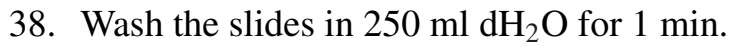

39. Dehydrate the slides as follows:

- $95 \% \mathrm{EtOH}, 2$ times for 1 min each.

- $100 \% \mathrm{EtOH}, 4$ times for $1 \mathrm{~min}$.

- Xylene, 3 times for 2 min each.

40. Coverslip with xylene-based mounting medium.

41. Dry the slides on a slide tray overnight at room temperature.

BASIC

\section{PROTOCOL 9}

Mouse Growth Plate Development

\section{PROLIFERATION ASSAYS: BrdU ASSAY TO EVALUATE CELL PROLIFERATION}

Measuring chondrocyte ability to proliferate is crucial for the study of endochondral bone development. The most accurate method to study chondrocyte proliferation rate is by directly measuring DNA synthesis through an antibody-based detection of the nucleoside analog bromo-deoxyuridine (BrdU) (Gratzner, 1982). BrdU is a uridine derivative that can be incorporated into DNA in place of thymidine during S-phase. BrdU is then detected by a direct immunoreaction using a labeled monoclonal anti-BrdU antibody. We currently use a specific kit (Invitrogen) to perform this technique (Schipani et al., 2001; Mangiavini et al., 2014). This assay requires the injection of BrdU intraperitoneally in a pregnant mouse. Figure 7 illustrates an example of BrdU assay in a fetal mouse growth plate.

\section{Materials}

Pregnant mouse

$10 \mathrm{mg} / \mathrm{ml}$ 5-bromo-2'-deoxyuridine (BrdU)-1.2 mg/ml 5-fluoro-2'-deoxyuridine (FdU) solution (see recipe)

Ice

$1 \times$ phosphate-buffered saline (PBS; see recipe)

5- $\mu \mathrm{m}$ paraffin-embedded tissue sections on Superfrost Plus slides (see Basic Protocol 1)

Xylene in Coplin jars

$100 \%$ EtOH in Coplin jars

95\% EtOH in Coplin jars (see recipe)

$3 \% \mathrm{H}_{2} \mathrm{O}_{2} / \mathrm{MeOH}$ (see recipe)

BrdU staining kit (Invitrogen, cat. no. 93-3943; see recipe for trypsin solution) containing:

Denaturing solution (Reagent \#2)

Blocking solution (Reagent \#3)

Biotinylated mouse anti-BrdU (Reagent \#4)

HRP-streptavidin solution (Reagent \#5)

Hematoxylin (Reagent \#7)

$\mathrm{dH}_{2} \mathrm{O}$

DAB HRP Peroxidase substrate kit (Vector Labs, cat. no. SK-4100; see recipe for DAB HRP substrate solution)

Xylene-based mounting medium

Balance

1-ml syringe equipped with a $27-\mathrm{G}$ needle 


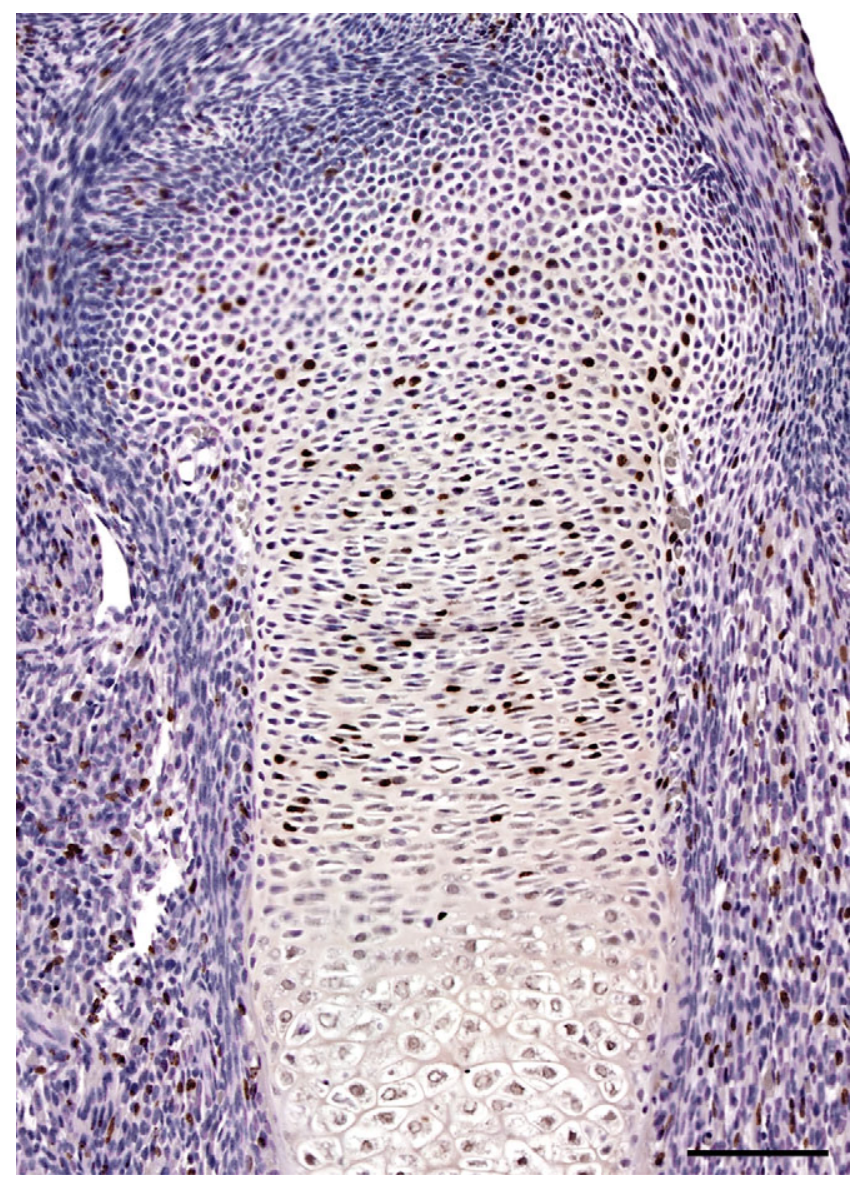

Figure 7 BrdU assay in E15.5 mouse proximal epiphysis of tibia (bar $=100 \mu \mathrm{m}$ ).

100-mm petri dishes, sterile

Slide warmer

Humidified chamber

Whatman paper

Rocking platform

PAP pen

Incubator at $37^{\circ} \mathrm{C}$

Kimwipes

Glass coverslips

Slide rack

250-ml Wheaton glass staining dishes (for $1 \times \mathrm{PBS}$ and $\mathrm{dH}_{2} \mathrm{O}$ )

Slide tray

\section{In vivo labeling with BrdU and FdU}

1. Weigh the pregnant mouse.

2. Using a $1-\mathrm{ml}$ syringe equipped with a $27-\mathrm{G}$ needle, inject intraperitoneally (i.p.) 10 $\mathrm{mg} / \mathrm{ml} \mathrm{BrdU}-1.2 \mathrm{mg} / \mathrm{ml} \mathrm{FdU}$ solution $2 \mathrm{hr}$ before sacrificing the mouse (see Basic Protocol 1, step 1) $(0.1 \mathrm{ml}$ of $10 \mathrm{mg} / \mathrm{ml}$ BrdU-1.2 mg/ml FdU stock solution per 10 $\mathrm{g}$ of mouse).

BrdU is a potential mutagen and teratogen. Handle and dispose of it according to its biohazard nature.

FdU is used to inhibit endogenous production of thymidine that could compete with BrdU.

Mouse Growth Plate Development 
The labeling time for skeletal tissues is typically 30 to 60 min for embryos at the gestation days 10.5 (E10.5) to E13.5, 1 to $2 \mathrm{hr}$ for E14.5 to E18.5 fetuses, and 2 to $4 \mathrm{hr}$ for post-natal mice.

3. Deliver the embryos by cesarean section as described in Basic Protocol 1 (see steps 1 to 4$)$.

4. Place the embryos on ice.

Upon isolation, immediately place the embryos on ice to ensure BrdU incorporation stops at same time for all embryos.

5. Separate mouse embryos and extensively rinse them with $10 \mathrm{ml}$ sterile $1 \times \mathrm{PBS}$ in petri dish.

6. Rinse each embryo three times, each time with $10 \mathrm{ml}$ sterile $1 \times$ PBS in clean petri dishes.

7. Fix, dissect, process and section specimens as described in Basic Protocol 1 (see steps 12 to 57 ).

\section{BrdU detection}

8. Dry the paraffin-embedded tissue sections on the slide warmer overnight at $60^{\circ} \mathrm{C}$.

9. Prepare humidified chambers (cover the bottom of the chamber with Whatman paper and distribute $50 \mathrm{ml}$ of $1 \times \mathrm{PBS}$ on the paper).

10. Deparaffinize, clear, and rehydrate the tissue sections as follows (use fresh xylene and ethanol):

- Xylene, 3 times for 5 min each.

- $100 \% \mathrm{EtOH}, 2$ times for 1 min each.

- $95 \% \mathrm{EtOH}, 1$ time for $1 \mathrm{~min}$.

- $1 \times$ PBS, 1 time for $5 \mathrm{~min}$.

11. Incubate the slides in $250 \mathrm{ml} 3 \% \mathrm{H}_{2} \mathrm{O}_{2} / \mathrm{MeOH}$ for $10 \mathrm{~min}$ at room temperature.

12. Wash the slides three times, each time with $250 \mathrm{ml} 1 \times \mathrm{PBS}$ for $2 \mathrm{~min}$ at room temperature on a rocking platform.

13. Dry the area around the tissue before applying the PAP pen without drying the tissue itself. Circle section with PAP pen.

14. Lay the slides flat in the humidified chamber.

15. Apply 100 to $200 \mu 1$ trypsin solution on each slide.

16. Incubate the slides in moist chamber for $15 \mathrm{~min}$ at $37^{\circ} \mathrm{C}$.

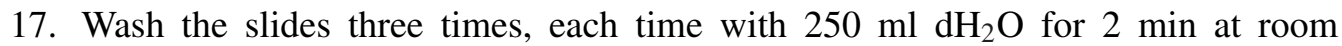
temperature on a rocking platform. Carefully remove the excess of liquid on the tissue sections with a Kimwipe after every washing step.

18. Apply 2 drops of denaturing solution(see staining kit) on each slide.

19. Incubate the slides in the moist chamber for $30 \mathrm{~min}$ at room temperature.

20. Wash the slides three times, each time with $250 \mathrm{ml} 1 \times$ PBS or $2 \mathrm{~min}$ at room temperature on a rocking platform.

21. Apply 2 drops of blocking solution (see staining kit)on each slide.

22. Incubate the slides in the moist chamber for $30 \mathrm{~min}$ at room temperature. 
23. Remove the blocking solution and apply 2 drops of biotinylated mouse anti-BrdU (see staining kit).

24. Incubate the slides in the moist chamber for $2 \mathrm{hr}$ at room temperature.

25. Wash the slides three times, each time with $250 \mathrm{ml} 1 \times$ PBS for $2 \mathrm{~min}$ at room temperature on a rocking platform.

26. Apply 2 drops of HRP-streptavidin solution (see staining kit).

27. Incubate the slides in the moist chamber for $15 \mathrm{~min}$ at room temperature.

28. Wash the slides three times, each time with $250 \mathrm{ml} 1 \times$ PBS for $2 \mathrm{~min}$ at room temperature on a rocking platform.

29. Apply $100 \mu 1$ of DAB HRP substrate solution on each section.

Protect DAB from the light and use the solution within $1 \mathrm{hr}$.

$D A B$ HRP Peroxidase substrate is also provided by the Invitrogen kit; however, we prefer using DAB HRP substrate kit from Vector labs as the signal is stronger.

It is possible to add 2 drops of Nickel solution to the DAB to obtain a darker signal.

Detection with a fluorescent dye is also possible (for details see Support Protocol 2).

30. Incubate the slides in the moist chamber for $10 \mathrm{~min}$ at room temperature.

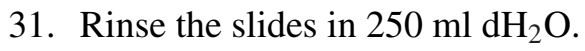

32. Counterstain the slides with 2 drops of hematoxylin (see staining kit).

33. Incubate the slides in the moist chamber for $5 \mathrm{~min}$ at room temperature.

34. Wash the slides in cold tap water for $2 \mathrm{~min}$.

35. Incubate the slides in $250 \mathrm{ml} 1 \times$ PBS for $30 \mathrm{sec}$.

36. Wash the slides in $250 \mathrm{ml} \mathrm{dH_{2 }} \mathrm{O}$ for $1 \mathrm{~min}$.

37. Dehydrate the slides as follows:

- $95 \% \mathrm{EtOH}, 2$ times for 1 min each.

- $100 \% \mathrm{EtOH}, 4$ times for $1 \mathrm{~min}$.

- Xylene, 3 times for 2 min each.

38. Coverslip the slides with xylene-based mounting medium.

39. Dry the slides on a slide tray overnight at room temperature.

\section{BrdU DETECTION WITH A FLUORESCENT DYE}

BrdU detection can also be accomplished by using a fluorescent dye. Fluorescent detection gives a stronger signal; however, the fluorescent dye fades away within few weeks. Thus, it is recommended to retrieve the signal immediately after the procedure. In Support Protocol 2 we briefly describe BrdU detection with a fluorescent dye.

Additional Materials (also see Basic Protocol 9)

Streptavidin Alexa -Fluor-conjugated

$5 \mathrm{mg} / \mathrm{ml}$ DAPI stock solution (see recipe)

300 nM DAPI working solution (see recipe)

ProLong Gold Antifade Mountant (Life Technologies, cat. no. P36930)

Aluminum foil 
ALTERNATE

PROTOCOL 2

Mouse Growth Plate Development
Microscope for fluorescence detection

1. Proceed as described in Basic Protocol 9 (steps 1 to 25).

2. Replace HRP-streptavidin solution (reagent \#5 from the Invitrogen kit) with Streptavidin Alexa-Fluor-conjugated (diluted 1:100 in blocking solution reagent \#1 from Invitrogen kit).

3. Incubate the slides in the humidified chamber (protected from light) for $15 \mathrm{~min}$ at room temperature.

4. Wash the slides three times, each time with $250 \mathrm{ml} 1 \times$ PBS for $2 \mathrm{~min}$ at room temperature on a rocking platform.

5. Apply $300 \mu 1$ DAPI working solution onto each section.

DAPI is a potential mutagen and teratogen. Handle and dispose of it according to institutional regulations.

6. Incubate the slides in humidified chamber (protected from light) for 2 to $5 \mathrm{~min}$ at room temperature.

7. Wash the slides three times, each time with $250 \mathrm{ml} 1 \times$ PBS for $2 \mathrm{~min}$ at room temperature on a rocking platform.

8. Coverslip with 200 to $250 \mu 1$ ProLong Gold Antifade Mountant.

9. Wrap the slides in aluminum foil and store them at $4{ }^{\circ} \mathrm{C}$.

Stained slides can be stored up to 2 weeks at $4{ }^{\circ} \mathrm{C}$ or up to 6 months at $-20^{\circ} \mathrm{C}$ (protected from the light).

10. Observe the sections with fluorescent microscopy within 7 days.

Use an excitation wavelength in the range of 350 to $400 \mathrm{~nm}$ and an emission wavelength of 450 to $500 \mathrm{~nm}$ (blue) to detect DAPI-stained nuclei and the appropriate excitation and emission wavelengths to detect Alexa Fluor-BrdU-positive cells.

\section{EdU ASSAY TO EVALUATE CELL PROLIFERATION}

A major disadvantage of BrdU detection is that it requires the use of trypsin (or similar reagents), which may cause tissue damage. Moreover, BrdU staining is a time-consuming procedure.

More recently, an easier and quicker proliferation assay has been developed (Salic and Mitchison, 2008). It utilizes 5-ethynyl-2'-deoxyuridine (EdU), which is a nucleoside analog of thymidine and is incorporated into DNA during S-phase. Detection is based on a copper-catalyzed cycloaddition, where a stable triazole ring is formed by covalently coupling between the alkaline group present in the EdU and the Alexa-Fluor-conjugated azide group. This technique also requires the injection of EdU intraperitoneally in pregnant mouse. An example of EdU assay in a fetal mouse growth plate is shown in Figure 8.

\section{Materials}

Pregnant mouse

Click-iT EdU Alexa Fluor 488 Imaging Kit (Invitrogen, cat. no. C10337; see recipe)

Ice

$1 \times$ phosphate-buffered saline (PBS; see recipe)

$70 \% \mathrm{EtOH}$ 

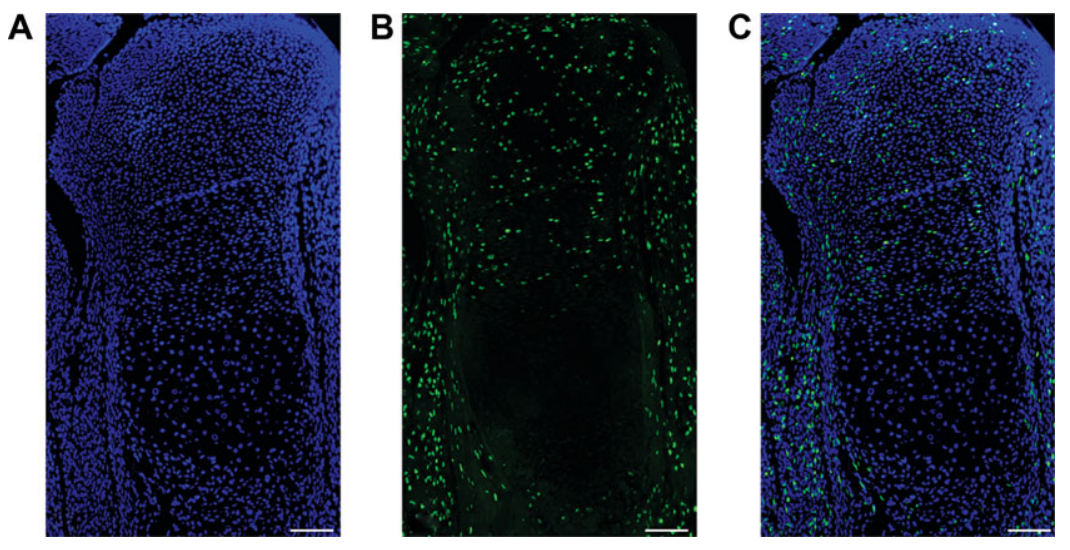

Figure 8 DAPI $(\mathbf{A})$ and $\mathrm{EdU}(\mathbf{B})$ assay in E15.5 mouse proximal epiphysis of tibia. Merged picture is shown in $(\mathbf{C})(\mathrm{bar}=100 \mu \mathrm{m})$.

5- $\mu$ m paraffin-embedded tissue sections on Superfrost Plus slides (see Basic Protocol 1)

Xylene in Coplin jars

$100 \%$ EtOH in Coplin jars

95\% EtOH in Coplin jars (see recipe \#5)

Click-iT EdU Alexa Fluor 488 Imaging Kit (Invitrogen, cat. no. C10337; see recipes)

Hoechst 33342 working solution (see recipe)

ProLong Gold Antifade Mountant (Life Technologies, cat. no. P36930)

Balance

1-ml syringes equipped with $27-\mathrm{G}$ needles

100 -mm petri dishes, sterile

Slide warmer

Humidified chamber

Whatman paper

PAP pen

Kimwipes

Glass coverslips

Slide rack

250-ml Wheaton glass dishes (for $1 \times$ PBS)

\section{In vivo labeling with $\mathrm{EdU}$}

1. Weigh the pregnant mouse.

2. Using a $1-\mathrm{ml}$ syringe equipped with a $27-\mathrm{G}$ needle, inject intraperitoneally (i.p.) EdU stock solution $2 \mathrm{hr}$ before sacrificing the mouse (see Basic Protocol 1, step 1) ( $0.1 \mathrm{ml}$ of $10 \mathrm{mM}$ EdU stock solution per $10 \mathrm{~g}$ of mouse).

EdU is a potential mutagen and teratogen. Handle and dispose of it according to institutional regulations.

3. Deliver the embryos by cesarean section as described in Basic Protocol 1 (see steps 1 to 4$)$.

4. Place the embryos on ice.

5. Separate mouse embryos and extensively rinse them with sterile $1 \times$ PBS.

Mouse Growth Plate Development 
6. Rinse each embryo three times, each time $10 \mathrm{ml}$ sterile $1 \times$ PBS in clean $100-\mathrm{mm}$ petri dishes.

7. Clean the instruments with $70 \% \mathrm{EtOH}$ between different embryos.

8. Fix, dissect, process, and section specimens as described in Basic Protocol 1 (see steps 12 to 57$)$.

\section{EdU detection}

9. Dry the paraffin-embedded tissue sections on the slide warmer overnight at $60^{\circ} \mathrm{C}$.

10. Prepare humidified chambers (cover the bottom of the chamber with Whatman paper and distribute $50 \mathrm{ml}$ of $1 \times$ PBS on the paper).

11. Place the slides in a slide rack; deparaffinize, clear, and rehydrate the tissue sections as follows (use fresh xylene and ethanol):

- Xylene, 3 times for 5 min each.

- $100 \% \mathrm{EtOH}, 2$ times for 1 min each.

- $95 \% \mathrm{EtOH}, 1$ time for $1 \mathrm{~min}$.

- $1 \times$ PBS, 1 time for 5 min.

12. Prepare the Click-iT reaction cocktail by combining the following items in this order:

- $430 \mu 11 \mathrm{X}$ Click-iT reaction buffer

- $20 \mu \mathrm{l} \mathrm{CuSO}_{4}$ (component E)

- $1.2 \mu 1$ Alexa Fluor azide working solution

- $50 \mu 1$ of $1 \times$ Click-iT EdU buffer additive working solution.

Prepare Click-iT reaction cocktail in that specific order to obtain the optimal reaction.

Use the Click-iT reaction cocktail within 15 min of preparation.

This volume $(500 \mu l)$ of Click-iT reaction cocktail can stain ten small tissue sections.

13. Dry the area around the tissue before applying the Pap pen without drying the tissue itself. Circle tissue sections with PAP pen.

14. Lay the slides flat in the humidified chamber.

15. Apply the Click-iT reaction cocktail ( 100 to $200 \mu \mathrm{l})$ to each section and incubate for $30 \mathrm{~min}$ at room temperature in the humidified chamber (protected from the light).

Perform all the assay steps in the dark.

16. Wash slides two times, each time with $250 \mathrm{ml} 1 \times \mathrm{PBS}$ for $2 \mathrm{~min}$ at room temperature (protected from the light). Carefully remove the excess of PBS on the tissue sections with a Kimwipe after every washing step.

17. Apply Hoechst 33342 working solution ( 100 to $200 \mu \mathrm{l}$ ) to each section and incubate for $2 \mathrm{~min}$ at room temperature in the humidified chamber (protected from the light).

300 nM DAPI working solution (see recipe) may be used instead of the Hoechst 33342 working solution.

Hoechst 33342 and DAPI are potential mutagens and teratogens. Handle and dispose of them according to their biohazard nature.

18. Wash the slides twice, each time with $250 \mathrm{ml} 1 \times \mathrm{PBS}$ for $2 \mathrm{~min}$ at room temperature (protected from the light).

19. Coverslip the slides with ProLong Gold Antifade Mountant. 
20. Wrap the slides in aluminum foil and store them at room temperature for $24 \mathrm{hr}$ and then at $4^{\circ} \mathrm{C}$.

Stained slides can be stored up to 2 weeks at $4^{\circ} \mathrm{C}$ or up to 6 months at $-20^{\circ} \mathrm{C}$ (protected from the light).

21. Observe the sections with fluorescence microscopy.

Use an excitation wavelength in the range of 350 to $400 \mathrm{~nm}$ and an emission wavelength of 450 to $500 \mathrm{~nm}$ (blue) to detect Hoechst 33342-stained nuclei (or DAPI) and an excitation wavelength in the range of 450 to $500 \mathrm{~nm}$ and an emission wavelength in the range of 515 to $565 \mathrm{~nm}$ (green) to detect Alexa Fluor 488-EdU-positive cells.

Retrieve the fluorescent signal within 7 days.

\section{PROLIFERATING CELL NUCLEAR ANTIGEN (PCNA) ASSAY}

Proliferating cell nuclear antigen (PCNA) is a cofactor of DNA polymerase delta and it is synthesized during S, G2, and M phases of mitosis (Moldovan et al., 2007). PCNA is thus considered an antigen expressed during DNA synthesis and its detection by immunohistochemistry represents a valid readout of cell proliferation. However, PCNA immunostaining is not the gold standard method to analyze cell proliferation as it reveals cells that are proliferating at the time of tissue collection, but not cells that were proliferating within a defined period of time (Yu et al., 1992). This assay is thus used as a second independent method to assess cell proliferation. The protocol discussed below has been modified from "Invitrogen PCNA staining kit" (Mangiavini et al., 2014).

\section{Materials}

5- $\mu$ m paraffin-embedded tissue sections on Superfrost Plus slides (see Basic Protocol 1)

Phosphate-buffered saline (PBS; see recipe)

Xylene in Coplin jars

$100 \%$ EtOH in Coplin jars

95\% EtOH in Coplin jars (see recipe)

Sodium citrate solution (see recipe)

$3 \% \mathrm{H}_{2} \mathrm{O}_{2} / \mathrm{MeOH}$ (see recipe)

PCNA staining kit (Invitrogen, cat. no. 93-1143) containing:

Blocking solution

Biotinylated mouse anti-PCNA

HRP-streptavidin

Hematoxylin

DAB HRP Peroxidase substrate kit (Vector Labs, cat. no. SK-4100; see recipe for

DAB HRP substrate solution)

$\mathrm{dH}_{2} \mathrm{O}$

Xylene-based mounting medium

Slide warmer

Whatman paper

Humidified chamber

250-ml plastic container for sodium citrate solution

Water bath at $95^{\circ} \mathrm{C}$

Rocking platform

PAP pen

Slide rack

Slide tray

Glass coverslips 
250-ml Wheaton glass staining dishes (for $1 \times$ PBS and $3 \% \mathrm{H}_{2} \mathrm{O}_{2} / \mathrm{MeOH}$ )

\section{Slide preparation}

1. Dry the paraffin-embedded tissue sections on the slide warmer overnight at $60^{\circ} \mathrm{C}$.

2. Prepare humidified chambers (cover the bottom of the chamber with Whatman paper and distribute $50 \mathrm{ml}$ of $1 \times$ PBS on the paper).

3. Place the slides in a slide rack; deparaffinize, clear, and rehydrate the tissue sections as follows (use fresh xylene and ethanol):

- Xylene, 3 times for 5 min each.

- $100 \% \mathrm{EtOH}, 2$ times for 1 min each.

- $95 \% \mathrm{EtOH}, 1$ time for $1 \mathrm{~min}$.

- $1 \times$ PBS, 1 time for $5 \mathrm{~min}$.

\section{Antigen retrieval}

4. Transfer the slides into the 250 - $\mathrm{ml}$ plastic container containing $250 \mathrm{ml}$ sodium citrate solution.

5. Incubate the slides in the sodium citrate solution for $10 \mathrm{~min}$ at $95^{\circ} \mathrm{C}$ in the water bath.

6. Remove the container from the water bath.

7. Leave the slides in the sodium citrate solution for approximately $30 \mathrm{~min}$ at room temperature.

\section{Endogenous peroxidase quenching}

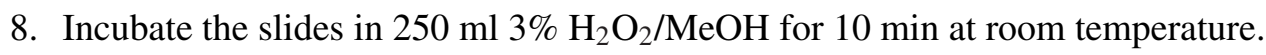

9. Wash the sections three times, each time with $250 \mathrm{ml} 1 \times$ PBS for $2 \mathrm{~min}$ at room temperature on a rocking platform.

10. Dry the area around the tissue before applying the Pap pen without drying the tissue itself. Circle tissue sections with PAP pen.

11. Lay the slides flat in the humidified chamber.

\section{PCNA detection}

12. Apply 2 to 3 drops of blocking solution (provided with the PCNA staining kit)onto each section.

13. Incubate the slides in the humidified chamber for $30 \mathrm{~min}$ at room temperature.

14. Apply 2 to 3 drops of biotinylated mouse anti-PCNA (provided with the PCNA staining kit) onto each section.

15. Incubate the sections in the humidified chamber for $1 \mathrm{hr}$ at room temperature.

16. Wash the sections three times, each time with $250 \mathrm{ml} 1 \times$ PBS for $2 \mathrm{~min}$ at room temperature on a rocking platform.

17. Apply 2 to 3 drops of HRP-Streptavidin (provided with the PCNA staining kit) on each section.

18. Incubate the slides in the humidified chamber for $10 \mathrm{~min}$ at room temperature.

19. Wash the sections three times, each time with $250 \mathrm{ml} 1 \times \mathrm{PBS}$ for $2 \mathrm{~min}$ at room temperature on a rocking platform. 
20. Apply $100 \mu 1$ DAB HRP substrate solution each section.

It is possible to add 2 drops of Nickel solution (from DAB HRP substrate kit) to the DAB to obtain a darker signal.

Detection with a fluorescent dye is also possible (see Support Protocol 3).

21. Incubate the slides in the moist chamber for $5 \mathrm{~min}$ at room temperature.

22. Rinse the slides in $250 \mathrm{ml} \mathrm{dH_{2 }} \mathrm{O}$ for $1 \mathrm{~min}$.

23. Counterstain the slides with 2 drops of hematoxylin (provided with the PCNA staining kit).

24. Incubate the slides in the moist chamber for $2 \mathrm{~min}$ at room temperature.

25. Wash the slides in cold tap water for 2 min.

26. Submerge the slides in $250 \mathrm{ml} 1 \times$ PBS for $1 \mathrm{~min}$.

27. Wash the slides in $250 \mathrm{ml} \mathrm{dH_{2 }} \mathrm{O}$ for $1 \mathrm{~min}$.

28. Dehydrate the slide as follows:

- $95 \% \mathrm{EtOH}, 2$ times for 1 min each.

- $100 \% \mathrm{EtOH}, 4$ times for $1 \mathrm{~min}$.

- Xylene, 3 times for 2 min each.

29. Coverslip with xylene-based mounting medium.

30. Dry the slides on a slide tray overnight at room temperature.

\section{PCNA DETECTION WITH A FLUORESCENT DYE}

As for BrdU detection, also PCNA can be detected by using a fluorescent dye. If the fluorescent detection is used, it is highly recommended to retrieve the signal immediately after the procedure. In Support Protocol 3 we briefly describe PCNA detection with a fluorescent dye.

\section{Additional Materials (also see Basic Protocol 10)}

Streptavidin Alexa-Fluor-conjugated (diluted 1:100 in blocking solution reagent \#1 from Invitrogen PCNA staining kit)

300 nM DAPI working solution (see recipe)

ProLong Gold Antifade Mountant (Life Technologies, cat. no. P36930)

Aluminum foil

Microscope for fluorescence detection

1. Proceed as described in Basic Protocol 10 (steps 1 to 16).

2. Apply 100 to $200 \mu \mathrm{l}$ of streptavidin Alexa-fluor-conjugated in the dark and protect slides from the light.

3. Incubate the sections in the humidified chamber for $10 \mathrm{~min}$ at room temperature.

4. Apply 100 to $200 \mu 1$ DAPI working solution.

DAPI is a potential mutagen and teratogen. Handle and dispose of it according to institutional regulations.

5. Incubate the sections in the humidified chamber for 2 to $5 \mathrm{~min}$ at room temperature. 
6. Wash the sections three times, each time with $250 \mathrm{ml} 1 \times$ PBS for $2 \mathrm{~min}$ at room temperature on a rocking platform. Carefully remove excess PBS on the tissue sections with a Kimwipe after every washing step.

7. Coverslip the slides with 200 to $250 \mu 1$ ProLong Gold Antifade Mountant.

8. Wrap the slides in aluminum foil and store them for $24 \mathrm{hr}$ at room temperature and then at $4^{\circ} \mathrm{C}$.

Stained slides can be stored up to 2 weeks at $4{ }^{\circ} \mathrm{C}$ or up to 6 months at $-20^{\circ} \mathrm{C}$ (protected from the light).

9. Observe the sections with fluorescence microscopy.

Use an excitation wavelength in the range of 350 to $400 \mathrm{~nm}$ and an emission wavelength of 450 to $500 \mathrm{~nm}$ (blue) to detect DAPI-stained nuclei and the right excitation and emission wavelength to detect positive cells based on the type of streptavidin Alexa-fluor-conjugated used.

Retrieve the fluorescent signal within 7 days.

BASIC PROTOCOL 11

\section{Er}

Mouse Growth Plate Development

\section{EF5 STAINING: A METHOD TO DETECT HYPOXIA IN THE DEVELOPING GROWTH PLATE}

EF5 is a pentafluorinated derivative of etanidazole, a compound developed at the University of Pennsylvania by Dr. Cameron Koch and Dr. Sydney Evans (Koch, 2002). EF5 has a nitro $\left(\mathrm{NO}_{2}\right)$ group attached to the imidazole ring structure. In hypoxia, the $\mathrm{NO}_{2}$ group is reduced to an amino group $\left(\mathrm{NH}_{2}\right)$ (Kizaka-Kondoh and Konse-Nagasawa, 2009; Horsman et al., 2012). One of the intermediate products of this reduction is highly reactive and can bind to any cellular protein, forming adducts that can be recognized with specific antibodies (Koch, 2002; Kizaka-Kondoh and Konse-Nagasawa, 2009; Horsman et al., 2012). EF5 is thus a marker to detect hypoxia and is used in vitro and in vivo (Koch, 2002; Kizaka-Kondoh and Konse-Nagasawa, 2009; Horsman et al., 2012). Chondrocytes in the developing growth plate survive and differentiate in a hypoxic environment; changes in oxygen levels in cartilage are therefore critical for cartilage development (Amarilio et al., 2007; Schipani et al., 2001; Provot and Schipani, 2007; Provot et al., 2007; Maes et al., 2012a). We analyze levels of hypoxia in the growth plate by immunofluorescent detection of EF5 adducts (Schipani et al., 2001; Provot et al., 2007). This assay requires the intraperitoneal injection of EF5 in a pregnant mouse. A representative picture of EF5 staining in a mouse forelimb is displayed in Figure 9.

\section{Materials}

Pregnant mouse

$10 \mathrm{mM}$ EF5 stock solution (see recipe)

Phosphate-buffered saline (PBS; see recipe)

Ice

10- $\mu \mathrm{m}$ freshly frozen tissue sections on Superfrost Plus slides (see Basic

Protocol 2)

$100 \%$ acetone

5\% mouse serum/PBS (blocking solution; see recipe \#60)

$3 \%$ BSA/PBS (antibody carrier; see recipe)

Anti-EF5 conjugated antibody

$\mathrm{dH}_{2} \mathrm{O}$

300 nM DAPI working solution (see recipe)

ProLong Gold Antifade Mountant (Life Technologies, cat. no. P36930)

Balance

1-ml syringes equipped with $27-\mathrm{G}$ needles 


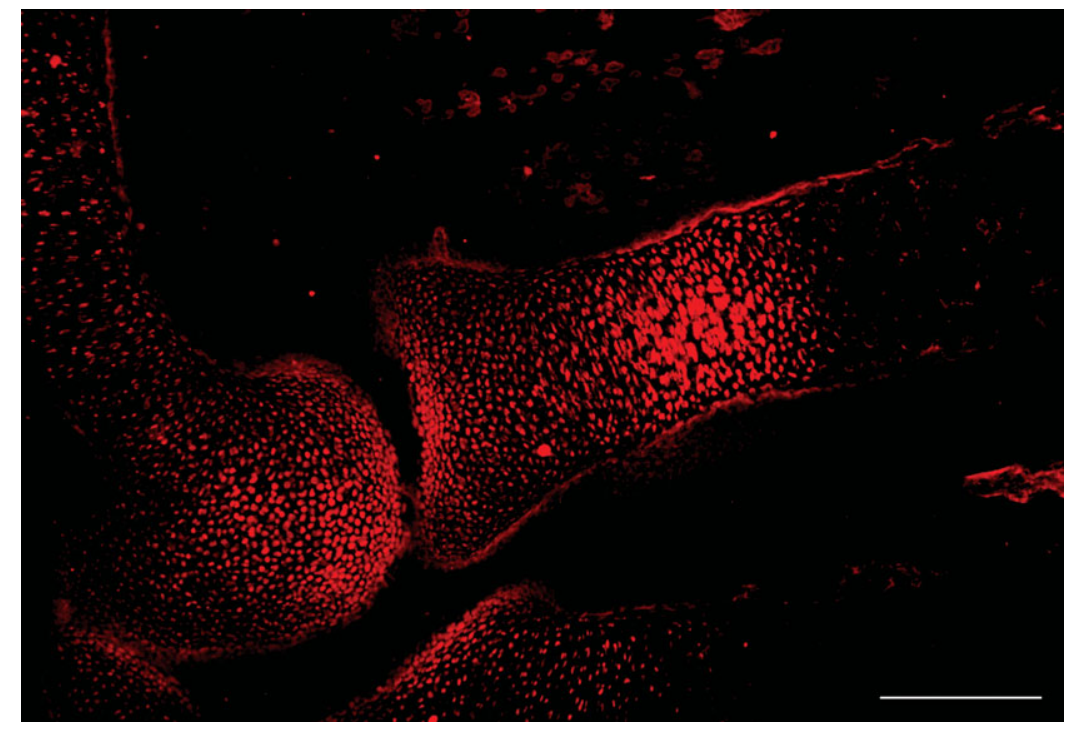

Figure 9 EF5 staining of E15.5 mouse elbow joint (bar $=100 \mu \mathrm{m})$.

100-mm petri dishes, sterile

Whatman paper

Humidified chamber

PAP pen

Coverslips

Aluminum foil

Slide racks

Microscope for fluorescence detection

250-ml Wheaton glass staining dishes (for $1 \times$ PBS and 100\% Acetone)

\section{In vivo labeling with $\mathrm{EF} 5$}

1. Weigh the pregnant mouse.

2. Using a $1-\mathrm{ml}$ syringe equipped with a $27-\mathrm{G}$ needle, inject intraperitoneally (i.p.) 10 mM EF5 stock solution $2 \mathrm{hr}$ before sacrificing the mouse (see Basic Protocol 1, step 1) $(0.1 \mathrm{ml}$ of $10 \mathrm{mM}$ EF5 stock solution per $10 \mathrm{~g}$ of mouse).

The EF5 powder and the antibodies need to be directly purchased from Dr. Cameron Koch (University of Pennsylvania Department of Radiation Oncology) at this site: http://hypoxia-imaging.org.

3. Deliver the embryos by cesarean section as described in Basic Protocol 1 (see steps 2 to 4$)$.

4. Place the embryos on ice.

5. Dissect mouse embryos and extensively rinse them with $10 \mathrm{ml}$ sterile $1 \times \mathrm{PBS}$ in a 100-mm petri dish.

6. Rinse each embryo three times, each time with $10 \mathrm{ml}$ sterile $1 \times$ PBS in clean petri dishes.

7. Clean the instruments with $70 \%$ EtOH between different embryos.

8. Dissect, process and section specimens as described in Basic Protocol 2 (steps 2 to 19). 


\section{EF5 detection}

9. Incubate the slides in $100 \%$ acetone for $10 \mathrm{~min}$ at $4^{\circ} \mathrm{C}$.

Place $100 \%$ acetone at $4{ }^{\circ} \mathrm{C}$ few hours before starting the stain.

10. Dry the freshly frozen sections overnight at room temperature.

11. Prepare humidified chambers (cover the bottom of the chamber with Whatman paper and distribute $50 \mathrm{ml}$ of $1 \times$ PBS on the paper).

12. Wash the sections twice, each time with $250 \mathrm{ml} 1 \times$ PBS for $2 \mathrm{~min}$ at room temperature. Do not wash slides on a rocking platform and be gentle in moving slides from one solution to another because frozen sections tend to easily detach.

13. Dry the area around the tissue before applying the Pap pen without drying the tissue itself. Circle tissue sections with PAP pen.

14. Lay the slides flat in the humidified chamber.

15. Apply 100 to $200 \mu 1$ of $5 \%$ mouse serum/PBS blocking solution on each section.

16. Incubate the slides in the humidified chamber for $30 \mathrm{~min}$ at room temperature.

17. Dilute anti-EF5 conjugated antibody 1:25 in 3\% BSA/PBS (protected from light).

18. Apply 100 to $200 \mu \mathrm{l}$ of the solution onto each section (negative controls get only $3 \% \mathrm{BSA} / \mathrm{PBS}$ ). Include a negative control with each staining experiment.

Protect slides from the light after the incubation with the anti-EF5 conjugated antibody.

The anti-EF5 antibody may be conjugated with the following substrates: biotin, Cy3, Cy5, or Alexa 488. We recommend the use of an anti-EF5 antibody conjugated with a fluorescent dye.

19. Incubate the slides in the humidified chamber for $2 \mathrm{hr}$ at room temperature in the dark.

20. Wash the sections twice, each time with $250 \mathrm{ml} 1 \times$ PBS for $2 \mathrm{~min}$ at room temperature in the dark.

21. Rinse in $250 \mathrm{ml} \mathrm{dH_{2 }} \mathrm{O}$ for $30 \mathrm{sec}$.

22. Apply 100 to $200 \mu 1$ of $300 \mathrm{nM}$ DAPI working solution on each section.

DAPI is a potential mutagen and teratogen. Handle and dispose of it according to institutional regulations.

23. Incubate the slides in the humidified chamber for $5 \mathrm{~min}$ at room temperature in the dark.

24. Coverslip the slides with 200 to $250 \mu 1$ ProLong Gold Antifade Mountant.

25. Wrap the slides in aluminum foil and store them for $24 \mathrm{hr}$ at room temperature and then at $4^{\circ} \mathrm{C}$.

Stained slides can be stored up to 2 weeks at $4^{\circ} \mathrm{C}$ or up to 6 months at $-20^{\circ} \mathrm{C}$ (protected from the light).

26. Observe the sections with fluorescence microscopy.

Use an excitation wavelength in the range of 350 to $400 \mathrm{~nm}$ and an emission wavelength of 450 to $500 \mathrm{~nm}$ (blue) to detect DAPI-stained nuclei and the right excitation and emission wavelength to detect positive cells based on the antibody used. 
QUANTIFICATION OF FLUORESCENT SIGNAL-LABELED CELLS USING IMAGE J

To fully understand the growth plate development it is crucial to quantitatively assess the information given by specific staining, immunostaining or labeling techniques. To quantify these signals, automatized techniques and image analysis tools have been developed. The general principle of the method consists, first, in designing a region of interest (ROI) within which the total cell number will be calculated. Then, in the defined ROI, cells exhibiting a positive signal will be counted. This allows calculating a ratio of positive cell/total cell number.

\section{Materials}

DAPI image (nuclei quantification or total cell number)

Fluorescent signal image (positive cell quantification)

Image $\mathbf{J}$ software

Adobe Photoshop software

\section{Image superimposition and region of interest design}

1. At the time of the image acquisition, make sure that you save two images of the same field:

- The first using the DAPI channel to quantify the total cell number.

- The second using the channel corresponding to the fluorochrome used.

- In Photoshop, open the DAPI and the fluorescent signal pictures.

2. Create a new file that is the size of your pictures (File/new ....).

3. Create three distinct layers (Layer/new/Layer... ).

4. On the first layer, copy and paste the DAPI picture.

5. On the second layer, copy and paste the fluorescent signal picture.

6. On the third layer, define the ROI using the rectangle or ellipse tool.

7. Save the ROI designed on the fluorescent signal image as a JPEG file.

8. Change the relative order of the layers 1 and 2, the ROI will now appear on the DAPI image. Save it as a JPEG file.

\section{Detection of the total cell number}

9. Open Image J software.

10. Open the DAPI + ROI JPEG file.

11. Select the ROI using the ellipse or rectangle tool and copy it to a new file.

It is particularly important to appropriately and consistently define the region of interest. This is crucial because the proportion of the cell exhibiting a positive signal or its intensity may vary from one tissue to another or even between different regions of a given tissue.

12. Go to Image, Adjust, Brightness/Contrast, Auto and save.

13. Go to Process, Binary, Make Binary (this will make a binary black and white image).

14. Go to Process, Binary, Watershed (this divides two adjacent cells that were eventually identified as one).

15. Go to Analyze, Analyze particles and select the following options:

- Size (pixel`2): 5 - Infinity, so that noise is eliminated. 
ALTERNATE PROTOCOL 3

Mouse Growth Plate Development
- Circularity: 0.00 to 1.00 , so that different shapes from completely elongated to perfectly circular are included.

- Show ellipses (so you can see where and which are the cells that the program identifies).

- Check the boxes:

- "Display results" (individual results will be displayed in a table that can be saved as an Excel file).

○ "Summarize" (summarized results will be displayed in a table that can be saved as an Excel file).

○ "Add to manager" (this plots the cells that the program identifies).

\section{Detection of positive cells}

16. Apply the sequence described in steps 9 to 15 to the fluorescent signal image.

\section{QUANTIFICATION OF SIGNAL-LABELED CELLS ON BRIGHTFIELD PICTURES USING IMAGE J}

Quantification of signals can also be performed on brightfield images with a method similar to the one described above. When brightfield images are used, the counting of both the total cell number and the positive stained cells is achieved on the same picture.

\section{Materials}

Brightfield image

Image J software

\section{Selection of the region of interest}

1. Open the Image $\mathbf{J}$ software.

2. Open the new file.

3. Select the ROI using the ellipse or rectangle tool and copy it to a new file.

4. Go to Image, Adjust, Brightness/Contrast, Auto and save.

It is particularly important to appropriately and consistently define the region of interest. This is crucial because the proportion of the cell exhibiting a positive signal or its intensity may vary from one tissue to another or even between different regions of a given tissue.

\section{Detection of the total cell number}

5. Go to Process, Binary, Make Binary (this will make a binary black and white image).

6. Go to Process, Binary, Watershed (this divides two adjacent cells that were eventually identified as one).

7. Go to Analyze, Analyze particles and select the following options:

- Size (pixel^2): 5 - Infinity, so that noise is eliminated.

- Circularity: 0.00 to 1.00 , so that different shapes from completely elongated to perfectly circular are included.

- Show ellipses (so you can see where and which are the cells that the program identifies).

- Check the boxes:

- "Display results" (individual results will be displayed in a table that can be saved as an Excel file).

- "Summarize" (summarized results will be displayed in a table that can be saved as an Excel file).

- "Add to manager" (this plots the cells that the program identifies). 
8. Go to Image/Adjust/Window bar (move the Window bar so that only positive cells can be visualized).

9. Go to Process, Binary, Make Binary (this will make a binary black and white image).

10. Go to Process, Binary, Watershed (this divides two adjacent cells that were eventually identified as one).

11. Go to Analyze, Analyze particles and select the following options:

- Size (pixel^2): 5 - Infinity, so that noise is eliminated.

- Circularity: 0.00 to 1.00 , so that different shapes from completely elongated to perfectly circular are included.

- Show ellipses (so you can see where and which are the cells that the program identifies).

- Check the boxes:

- "Display results" (individual results will be displayed in a table that can be saved as an Excel file).

- "Summarize" (summarized results will be displayed in a table that can be saved as an Excel file).

"Add to manager" (this plots the cells that the program identifies).

\section{IN VITRO RECOMBINATION: A TOOL TO STUDY GROWTH PLATE DEVELOPMENT}

The Cre/loxP strategy represents a valuable resource in mouse genetics as it allows a variety of modifications of the mouse genome (Nagy, 2000). The strategy is based on the use of $\mathrm{Cre}$ recombinase, which catalyzes the recombination between two recognition sites (lox- $P$ ) inserted within specific DNA segments (Hamilton and Abremski, 1984; Schipani, 2002). This system is widely applied both for in vivo and in vitro studies to analyze the role of specific genes in growth plate development (Schipani et al., 2001; Pfander et al., 2004; Provot and Schipani, 2007; Aro et al., 2012; Maes et al., 2012a; Mangiavini et al., 2014). For in vitro studies, chondrocytes can be isolated from mouse models with DNA sequences of specific genes flanked by two loxP sites. Recombination of the two loxP sites and consequent alteration of the gene function can be achieved by in vitro transduction with adenovirus expressing $C r e$ recombinase. Hereafter, method for mouse chondrocyte isolation and transduction will be described (Pfander et al., 2004; Provot et al., 2007; Aro et al., 2012; Mangiavini et al., 2014).

\section{Materials}

Hanks' Balanced Salt Solution (HBSS; Gibco, cat. no. 24020)

Mouse embryos or newborn pups

$70 \% \mathrm{EtOH}$ (see recipe)

Ice

Trypsin-EDTA $0.25 \%$ (Gibco, cat. no. 25200)

$10 \times$ collagenase type II stock solution (Worthington Biochemicals, cat. no. 4174)

DMEM, high glucose, GlutaMAX Supplement, pyruvate (Gibco, cat. no.10569)

Fetal bovine serum (FBS; GE healthcare, cat. no. SH30070.03)

Penicillin-Streptomycin (5,000 U/ml) (Gibco, cat. no. 15070)

Cre Recombinase adenovirus (Vector Biolabs, cat. no. 1045]

$\beta$-gal/LacZ adenovirus (Vector Biolabs, cat. no. 1080]

100-mm petri dishes

Mouse Growth

Plate Development

111 
Dissection tools including:

Scalpel

Scissors

Forceps

Microdissecting scissors

Forceps

Stereomicroscope

50-ml tubes

Class II biological safety cabinet

Agitated water bath or oven

5-, 10-, 25-, and 50-ml serological sterile pipets

Micropipet and sterile tips

$70-\mu \mathrm{m}$ sterile nylon mesh cell strainer (BD Falcon, cat. no. 352350)

Centrifuge

Hemacytometer

Primaria 6-Well Cell Clear Flat Bottom Surface-Modified Multiwell Culture

(Corning, cat. no. 353846)

$37^{\circ} \mathrm{C}$ incubator

Phase contrast microscope

\section{Chondrocyte isolation}

1. Prepare a series of 50-ml aliquots of HBSS, in sterile conditions and warm them to $37^{\circ} \mathrm{C}$.

2. Sacrifice the embryos or newborn mice according to your protocol and institutional guidelines. Rinse the pups with $70 \% \mathrm{EtOH}$.

If mice have different genotypes, treat them individually and save a piece of tail for genotyping. Use a set of clean dissection tools for each pup, or thoroughly clean the instruments with $70 \%$ EtOH in between each specimen.

3. In a 100-mm petri dish filled with HBSS, dissect forelimb and hindlimbs using microdissection tools.

4. For each limb, cut the paw under the stereomicroscope; remove the skin and muscles. Cut the epiphyses of the bones with a scalpel and place them in a 50-ml tube containing approximately $40 \mathrm{ml}$ HBSS stored on ice.

5. Once all the pups are completed, wash the dissected epiphyses twice in HBSS in a class II biological safety cabinet.

6. Warm the $0.25 \%$ trypsin-EDTA at $37^{\circ} \mathrm{C}$ for $10 \mathrm{~min}$ before use.

7. Remove HBSS and treat the epiphyses with $20 \mathrm{ml}$ of $0.25 \%$ trypsin-EDTA at $37^{\circ} \mathrm{C}$ under agitation for 30 to $40 \mathrm{~min}$.

8. After the first digestion step, let the tube stand $1 \mathrm{~min}$ for the epiphyses to pellet down.

9. In the meantime, dilute the $2-\mathrm{ml}$ aliquot of $10 \times$ collagenase type II stock solution in $18 \mathrm{ml}$ of warm HBSS to obtain a $1 \times$ collagenase type II working solution at 195 $\mathrm{U} / \mathrm{ml}$.

10. Using a 5-ml pipet, carefully remove the $0.25 \%$ trypsin-EDTA supernatant without removing the predigested epiphyses.

11. Transfer the $1 \times$ collagenase type II working solution on the epiphyses and incubate $2 \mathrm{hr}$ at $37^{\circ} \mathrm{C}$ under agitation. 
12. Prepare the culture medium: DMEM, high glucose, GlutaMAX Supplement, pyruvate, $10 \%$ fetal bovine serum, $1 \%$ Penicillin-Streptomycin and warm it at $37^{\circ} \mathrm{C}$.

13. To stop the digestion, add $20 \mathrm{ml}$ of culture medium to the tube containing the epiphyses and homogenize the suspension by pipetting back and forth.

14. Place $70-\mu \mathrm{m}$ nylon mesh cell strainer on a clean 50-ml tube and filter the suspension through to remove eventual undigested particles.

15. Save $50 \mu l$ of the cell suspension for cell counting and centrifuge the rest of it for 15 min at $250 \times g$, at room temperature, to pellet the cells.

16. During the centrifugation, proceed to cell counting using a hemacytometer under a phase contrast microscope.

17. Once the cells are pelleted, carefully remove the supernatant without disturbing the cell pellet and suspend the chondrocytes in 10 to $15 \mathrm{ml}$ culture medium.

18. Using the phase contrast microscope count the cells and seed them in 6-well plate at a density of $40,000 \mathrm{cell} / \mathrm{cm}^{2}$ (approximately 400,000 cell/well) and let them adhere onto the culture surface for $24 \mathrm{hr}$ in the incubator at $37^{\circ} \mathrm{C}$ without shaking or agitation.

\section{Mouse chondrocytes transduction}

19. The next day, remove the culture medium to eliminate the nonadherent cells and add 2 to $3 \mathrm{ml}$ of fresh pre-warmed culture medium per well.

20. Remove the adenoviruses from the $-80^{\circ} \mathrm{C}$ freezer and thaw them on ice.

21. Infect one set of the cultured-chondrocytes with the Cre Recombinase adenovirus to initiate the recombination of the floxed gene and an other set of chondrocytes with the $\beta$-gal/LacZ adenovirus (as a control) using a MOI (multiplicity of infection) of 400 viral particles/cell.

To use a MOI of 400 viral particles/cell on 400,000 cells, 160 million of viral particles will be needed. Having an adenovirus preparation with a given viral titer of $1 \times 1010$ pfu/ml, $16 \mu l$ will have to be added per well.

22. The day after infection, refresh cell culture medium.

Waste that has been in contact with adenovirus has to be inactivated according to the protocol approved by the institution (bleach or autoclave treatment).

23. At a time point $48 \mathrm{hr}$ to $72 \mathrm{hr}$ post-infection the cell culture can be stopped and cells used for the desired analysis.

\section{X COLLAGENASE TYPE II STOCK SOLUTION PREPARATION}

Collagenase digestion is an essential step for chondrocyte isolation. The enzyme digests the cartilaginous matrix and it allows the isolation of cells. In Support Protocol 4 we briefly describe the preparation of Collagenase type II stock solution.

\section{Materials}

Hanks' Balanced Salt Solution (HBSS; Gibco, cat. no. 24020)

Collagenase type II (Worthington Biochemicals, cat. no. 4174)

50-ml tubes

Class II biological safety cabinet

1-ml syringe Luer-Lok Tip (Becton Dickinson, cat. no. 309628)

20-G needle (Becton Dickinson, cat. no. 305175) 
Vortex mixer

1-ml micropipets and clean tips

60-ml syringe Luer-Lok Tip (Becton Dickinson, cat. no. 309653)

18-G needle (Becton Dickinson, cat. no. 305196)

$0.22-\mu \mathrm{m}$ syringe-driven filter unit (Millex, cat. no. SLGV004SL)

1. Under sterile conditions, pipet $50 \mathrm{ml}$ HBBS from the bottle into a clean and labeled 50-ml tube in a class II biological safety cabinet.

2. Assemble together the $1-\mathrm{ml}$ syringe and the $20-\mathrm{G}$ needle. Take $1 \mathrm{ml}$ from the $50 \mathrm{ml}$ HBSS aliquot and inject HBSS directly through the septum of the collagenase type II vial.

3. Vortex the vial until the enzyme is totally dissolved.

4. Carefully remove the aluminum cap and the septum from the vial.

5. Using a 1-ml micropipet and a clean tip, transfer the content of the vial into a clean and properly labeled 50-ml tube.

6. Using a 1-ml micropipette and a clean tip, rinse the collagenase type II vial with 1 $\mathrm{ml}$ HBSS from the 50-ml aliquot and transfer it into the 50-ml tube containing the enzyme solution.

Collagenase type II vial needs to be kept at $4{ }^{\circ} \mathrm{C}$ to preserve the enzymatic activity.

Directly injecting through the septum of the vial, limits the loss of the lyophilized powder that may occur when you open the vial.

Collagenase type II is supplied with an activity $\geq 125$ U/mg dry weight. For instance, a vial containing $100 \mathrm{mg}$ of lyophilized powder with an activity of $360 \mathrm{U} / \mathrm{mg}$ has to be diluted in a final volume of $18.5 \mathrm{ml} \mathrm{HBSS}$.

7. Repeat the previous step 3 times to obtain $5 \mathrm{ml}$ of the enzyme solution.

8. Dilute the $5 \mathrm{ml}$ enzyme solution with HBSS to obtain a " $10 \times$ collagenase type II stock solution" of 1950 enzymatic U/ml.

9. Assemble together the $60-\mathrm{ml}$ syringe and the $18-\mathrm{G}$ needle. Collect the entire volume of the $10 \times$ collagenase type II stock solution. Remove the needle from the syringe and place the filter unit instead. Sterilize the $10 \times$ collagenase type II stock solution by filtration through a $0.22-\mu \mathrm{m}$ pore membrane device.

10. Divide the $10 \times$ collagenase type II stock solution in 2-ml aliquots properly labeled and store them at $-20^{\circ} \mathrm{C}$.

Aliquots may be stored up to 2 years at $-20^{\circ} \mathrm{C}$.

\section{REAGENTS AND SOLUTIONS}

For culture recipes and steps, use sterile tissue-grade water. For other purposes, use deionized, distilled water or equivalent in recipes and protocol steps.

\section{Acetic water (1000 $\mathrm{ml}), 1 \%$}

$10 \mathrm{ml}$ acetic acid

$990 \mathrm{ml} \mathrm{dH_{2 } \mathrm { O }}$

Mix well

Store up to 1 month at room temperature 
Alcian Blue (0.3\%)/70\%EtOH stock solution

$1.5 \mathrm{~g}$ Alcian Blue $8 \mathrm{GX}$

$500 \mathrm{ml}$ of $70 \% \mathrm{EtOH}$ (see recipe)

Thoroughly mix and filter using a $25-\mu \mathrm{m}$ filter

Store up to 6 months at room temperature

Alcian Blue/Alizarin Red Staining working solution

$1 \mathrm{ml}$ of $0.3 \%$ Alcian Blue stock solution (see recipe)

$1 \mathrm{ml}$ of $0.1 \%$ Alizarin Red stock solution (see recipe)

$1 \mathrm{ml}$ Acetic acid, glacial

$17 \mathrm{ml}$ of $70 \% \mathrm{EtOH}$ (see recipe)

Make at least $20 \mathrm{ml}$ for each embryo

Prepare fresh just before use

Alexa Fluor 488 azide working solution (Click-iT EdU Alexa Fluor 488 Imaging Kit)

1 vial Alexa Fluor 488 azide (component B)

$70 \mu 1$ DMSO (component C)

Prepare the Alexa Fluor azide working solution in the dark and mix well

Divide into 5- $\mu \mathrm{l}$ aliquots

Store up to 1 year at $-20^{\circ} \mathrm{C}$

Alizarin Red S (0.1\%)/95\% EtOH stock solution

0.5 g Alizarin Red S

$500 \mathrm{ml}$ of $95 \% \mathrm{EtOH}$ (see recipe)

Thoroughly mix and filter using a $25-\mu \mathrm{m}$ filter

Store up to 6 months at room temperature

$10 \mathrm{mg} / \mathrm{ml} \mathrm{BrdU}-1.2 \mathrm{mg} / \mathrm{ml} \mathrm{FdU}$ solution

Mix $100 \mathrm{mg} \mathrm{BrdU}$ and $12 \mathrm{mg}$ FdU in $1 \mathrm{ml}$ of $10 \times$ PBS until fully dissolved

Bring the volume to $10 \mathrm{ml}$ with $\mathrm{ddH}_{2} \mathrm{O}$

Divide into $400-\mu 1$ aliquots

Store up 4 years at $-20^{\circ} \mathrm{C}$

BSA/PBS (antibody carrier), 3\%

$300 \mathrm{mg}$ bovine serum albumin (BSA)

$10 \mathrm{ml}$ of $1 \times$ PBS (see recipe)

Mix well until the powder is fully dissolved

Prepare fresh and store at $4^{\circ} \mathrm{C}$ until use

Click-iT reaction buffer, $1 \times$ (Click-iT EdU Alexa Fluor 488 Imaging Kit)

Dilute $10 \times$ Click-iT reaction buffer (component D) 1:10 with $\mathrm{dH}_{2} \mathrm{O}$. After use, store any remaining $1 \times$ Click-iT reaction buffer at $4^{\circ} \mathrm{C}$ protected from the light. This $1 \times$ solution is stable for up to 6 months.

Click-iT EdU buffer additive stock solution, 10x (Click-iT EdU Alexa Fluor 488 Imaging Kit)

$400 \mathrm{mg}$ Click-iT EdU buffer additive (component F)

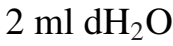

Mix well until all the powder is fully dissolved

Divide into $50-\mu 1$ aliquots

Store up to 1 year at $-20^{\circ} \mathrm{C}$

If the solution develops a brown color, it has degraded and should be discarded.

Mouse Growth Plate Development 
Click-iT EdU buffer additive working solution, $1 \times$

Dilute the $10 \times$ Click-iT EdU buffer additive stock solution (see recipe) 1:10 with $\mathrm{dH}_{2} \mathrm{O}$. Prepare fresh.

\section{DAB HRP substrate solution (from Vector Labs kit)}

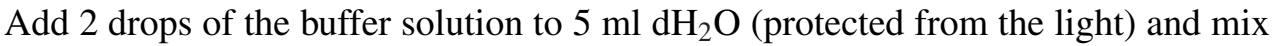
well by vortexing. Then, add 4 drops DAB stock solution and mix well by vortexing. Lastly, add 2 drops of the $\mathrm{H}_{2} \mathrm{O}_{2}$ solution and mix well by vortexing. Prepare fresh.

\section{DAPI stock solution, $5 \mathrm{mg} / \mathrm{ml}$}

$10 \mathrm{mg}$ of $14.3 \mathrm{mM}$ DAPI dihydrochloride, FluoroPure



Suspend the powder until fully dissolved

Divide into $50-\mu 1$ aliquots

Store up to 2 years at $-20^{\circ} \mathrm{C}$

\section{DAPI working solution, $300 \mathrm{nM}$}

Dilute DAPI stock solution (see recipe) 1:5000 in $1 \times$ phosphate-buffered saline (PBS; see recipe)

Store up to 6 weeks at $4^{\circ} \mathrm{C}$ protected from the light

\section{Denhardt's solution, $50 \times$}

$5 \mathrm{~g}$ Ficoll

5 g polyvinylpyrrolidone

$5 \mathrm{~g}$ bovine serum albumin (BSA)

$\sim 500 \mathrm{ml}$ DEPC-treated water

Bring the volume to $500 \mathrm{ml}$ and suspend the powders until fully dissolved

Divide into $10 \mathrm{ml}$ aliquots

Store up to 2 years at $-20^{\circ} \mathrm{C}$

Clean all the supplies with RNase away.

\section{Dithiothreitol (DTT), 1 M}

$3.09 \mathrm{~g}$ DTT

$\sim 20 \mathrm{ml}$ of $10 \mathrm{mM}$ sodium acetate, $\mathrm{pH} 5.2$ (see recipe)

Suspend the powder and bring the volume to $20 \mathrm{ml}$

Divide into $500-\mu 1$ aliquots

Store up to 2 years at $-20^{\circ} \mathrm{C}$

Clean all the supplies with RNase away

EdU stock solution (Click-iT EdU Alexa Fluor 488 Imaging Kit), 10 mM

$5 \mathrm{mg}$ EdU (component A)

2 ml Dimethyl sulfoxide (DMSO; component C)

Mix the powder until fully dissolved

Divide into $500-\mu 1$ aliquots

Store up to 1 year at $-20^{\circ} \mathrm{C}$

$1 \times P B S$ may be used as an alternative to DMSO.

\section{EF5 stock solution, $10 \mathrm{mM}$}

\section{$3.02 \mathrm{mg}$ EF5}

$1 \mathrm{ml}$ of $0.9 \% \mathrm{NaCl}$ (see recipe)

Sonicate the powder for approximately $4 \mathrm{hr}$ at $37^{\circ} \mathrm{C}$ to completely dissolve it 
EtOH, 70\% (1 liter)

$700 \mathrm{ml}$ of $100 \% \mathrm{EtOH}$

$300 \mathrm{ml} \mathrm{dH_{2 } \mathrm { O }}$

Store up to 6 months at room temperature

EtOH, $80 \%$ (1 liter)

$800 \mathrm{ml}$ of $100 \% \mathrm{EtOH}$

$200 \mathrm{ml} \mathrm{dH}_{2} \mathrm{O}$

Store up to 6 months at room temperature

EtOH, 95\% (1 liter)

$950 \mathrm{ml}$ of $100 \% \mathrm{EtOH}$

$50 \mathrm{ml} \mathrm{dH_{2 } \mathrm { O }}$

Store up to 6 months at room temperature

$70 \% \mathrm{EtOH} / 0.1 \times \mathrm{SSC}$

$420 \mathrm{ml}$ of $100 \% \mathrm{EtOH}$

$177 \mathrm{ml} \mathrm{dH_{2 } \mathrm { O }}$

$3 \mathrm{ml}$ of $20 \times \mathrm{SSC}$

Mix well

Add $3 \mathrm{ml}$ of $20 \times$ SCC just before use

$80 \% \mathrm{EtOH} / 0.1 \times \mathrm{SSC}$

$480 \mathrm{ml}$ of $100 \% \mathrm{EtOH}$

$117 \mathrm{ml} \mathrm{dH_{2 } \mathrm { O }}$

$3 \mathrm{ml}$ of $20 \times \mathrm{SSC}$

Mix well

Add $3 \mathrm{ml}$ of $20 \times$ SCC just before use

95\% EtOH/0.1 x SSC

$570 \mathrm{ml}$ of $100 \% \mathrm{EtOH}$

$27 \mathrm{ml} \mathrm{dH}_{2} \mathrm{O}$

$3 \mathrm{ml}$ of $20 \times \mathrm{SSC}$

Mix well

Add $3 \mathrm{ml}$ of $20 \times$ SCC just before use

Fast Green solution (100 $\mathrm{ml}), 0.1 \%$

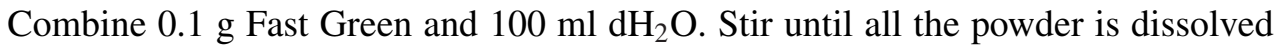
and then filter using a $25-\mu \mathrm{m}$ filter. Store up to 1 week at room temperature (re-filter before use).

\section{Glycerol (20\%)/1\% KOH}

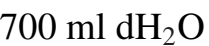

$200 \mathrm{ml}$ Glycerol

$100 \mathrm{ml}$ of $10 \% \mathrm{KOH}$ stock solution

Store up to 6 months at room temperature

Glycerol (50\%)/1\% KOH

$400 \mathrm{ml} \mathrm{dH_{2 }} \mathrm{O}$

$500 \mathrm{ml}$ Glycerol

$100 \mathrm{ml}$ of $10 \% \mathrm{KOH}$ stock solution

Stored up to 6 months at room temperature 
Glycerol (80\%)/1\% КОH

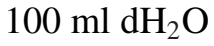

$800 \mathrm{ml}$ Glycerol

$100 \mathrm{ml}$ of $10 \% \mathrm{KOH}$ stock solution

Stored up to 6 months at room temperature

Glycerol stock solution, $40 \%$

$40 \mathrm{ml}$ of $100 \%$ Glycerol

$60 \mathrm{ml} \mathrm{dH}{ }_{2} \mathrm{O}$

Mix well

Store up to 6 months at room temperature

Glycerol working solution, $2 \%$

$1 \mathrm{ml}$ of $40 \%$ glycerol stock solution (see recipe)

$19 \mathrm{ml} \mathrm{dH_{2 } \mathrm { O }}$

Mix well

Prepare fresh

$3 \% \mathrm{H}_{2} \mathrm{O}_{2} / \mathrm{MeOH}$ (quenching solution)

$25 \mathrm{ml}$ of $30 \% \mathrm{H}_{2} \mathrm{O}_{2}$

$225 \mathrm{ml} \mathrm{MeOH}$

Prepare fresh

$\mathrm{HCl}, 0.2 \mathrm{~N}$

Add $10 \mathrm{ml}$ of $12 \mathrm{~N} \mathrm{HCl}$ to $590 \mathrm{ml} \mathrm{dH}_{2} \mathrm{O}$

Prepare fresh

Hoechst 33342 working solution (Click-iT EdU Alexa Fluor 488 Imaging Kit)

Dilute Hoechst 33342 (component G) 1:2000 with 1× PBS in the dark. Prepare Hoechst 33342 working solution right before use and protect it from the light.

\section{Hybridization solution (50 $\mathrm{ml})$}

Combine the following:

$25 \mathrm{ml}$ UltraPure formamide

$500 \mu l$ of $1 \mathrm{M}$ Tris.Cl, $\mathrm{pH} 7.6$

$1 \mathrm{ml}$ of $10 \mathrm{mg} / \mathrm{ml} \mathrm{tRNA}$

$1 \mathrm{ml}$ of $50 \times$ Denhardt's solution (see recipe)

$10 \mathrm{ml}$ of $50 \%$ Dextran Sulfate

$6 \mathrm{ml}$ of $5 \mathrm{M} \mathrm{NaCl}$

$1.25 \mathrm{ml}$ of $10 \%$ SDS

$5.25 \mathrm{ml}$ DEPC-treated water

Mix thoroughly by hand

Divide into 5-ml aliquots

Store up to 2 years at $-20^{\circ} \mathrm{C}$

Clean all the supplies with RNase away.

\section{Kodak developer solution}

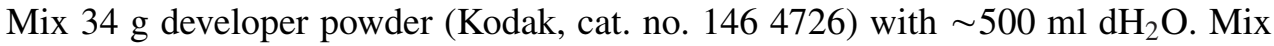
until the powder is fully dissolved and bring the volume to $500 \mathrm{ml}$. The solution should be slightly yellow. Prepare fresh. 
Kodak fixer solution

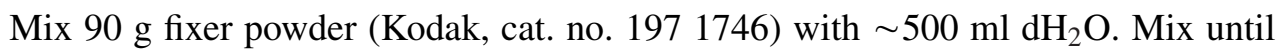
the powder is fully dissolved and bring the volume to $500 \mathrm{ml}$. The solution should be cloudy white. Prepare fresh.

\section{$\mathrm{KOH}$ working solution, $1 \%$}

$100 \mathrm{ml}$ of $10 \% \mathrm{KOH}$

$900 \mathrm{ml} \mathrm{dH_{2 } \mathrm { O }}$

Store up to 6 months at room temperature

Mouse serum/PBS (blocking solution), 5\%

$0.5 \mathrm{ml}$ Normal Mouse Serum

$9.5 \mathrm{ml}$ of $1 \times$ PBS

Mix well

Divide into $400-\mu 1$ aliquots

Store up to 1 year at $-20^{\circ} \mathrm{C}$

NTE, $5 \mathrm{x}$

$5 \mathrm{ml}$ of $1 \mathrm{M}$ Tris $\cdot \mathrm{Cl}, \mathrm{pH} 7.5$

$5 \mathrm{ml}$ of $0.5 \mathrm{M}$ EDTA, $\mathrm{pH} 8.0$

$5 \mathrm{ml}$ of $5 \mathrm{M} \mathrm{NaCl}$

$35 \mathrm{ml}$ DEPC-treated water

Clean all the supplies with RNase Away

Divide into $500-\mu 1$ aliquots

Store up to 1 year at $-20^{\circ} \mathrm{C}$

\section{Paraformaldehyde (PFA), 4\% (for $600 \mathrm{ml}$ solution)}

Warm $540 \mathrm{ml} \mathrm{dH}_{2} \mathrm{O}$ in the microwave until it reaches $60^{\circ} \mathrm{C}(\sim 1 \mathrm{~min})$. Place a 1-liter glass beaker on heating block in a chemical hood set at $60^{\circ} \mathrm{C}$ and start stirring. Add $600 \mu \mathrm{l}$ of $10 \mathrm{~N} \mathrm{NaOH}$ first and then the $24 \mathrm{~g}$ PFA in a fume hood. When powder goes into solution, turn off heat and add $60 \mathrm{ml}$ of $10 \times$ PBS. Add $600 \mu \mathrm{l}$ diethylpyrocarbonate and let stir for another $10 \mathrm{~min}$.

Check that $\mathrm{pH}$ is between 7.0 and 7.4 using pH strip. (Add $10 \mathrm{~N} \mathrm{NaOH}$ or $12 \mathrm{~N} \mathrm{HCl}$, if necessary). Cool down the solution to room temperature before use. Use 4\% PFA within few hours.

Store for 2 to 3 days at $4^{\circ} \mathrm{C}$. For long-term storage, $4 \%$ PFA may be divided into aliquots and stored up to 6 months at $-20^{\circ} \mathrm{C}$.

\section{Permeabilization solution}

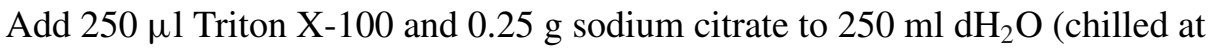
$4^{\circ} \mathrm{C}$ ) in a coldroom while stirring. Prepare fresh.

\section{Phosphate-buffered saline (PBS), $1 \times$}

$100 \mathrm{ml}$ of $10 \times$ phosphate-buffered saline (PBS; see recipe)

$900 \mathrm{ml} \mathrm{dH_{2 } \mathrm { O }}$

Stir the solution and sterilize it. Store up to 1 month at $4^{\circ} \mathrm{C}$

\section{Proteinase K stock solution, $10 \mathrm{mg} / \mathrm{ml}$}

Suspend $100 \mathrm{mg}$ Proteinase K powder in $10 \mathrm{ml}$ DEPC-treated water until fully dissolved. Divide into $600-\mu 1$ aliquots. Store up to 1 year at $-20^{\circ} \mathrm{C}$. 
Proteinase $\mathrm{K}$ working solution, $10 \mu \mathrm{g} / \mathrm{ml}$

$600 \mu \mathrm{l}$ of $10 \mathrm{mg} / \mathrm{ml}$ proteinase $\mathrm{K}$ stock solution (see recipe)

$600 \mathrm{ml}$ of $1 \times$ phosphate-buffered saline (PBS; see recipe)

Add the $10 \mathrm{mg} / \mathrm{ml}$ Proteinase K stock solution directly into the glass dish immediately before use

Clean all the supplies with RNase away.

\section{RNase A, $20 \mathrm{mg} / \mathrm{ml}$}

$200 \mathrm{mg}$ RNase A

$\sim 10 \mathrm{ml}$ of $10 \mathrm{mM}$ Tris/15 mM NaCl buffer, $\mathrm{pH} 7.6$

Mix by inversion

Bring the volume to $10 \mathrm{ml}$

Divide into $900-\mu 1$ aliquots

Store up to 1 year at $-20^{\circ} \mathrm{C}$

\section{Safranin O solution $(100 \mathrm{ml}), 0.08 \%$}

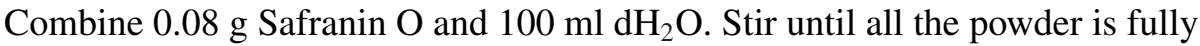
dissolved and filter using a $25-\mu \mathrm{m}$ filter. Store up to 1 week at room temperature (re-filter before use).

\section{Saline solution, $0.9 \%$}

$9 \mathrm{~g}$ sodium chloride $(\mathrm{NaCl})$

$1000 \mathrm{ml} \mathrm{dH} \mathrm{H}_{2} \mathrm{O}$

Stir until all the powder goes into solution

Sterilize by autoclaving the solution for 15 minutes at $121^{\circ} \mathrm{C}$

Store up to 6 months at room temperature

Sodium acetate, $10 \mathrm{mM}, \mathrm{pH} 5.2$

$100 \mu \mathrm{l}$ of $3 \mathrm{M}$ sodium acetate, $\mathrm{pH} 5.5$

$\sim 30 \mathrm{ml}$ DEPC-treated water

Adjust the $\mathrm{pH}$ to 5.2 with $\mathrm{HCl}$

Bring the volume to $30 \mathrm{ml}$

Divide into 1-ml aliquots

Store up to 2 years at $-20^{\circ} \mathrm{C}$

Clean all the supplies with RNase away.

\section{Sodium citrate solution (antigen retrieval solution)}

$12.5 \mathrm{ml}$ Citrate buffer, $\mathrm{pH} 6.0$

$237.5 \mathrm{ml} \mathrm{ddH}_{2} \mathrm{O}$

Mix well and microwave the solution until it reaches $90^{\circ}$ to $95^{\circ} \mathrm{C}(\sim 2 \mathrm{~min})$

Place it in a heated water bath at $95^{\circ} \mathrm{C}$ and let the solution equilibrate for about 30 $\min$

Prepare fresh

$S S C, 1 \times$

$30 \mathrm{ml}$ of $20 \times \mathrm{SSC}$

$570 \mathrm{ml} \mathrm{dH_{2 } \mathrm { O }}$

Prepare fresh

$S S C, 2 \times$ 
Mix well

Distribute $600 \mathrm{ml}$ in each glass dish

Prepare fresh

$S S C, 4 \mathrm{x}$

$180 \mathrm{ml}$ of $20 \times \mathrm{SSC}$

$720 \mathrm{ml} \mathrm{dH_{2 } \mathrm { O }}$

Stir the solution

Distribute $\sim 600 \mathrm{ml}$ in each glass dish

Prepare fresh

SSC, $4 \times /$ formamide $50 \% / 50 \%$

Distribute $300 \mathrm{ml}$ of $4 \times \mathrm{SSC}$ (see recipe) into three glass containers

Warm one container in the microwave for 2 min to $\sim 85^{\circ} \mathrm{C}$

Add $300 \mathrm{ml}$ formamide in fume hood

Place the container, with lid, into a $52^{\circ} \mathrm{C}$ water bath

Repeat the passages for the other two containers.

Prepare fresh

\section{Sucrose $(30 \%) / P B S$}

$30 \mathrm{~g}$ sucrose

$100 \mathrm{ml}$ of $1 \times$ phosphate-buffered saline (PBS; see recipe)

Add progressively the $1 \times$ PBS to the sucrose and bring the volume up to $100 \mathrm{ml}$

Prepare fresh just before use

TBS, $1 \times$

$100 \mathrm{ml}$ of $10 \times$ TBS

$900 \mathrm{ml} \mathrm{dH}_{2} \mathrm{O}$

Prepare fresh

\subsection{TEA/30 mM AA, pH 7.5}

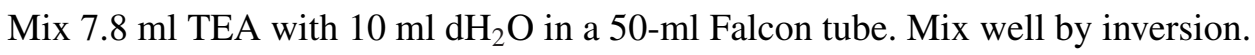

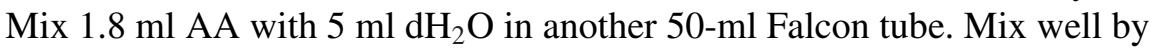
inversion. Do not combine the two solutions. Prepare both solutions immediately before use.

\section{TNB (blocking solution)}

0.05 g NEN block reagent (TSA kit; Perkin Elmer, cat. no. NEL700A)

$10 \mathrm{ml}$ of $1 \times$ TBS (see recipe)

Heat $1 \times$ TBS on a stir plate to dissolve block reagent

Divide into 10-ml aliquots

Store up to 2 years at $-20^{\circ} \mathrm{C}$

TNT, $1 \times$

$400 \mathrm{ml}$ of $10 \times$ TBS

$3600 \mathrm{dH}_{2} \mathrm{O}$

$2 \mathrm{ml}$ Tween-20

Mix well and add Tween-20 while the solution is stirring

Prepare fresh

Trypsin solution (Brdu Staining kit)

1 part Solution $1 \mathrm{~A}$

2 part Solution 1B

Mix right before use 


\section{TUNEL reaction mixture (for 10 small sections)}

$50 \mu 1$ enzyme solution (from In Situ Cell Death Detection kit; Roche, cat. no. 11684817910)

$450 \mu 1$ label solution (from In Situ Cell Death Detection kit; Roche, cat. no. 11684817910)

Keep the reagents on ice and mix them by pipetting

Prepare fresh

\section{Weigert's iron hematoxylin working solution}

Mix 50\% solution A (Weigert's Iron Hematoxylin Solution A; Sigma, cat. no. HT107) with 50\% solution B (Weigert's Iron Hematoxylin Solution B; Sigma, cat. no. HT109). Filter the solution using a $25-\mu \mathrm{m}$ filter

Prepare the working solution immediately before use and use within few hours.

A prepared Weigert's Iron Hematoxylin is commercially available (Sigma). This solution also needs to be filtered before use.

\section{COMMENTARY}

\section{Background Information}

The staining properties of Alcian Blue and Alizarin Red have been known for over a century (Schultze, 1897) but only in more recent years, a protocol has been optimized for the study of mouse growth plate (Jegalian and De Robertis, 1992).

H\&E staining, together with Safranin O, has also been essential to understand the morphological changes that occur during endochondral ossification. $\mathrm{H} \& \mathrm{E}$ staining has been introduced in the 1800s (Böhmer, 1865; Fischer, 1876) and it has become the most widely used stain in medical diagnosis (Wissowzky, 1877). Safranin O, which was first introduced as a nuclear counterstaining in analysis of bacteria (Coico, 2005), is routinely used to detect GAGs in the cartilaginous matrix (Schmitz et al., 2010). Both stainings are thus commonly performed to evaluate chondrocyte morphology and growth plate matrix composition.

In situ hybridization, which was first introduced in the early 1970s (Gall and Pardue, 1969), is a critical technique to study expression of chondrocyte mRNAs on histological sections in vivo.

TUNEL assay, which has been first described in 1992 (Gavrieli et al., 1992), classically detects cells that undergo death and it is commonly used for this purpose in the analysis of the growth plate.

The process of detecting antigens (e.g., proteins) in cells of a tissue section by exploiting the principle of antibodies binding specifically to antigens in biological tissues was first developed by Albert Coons (Coons et al., 1941) and has also become one of the gold standard techniques to evaluate accumulation of specific proteins in chondrocytes in vivo.

The original protocol to assess cell proliferation was developed with the use of ${ }^{3}$ H-thymidine (Hughes et al., 1958). More recently, this protocol has been replaced with a more sensitive and nonradioactive method that uses the thymidine analog BrdU (Gratzner, 1982). BrdU analysis in growth plate development revealed that only two layers of chondrocytes are proliferating (the round proliferative and the columnar proliferative chondrocytes), while hypertrophic chondrocytes are postmitotic cells that have exited the cell cycle. More recently, EdU detection assay, which represents an easier and highly sensitive method to detect cell proliferation, was developed (Salic and Mitchison, 2008) and it is now routinely used to detect cell proliferation in the growth plate.

EF5 detection has been recently developed by Drs. Cameron Koch and Sydney Evans (Koch, 2002). EF5 is routinely used as hypoxia marker in vivo especially in cancer research (Evans et al., 2001), and in vitro to establish levels of oxygenation of different cell types under different culture conditions (Koch, 2002). Moreover, a few years ago, use of EF5 staining revealed the presence of an inner, hypoxic region in the fetal growth plate (Schipani et al., 2001).

Lastly, the introduction of the Cre/loxP strategy allowed the evaluation of the role of a specific gene in chondrocyte biology both in vivo and in vitro. In particular, the use of $\mathrm{Cre}$ recombinase expressing adenoviruses (Anton and Graham, 1995; Wang et al., 1996) has allowed studying of the physiological 
functions of specific genes in primary cells in vitro.

\section{Critical Parameters and Troubleshooting}

\section{Basic Protocol 1}

An inadequate fixation or processing of the specimens may lead to alterations in the stainings. It is therefore critical to avoid overfixation, over- or under-processing of the samples.

Over-fixation can be prevented by:

- Avoiding prolonged fixation of the skeletal tissues (do not leave specimens in 70\% EtOH for more than 1 week before dissecting and processing).

Over-processing can be prevented by:

- Decreasing the time in the dehydrating solutions.

Under-processing can be prevented by:

- Using fresh xylene and ethanol.

Specimen orientation is another critical step to obtain complete and informative sections of the fetal growth plate. An incorrect orientation may occur and can be prevented by:

- Ensuring the correct placement of the specimen in the mold (right versus left specimens; see Basic Protocol 1).

- Checking that the specimen is completely flat at the bottom of the mold.

- Applying a light pressure over the entire specimen during the initial chilling of the paraffin block.

- Quickly embedding to avoid that the paraffin chills before the specimen has adhered to the base of the mold.

Moreover, it is mandatory to obtain complete longitudinal sections of embryonic mouse limbs to be able to compare and analyze the growth plates. A good expertise in sectioning is therefore essential and it requires a specific training. Common problems during sectioning are failure to form a ribbon, wrinkled sections, varied thickness of sections, and holes in the sections. Failure to form a ribbon can be caused by a dull blade, inappropriate angle of the blade, or warm paraffin block. These issues can be prevented by:

- Changing the blade.

- Decreasing the tilt of the blade.

- Cooling the paraffin block on the ice block for a longer period of time $(\sim 15-20$ $\min$ ).

Wrinkled sections may be caused by an incorrect processing, microtome vibrations, a dull blade, warm paraffin block, or water bath temperature that is to low. These issues can be avoided by:
- Performing a correct fixation and processing of the specimens.

- Checking that the microtome is on a firm table and in good working order.

- Changing the blade.

- Cooling the paraffin block on the ice block for a longer period of time ( $\sim 15$ to 20 $\min$ ).

- Increasing water bath temperature (not higher that $56^{\circ} \mathrm{C}$ ) or leaving the ribbon on water for a prolonged time (10 to $15 \mathrm{~min}$ ).

Varied thickness of sections may be due to too little blade tilt or to loose or worn microtome parts. This can be solved by:

- Increasing the tilt of the blade.

- Checking that the microtome is on a firm table and in good working order.

In the context of fetal limbs, holes usually occur at the bone marrow cavity and they are caused by an excessive dehydration of this region. This problem can be prevented by:

- Cutting short ribbons (three to four sections).

- Briefly soaking the block in the water bath (no more than $10 \mathrm{sec}$ ) after each ribbon, then drying and cooling it on the ice block for 15 to $20 \mathrm{~min}$.

\section{Basic Protocol 2}

Correct orientation, embedding, and sectioning are also mandatory during the preparation of fresh frozen specimens. Thus, inadequate frozen sections are often the result of issues occurring during these critical steps. Incorrect orientation or embedding can be avoided by:

- Ensuring the correct placement in the mold (right versus left specimens; see Basic Protocol 1).

- Checking that the dry ice block is completely flat.

- Checking that the specimen is completely flat at the bottom of the mold.

Applying a light pressure over the entire specimen during the initial chilling of the OCT block.

Common problems in sectioning frozen specimens are wrinkled sections, varied thickness of sections, and holes in the sections. Wrinkled sections are generally caused by a dull blade or an improper cryostat temperature. This can be solved by:

- Changing the blade.

- Increasing the cryostat temperature (up to $-15^{\circ} \mathrm{C}$ ).

Varied thickness of sections occurs if the blade is dull or if the cryostat has loose or worn parts. It can be prevented by:
Mouse Growth Plate Development 
- Changing the blade.

- Checking that the cryostat is in good working order and all the parts are tightly closed.

In the context of fetal limbs, holes usually occur at the level of the bone marrow cavity due to the different consistence of the bone marrow compared to the growth plate. The problem can be prevented by:

- Increasing the cryostat temperature (up to $-15^{\circ} \mathrm{C}$ ).

- Touching the bone marrow cavity with a finger to slightly increase the temperature at that site.

\section{Basic Protocol 3}

A good contrast between Alizarin Red and Alcian Blue is required to clearly define bone and cartilage. It is thus mandatory to properly fix, stain, and digest the specimens to obtain an informative staining. An incomplete or weak staining may be caused by expired solutions, improper dissection or fixation of the specimen, or short incubation time in Alcian Blue/Alizarin Red Staining working solution. This can be prevented by:

- Checking expiration dates of the reagents.

- Preparing fresh solutions each time.

- Filtering the solutions immediately before use.

- Carefully removing all the skin, organs and fat.

- Prolonging the fixation time in $95 \%$ EtOH and $100 \%$ acetone (up to 5 to 7 days each).

- Increasing the incubation time in Alcian Blue/Alizarin Red staining working solution (up to 10 days).

Under-digestion of the specimens may also lead to an improper staining. This is usually caused by a too short incubation time in $1 \%$ $\mathrm{KOH}$ and it can be avoided by:

- Changing $1 \% \mathrm{KOH}$ each day

- Prolonging the incubation time in $1 \%$ $\mathrm{KOH}$ (up to 5 to 7 days).

By contrast, over-digestion results in disintegration of the specimen or disarticulation of skeletal elements and it is caused by an excessive incubation time in $1 \% \mathrm{KOH}$. It can be prevented by:

- Reducing the incubation time in $1 \%$ $\mathrm{KOH}$.

- Proceeding to $20 \%$ Glycerol/1\% $\mathrm{KOH}$ as soon as the skeleton is clearly visible through the surrounding tissue.

\section{Basic Protocol 4}

$\mathrm{H} \& \mathrm{E}$ staining is the first assay to be performed during the study of the growth plate as it allows an immediate evaluation of the tissue morphology. An insufficient contrast between hematoxylin and eosin, due to inadequate nuclear or cytoplasmic staining, affects the analysis of the growth plate and needs to be avoided. In particular, pale nuclear staining, due to over-fixation of the specimen, inadequate incubation time in hematoxylin or use of depleted hematoxylin, can be prevented by:

- Leaving the specimen in fixative only for a limited amount of time (few days).

- Increasing the incubation time in hematoxylin.

- Changing often hematoxylin (every 3 to 4 stainings).

Dark nuclear staining is usually caused by excessive incubation time in hematoxylin or excessive thickness of the sections and it can be avoided by:

- Decreasing the incubation time in hematoxylin.

- Carefully checking the thickness of the sections during the cutting.

In addition, if the nuclear color is not blue, either the hematoxylin is too old or the bluing step in tap water has not been properly performed. The problem can be overcome by:

- Checking the quality of the hematoxylin.

- Checking that the tap water is cold and eventually increasing the time in tap water.

Pale cytoplasmic staining may be caused by a prolonged time in the dehydrating solutions, an inadequate incubation time in eosin or by a reduced thickness of the sections. This issue can be prevented by:

- Reducing the timing in EtOH.

- Increasing the incubation time in eosin.

- Carefully checking the thickness of the sections during the cutting.

Dark cytoplasmic staining is caused by excessive incubation time in eosin or excessive thickness of the sections and it can be prevented by:

- Decreasing the incubation time in eosin.

- Carefully checking the thickness of the sections during the cutting.

\section{Basic Protocol 5}

Safranin O staining is also critical important in the evaluation of fetal growth plate. Similarly to H\&E staining, a common issue during this staining is an incorrect contrast between Safranin O and Fast Green. Pale 
Safranin O may be due to expired reagents and solutions, contaminated solutions with other stainings (i.e., H\&E staining), over-fixation of the specimens, or inadequate incubation time in the solution. To avoid this issue:

- Use fresh xylene and EtOH to deparaffinize and dehydrate the sections.

- Prepare fresh solutions every time.

- Leave the specimen in fixative only for a limited amount of time (few days).

- Increase incubation time in Safranin O. Another common problem during Safranin $\mathrm{O}$ staining is the formation of blue-black precipitates, which are caused by Weigert's Hematoxylin debris and can be avoided by:

- Filtering the solutions immediately before use.

- Extensively rinsing the sections in $\mathrm{dH}_{2} \mathrm{O}$ after the Weigert's Hematoxylin incubation.

\section{Basic Protocol 6}

In situ hybridization is a very sensitive assay, which requires special care at each step. Particular attention in avoiding contamination with RNases is necessary during the preparation of the riboprobes. Moreover, a variety of issues may occur at different steps and they will be more thoroughly discussed below.

\section{Labeling riboprobes}

An adequate CPM is required to obtain properly labeled riboprobes. CPM lower than 500,000 means that an inadequate ${ }^{35}$ S-UTP incorporation occurred due to expired reagents, incomplete linearization of the plasmid, inefficient reaction, or expired ${ }^{35} \mathrm{~S}$-UTP. To avoid this problem:

- Properly store all the reagents.

- Do not use expired reagents.

- Check the linearization of the cDNA with $1 \%$ agarose gel.

- Check the water bath temperature during the reaction.

- Avoid using ${ }^{35}$ S-UTP 3 to 4 weeks past the reference date ${ }^{35}$ S-UTP half life is 87.4 days)

CPM greater than 2,000,000 means an excess of un-incorporated ${ }^{35} \mathrm{~S}$-UTP. If this inconvenient occurs:

- Re-purify the riboprobe with mini Probequant G-50 columns.

\section{Pre-hybridization, hybridization, and post-hybridization}

A weak signal or an intense background represent the most common issues during these steps. Weak signals may be caused by overfixation of the specimens or by a too high stringency of the procedure. It can be solved by:

- Leaving the specimen in fixative only for a limited amount of time (few days).

- Increasing the incubation time in proteinase $\mathrm{K}$.

- Decreasing the incubation temperatures, the salt $(5 \mathrm{NaCl}$ and SSC) or detergent $(10 \%$ SDS $)$ concentrations in the hybridization solution and in the post-hybridization step to reduce the stringency.

An intense background signal is due to nonspecific binding of the riboprobe to free amino acids. To reduce nonspecific binding:

- Increase the incubation time in $0.1 \mathrm{M}$ TEA/AA, pH 7.5.

- Increase the incubation temperatures, the salt ( $5 \mathrm{NaCl}$ and SSC) or detergent (10\% SDS) concentration in the hybridization solution and in the post-hybridization step to augment the stringency.

- Extend incubation time in RNase A (up to $90 \mathrm{~min}$ ).

\section{Dipping}

An intense background signal may also derive from the use of expired emulsion or from the use of emulsion exposed to light. To avoid this issue:

- Do not use expired emulsion.

- Properly store emulsion at $4^{\circ} \mathrm{C}$ and protected from light (with three layers of aluminum foil).

- Use a red LED safety light in the darkroom and check for light leaking in the room.

- Cover the water bath display with aluminum foil to avoid exposing the emulsion to light.

\section{Developing and counterstaining}

The developing step can be altered either by the use of expired solutions or by exposure to light. The developing step thus can be easily improved by:

- Preparing fresh solutions each time.

- Avoiding light exposure during the incubation in developer and fixer solutions.

For problems in counterstaining refer to the troubleshooting section for Basic Protocol 4.

\section{Basic Protocol 7}

TUNEL assay is also a very sensitive procedure; it is thus critical to obtain an intense fluorescent signal when performing this staining. Occasionally, the signal may be weak or the fluorescent background may be too intense. Weakness in the signal may be caused by the
Mouse Growth Plate Development 
over-fixation of the specimens or by the use of expired reagents. To obtain a better signal:

- Avoid prolonged fixation of the specimens.

- Do not proceed with the experiment until the permeabilization solution has reached $4^{\circ} \mathrm{C}$.

- Do not use expired reagents.

- Properly store reagents and solutions.

- Prepare the TUNEL mixture solution immediately before use and keep it on ice until use.

A high background is caused by nonspecific binding or by an excessive dehydration of the sections. To reduce the background:

- Do not use any enzymatic antigen retrieval in addition to the permeabilization.

- Include a negative control with each staining experiment to assess the degree of background staining.

- Do not let the sections dry out during the staining procedure.

\section{Basic Protocol 8}

Immunohistochemistry is a complex procedure, which involves many critical steps. Issues may thus occur at different steps and they usually lead to the detection of a weak signal or detection of intense background. Detection of a weak signal is caused by a variety of reasons including: over-fixation of the specimens, inefficacy of the antigen retrieval, inadequate primary antibody concentration, wrong incubation time or temperature with the primary antibody and, finally, wrong choice of the primary antibody. Different adjustments in the protocol may increase the signal, such as:

- Avoiding prolonged fixation of the specimens.

- Trying a different antigen retrieval method (i.e., trypsin, proteinase K, chondroitinase or hyaluronidase).

- Carefully titrating the antibody to find the best concentration (following the manufacturers' indications).

- Trying a different incubation time or temperature for the primary antibody (e.g., 1 $\mathrm{hr}$ at room temperature).

- Adding multiple amplification steps with tyramide and HRP-streptavidin.

- Carefully choosing the primary antibody by comparing different manufacturers and by checking the literature.

Intense background is due to nonspecific binding. Nonspecific binding may be the consequence of: endogenous peroxidase, crossreaction of the secondary anti-mouse antibody to endogenous mouse tissue immunoglobulins and other components, excessive incubation time in DAB HRP substrate solution. To reduce nonspecific binding:

- Increase the incubation time in $3 \% \mathrm{H}_{2} \mathrm{O}_{2} / \mathrm{MeOH}$ if HRP-conjugated antibody or streptavidin is used.

- Try different blocking solutions (i.e., BSA, normal mouse serum).

- Avoid using primary antibodies raised in the same species of the specimens.

- Try to use polyclonal antibodies rather than monoclonal ones when mouse tissue is analyzed.

- Decrease incubation time with the DAB HRP substrate solution.

- Include a negative control (in which primary antibody is omitted) with each staining experiment to assess the degree of background staining.

\section{Basic Protocol 9}

Both BrdU and EdU require the injection in the abdominal cavity of the pregnant female. Thus, a possible complication during these assays is an ineffective in vivo labeling, which results in the detection of a weak signal. To avoid this issue:

- Use new reagents and properly store them.

- During injection, point the needle towards diaphragm at shallow angle in the center of the abdomen to avoid uterus and guts.

- Adjust the labeling time based on the age of the embryos. The labeling time for skeletal tissues is typically 30 to $60 \mathrm{~min}$ for embryos at the gestation days 10.5 (E10.5) to E13.5, 1 to $2 \mathrm{hr}$ for E14.5 to E18.5 fetuses, and 2 to $4 \mathrm{hr}$ for post-natal mice.

A weak signal can also be determined by other complications that may be encountered performing an immunostaining (See Troubleshooting for Basic Protocol 8 for details). Moreover, during EdU assay, a high fluorescence background can be detected and it is usually caused by the dehydration of the tissue sections. To prevent this problem:

- Do not let the sections dry out during the staining procedure.

\section{Basic Protocol 10}

Problems during the PCNA staining are the common complications that may be encountered during an immunohistochemical analysis. See Troubleshooting for Basic Protocol 8 for details.

\section{Basic Protocol 11}

Similarly to BrdU and EdU, EF5 staining also requires an intraperitoneal injection in a 
pregnant female. An ineffective in vivo labeling can therefore cause detection of a weak signal. To avoid this issue:

- Use new reagents and properly store them. In particular, store EF5 powder protected from the light and with desiccant at RT.

- Prepare the $10 \mathrm{mM}$ EF5 stock solution the day before the injection.

- Thoroughly dissolve the EF5 powder with a sonicator.

- During injection, point the needle towards diaphragm at shallow angle in the center of the abdomen to avoid uterus and guts.

General immunohistochemical difficulties may also be encountered during the EF5 staining (See Troubleshooting for Basic Protocol 8 for details).

\section{Basic Protocol 12}

Background noise may interfere with the quantification of signals. It could be assimilated as positive signal and therefore interpreted as false positive during the analysis. It is thus recommended to reduce the background at minimum levels by increasing the contrast and the threshold size. Contrast can be improved using the Image $\mathrm{J}$ software:

- Go to Image/Adjust/ Brightness/Contrast and progressively increase the contrast.

Moreover, Image $\mathbf{J}$ enables to reduce the background by intensifying the threshold size:

- Go to Analyze, Analyze particles and gradually increase the "Size (pixel`2)" value until background noise is completed eliminated.

\section{Basic Protocol 13}

Chondrocyte isolation must be performed in sterile conditions to avoid contamination, which may affect the cells. Moreover, yield and or cell viability may occasionally vary during the procedure. Different parameters can be adjusted to obtain a higher number of viable cells.

Incubation time:

- If the tissue is not fully digested, the incubation time may be increased. By contrast, if the tissue is fully digested but the cells are damaged, incubation time can be reduced to preserve cell viability.

Enzyme concentration:

- If the tissue is not fully digested, increase the enzyme concentration. If the enzyme is overly active and impairs cell viability, its concentration can be reduced. Another way to decrease the enzymatic activity is to add an exogenous source of protein (bovine serum al- bumin $0.1 \%$ to $0.5 \% \mathrm{w} / \mathrm{v}$, fetal calf serum $1 \%$ to $10 \% \mathrm{v} / \mathrm{v}$ ).

When Cre/lox-P strategy is used, recombination efficiency is another critical parameter that needs to be appropriately modulated to reach a sufficient number of transfected cells.

To improve recombination efficiency, the MOI can be adjusted. If cell viability is impaired due to a too high MOI but recombination efficiency is low, a repeated infection procedure at low MOI can be implemented. The goal is to expose the cell to a sustained infection with a viral load of lower intensity:

- Briefly, on a 3-day period, repeat daily the infection step using a MOI of 100.

\section{Anticipated Results}

All the techniques described in this article have been optimized and standardized for the evaluation of mouse fetal growth plate. Thus, we can predict the outcome of the assays performed on mouse embryos in physiological conditions. In particular, whole mount Alizarin Red/Alcian Blue staining is supposed to show the presence of both mineralized matrix and cartilage during fetal bone development. In addition, we expect to detect the presence of GAGs by Safranin O staining throughout the proliferative and columnar layer of the growth plate. Moreover, common mRNA markers of proliferative (i.e., Col2a1 and aggrecan) and hypertrophic (i.e. Col10a1 and SPP1) chondrocytes should be clearly identifiable by in situ hybridization. We expect to detect BrdU or EdU positive cells in the proliferative chondrocytes as well, while we do not expect positive signals in the hypertrophic layer. At the fetal developmental stage we do not normally notice a significant number of TUNEL-positive cells within the growth plate, except for a few cells at the border with the primary spongiosa, but we usually detect cell death in the perichondrium, which therefore represents a good positive internal control. Moreover, consistent with the presence of an inner hypoxic region (Schipani et al., 2001), we should detect positive EF5 staining in the inner portion of the fetal growth plate, particularly in proximity of the articular surface and in the pre-hypertrophic region.

\section{Time Considerations}

The preparation and analysis of the samples for an exhaustive study on the fetal growth plate may require up to 1 month. Some initial steps of the process, such as fixation and processing, are standardized and completed within 4 days. By contrast, dissection and
Mouse Growth Plate Development 
embedding timing depends on the expertise of the operator and may therefore take between few minutes to one hour.

Timing required to complete the different stainings described in this article varies between few hours and few weeks. In particular, whole mount Alizarin Red/Alcian Blue staining and in situ hybridization are the most time consuming techniques as they may take up to 2 or 4 weeks depending on the age of the specimens and on the mRNA species to be detected, respectively. H\&E, Safranin O and TUNEL assays on the other hand can be completed within $2 \mathrm{hr}$. An immunohistochemical analysis may require between $5 \mathrm{hr}$ and 2 days depending on the immunostaining to be performed (see Basic Protocol 8 for details). Some of the techniques presented in this Review (BrdU, EdU and EF5 assays) require an in vivo labeling step of generally 3 to $4 \mathrm{hr}$ (time may vary depending on the age of the embryos). Detection of signal on the BrdU and EdU assay is calculated between 5 to $7 \mathrm{hr}$ and $1 \mathrm{hr}$, respectively. EdU assay has therefore a considerable advantage on the BrdU assay. PCNA staining is generally performed in 4 to $6 \mathrm{hr}$. Preparation of the $10 \mathrm{mM}$ EF5 stock solution is the most time consuming step of the EF5 assay as the dissolution of the powder may require up to 4 to $6 \mathrm{hr}$. EF5 detection is then performed in 3 to $4 \mathrm{hr}$. Image analysis and signal quantification are also standardized procedures that should not take more than 10 to $15 \mathrm{~min}$ for each image. Lastly, mouse chondrocyte isolation can be performed in approximately $6 \mathrm{hr}$; however, timing may significantly vary depending on the expertise of the operator and on the number of samples.

\section{Acknowledgments}

This work was supported by the NIH RO1 AR065403 grant (to Ernestina Schipani). Christophe Merceron received funding from the People Programme (Marie Curie Actions) of the European Union's Seventh Framework Programme (FP7/2007-2013) registered under the Research Executive Agency grant agreement no300388.

\section{Conflict of Interest}

The authors have declared no conflicts of interest for this article.

\section{Literature Cited}

Aigner, T. and Stove, J. 2003. Collagensmajor component of the physiological cartilage matrix, major target of cartilage degeneration, major tool in cartilage repair.
Adv. Drug Deliv. Rev. 55:1569-1593. doi: 10.1016/j.addr.2003.08.009.

Amarilio, R., Viukov, S.V., Sharir, A., EshkarOren, I., Johnson, R.S., and Zelzer, E. 2007. HIF1alpha regulation of Sox9 is necessary to maintain differentiation of hypoxic prechondrogenic cells during early skeletogenesis. Development 134:3917-3928. doi: 10.1242/dev.008441.

Anton, M. and Graham, F. L. 1995. Site-specific recombination mediated by an adenovirus vector expressing the Cre recombinase protein: a molecular switch for control of gene expression. J. Virol. 69:4600-4606.

Aro, E., Khatri, R., Gerard-O'Riley, R., Mangiavini, L., Myllyharju, J., and Schipani, E. 2012. Hypoxia-inducible factor-1 (HIF-1) but not HIF-2 is essential for hypoxic induction of collagen prolyl 4-hydroxylases in primary newborn mouse epiphyseal growth plate chondrocytes. J. Biol. Chem. 287:37134-37144. doi: 10.1074/jbc.M112.352872.

Bogen, S.A., Vani, K., and Sompuram, S.R. 2009. Molecular mechanisms of antigen retrieval: Antigen retrieval reverses steric interference caused by formalin-induced crosslinks. Biotech. Histochem. 84:207-215. doi: 10.3109/10520290903039078.

Böhmer, F. 1865. Anatomie der Meningitis cerebromedularis epidemica. Aerztl Intelligenzb. 12:539-550.

Coico, R. 2005. Gram staining. Curr. Protoc. Microbiol. 00:3C:A.3C.1-A.3C.2. doi: 10.1002/9780471729259.mca03cs00.

Coons, A.H. and Kaplan, M.H. 1950. Localization of antigen in tissue cells; improvements in a method for the detection of antigen by means of fluorescent antibody. J. Exp. Med. 91:1-13. doi: 10.1084/jem.91.1.1.

Coons, A.H., Creech, C.H., and Jones, R.N. 1941. Immunological properties of an antibody containing a fluorescent group. Proc. Soc. Exp. Biol. Med. 47:200-202.

Coons, A.H., Leduc, E.H., and Connolly, J.M. 1955. Studies on antibody production. I. A method for the histochemical demonstration of specific antibody and its application to a study of the hyperimmune rabbit. J. Exp. Med. 102:49-60. doi: $10.1084 /$ jem.102.1.49.

Esko, J.D., Kimata, K., and Lindahl, U. 2009. Proteoglycans and sulfated glycosaminoglycans. In Essentials of Glycobiology, 2nd ed. (A. Varki, R.D. Cummings, J.D. Esko, H.H. Freeze, P. Stanley, C.R. Bertozzi, G.W. Hart, and M.E. Etzler, eds.) Cold Spring Harbor Laboratory Press, Cold Spring Harbor, New York.

Evans, S.M., Hahn, S.M., Magarelli, D.P., and Koch, C.J. 2001. Hypoxic heterogeneity in human tumors: EF5 binding, vasculature, necrosis, and proliferation. Am. J. Clin. Oncol. 24:467-472. doi: 10.1097/00000421-200110000-00011.

Fischer, E. 1876. Eosin als tinctionsmittel für mikroskopische präparate. Archiv für mikrosk. Anat. 12:349-352. doi: 10.1007/BF02933896. 
Gall, J.G. and Pardue, M.L. 1969. Formation and detection of RNA-DNA hybrid molecules in cytological preparations. Proc. Natl. Acad. Sci. U.S.A. 63:378-383. doi: 10.1073/pnas.63.2.378.

Gavrieli, Y., Sherman, Y., and Ben-Sasson, S.A. 1992. Identification of programmed cell death in situ via specific labeling of nuclear DNA fragmentation. J. Cell Biol. 119:493-501. doi: 10.1083/jcb.119.3.493.

Gratzner, H.G. 1982. Monoclonal antibody to 5-bromo- and 5-iododeoxyuridine: A new reagent for detection of DNA replication. Science 218:474-475. doi: 10.1126/science. 7123245 .

Gross, A.J. and Sizer, I.W. 1959. The oxidation of tyramine, tyrosine, and related compounds by peroxidase. J. Biol. Chem. 234:16111614.

Guesdon, J.L., Ternynck, T., and Avrameas, S. 1979. The uses of avidin-biotin interaction in immunoenzymatic techniques. J Histochem Cytochem. 27:1131-1139. doi: 10.1177/27.8.90074.

Hamilton, D.L. and Abremski, K. 1984. Sitespecific recombination by the bacteriophage P1 lox-Cre system. Cre-mediated synapsis of two lox sites. J. Mol. Biol. 178:481-486. doi: 10.1016/0022-2836(84)90154-2.

Heinegard, D. 2009. Proteoglycans and morefrom molecules to biology. Int. J. Exp. Pathol. 90:575-586. doi: 10.1111/j.1365-2613.2009. 00695.x.

Horobin, R. 2010. How do dyes impart color to different components of the tissues? In Educational guide special stains H\&E, 2nd ed. Carpinteria, Calif.

Horsman, M.R., Mortensen, L.S., Petersen, J.B., Busk, M., and Overgaard, J. 2012. Imaging hypoxia to improve radiotherapy outcome. Nat. Rev. Clini. Oncol. 9:674-687. doi: 10.1038/nrclinonc.2012.171.

Hughes, W.L., Bond, V.P., Brecher, G., Cronkite, E.P., Painter, R.B., Quastler, H., and Sherman, F.G. 1958. Cellular Proliferation in the Mouse as Revealed by Autoradiography with Tritiated Thymidine. Proc. Natl. Acad. Sci. U.S.A. 44:476-483. doi: 10.1073/pnas.44.5.476.

Jegalian, B.G. and De Robertis, E.M. 1992. Homeotic transformations in the mouse induced by overexpression of a human Hox3.3 transgene. Cell 71:901-910. doi: 10.1016/0092-8674(92)90387-R.

Karsenty, G. 2003. The complexities of skeletal biology. Nature 423:316-318. doi: 10.1038/nature01654.

Karsenty, G. and Ferron, M. 2012. The contribution of bone to whole-organism physiology. Nature 481:314-320. doi: 10.1038/nature10763.

Kizaka-Kondoh, S. and Konse-Nagasawa, H. 2009. Significance of nitroimidazole compounds and hypoxia-inducible factor-1 for imaging tumor hypoxia. Cancer Sci. 100:1366-1373. doi: 10.1111/j.1349-7006.2009.01195.x.
Koch, C.J. 2002. Measurement of absolute oxygen levels in cells and tissues using oxygen sensors and 2-nitroimidazole EF5. Methods Enzymol. 352:3-31. doi: 10.1016/S0076-6879(02) 52003-6.

Kronenberg, H.M. 2003. Developmental regulation of the growth plate. Nature 423:332-336. doi: 10.1038 /nature01657.

Levdik, T.I. 1989. Unification of the staining of histological preparations and histoautoradiograms with Harris hematoxylin. Arkh. Patol. 51:8182.

Loo, D.T. and Rillema, J.R. 1998. Measurement of cell death. In Methods in Cell Biol., vol. 57 (J. P. a. B. Mather, D., ed.) pp. 251-254. Academic Press, San Diego, Calif.

Maes, C., Carmeliet, G., and Schipani, E. 2012b. Hypoxia-driven pathways in bone development, regeneration and disease. Nat. Rev. Rheumatol. 8:358-366. doi: 10.1038/nrrheum.2012.36.

Maes, C., Araldi, E., Haigh, K., Khatri, R., Van Looveren, R., Giaccia, A.J., Haigh, J.J., Carmeliet, G., and Schipani, E. 2012a. VEGFindependent cell-autonomous functions of HIF1alpha regulating oxygen consumption in fetal cartilage are critical for chondrocyte survival. J. Bone Miner. Res. 27:596-609. doi: 10.1002/jbmr.1487.

Mangiavini, L., Merceron, C., Araldi, E., Khatri, R., Gerard-O'Riley, R., Wilson, T.L., Rankin, E.B., Giaccia, A.J., and Schipani, E. 2014. Loss of VHL in mesenchymal progenitors of the limb bud alters multiple steps of endochondral bone development. Dev. Biol. 393:124-136. doi: 10.1016/j.ydbio.2014.06.013.

McLeod, M.J. 1980. Differential staining of cartilage and bone in whole mouse fetuses by alcian blue and alizarin red S. Teratology 22:299-301. doi: 10.1002/tera.1420220306.

Michigami, T. 2013. Regulatory mechanisms for the development of growth plate cartilage. Cell. Mol. Life Sci. 70:4213-4221. doi: 10.1007/s00018-013-1346-9.

Moldovan, G.L., Pfander, B., and Jentsch, S. 2007. PCNA, the maestro of the replication fork. Cell 129:665-679. doi: 10.1016/j.cell.2007.05.003.

Mouse Genome Sequencing, 2002. Initial sequencing and comparative analysis of the mouse genome. Nature 420:520-562. doi: 10.1038/nature01262.

Nagy, A. 2000. Cre recombinase: The universal reagent for genome tailoring. Genesis 26:99109. doi: 10.1002/(SICI)1526-968X(200002) 26:2\%3c99::AID-GENE1\%3e3.0.CO;2-B.

Nguyen, D. and $\mathrm{Xu}, \mathrm{T}$. 2008. The expanding role of mouse genetics for understanding human biology and disease. Dis. Model. Mech. 1:56-66. doi: $10.1242 / \mathrm{dmm} .000232$.

Pfander, D., Kobayashi, T., Knight, M.C., Zelzer, E., Chan, D.A., Olsen, B.R., Giaccia, A.J., Johnson, R.S., Haase, V.H., and Schipani, E. 2004. Deletion of Vhlh in chondrocytes reduces cell proliferation and increases matrix deposition
Mouse Growth Plate Development 
during growth plate development. Development 131:2497-2508. doi: 10.1242/dev.01138.

Piret, S.E. and Thakker, R.V. 2011. Mouse models for inherited endocrine and metabolic disorders. J. Endocrinol. 211:211-230. doi: 10.1530/JOE-11-0193.

Polak, J.M. and Van Noorden, S. 2003. Introduction to Immunocytochemistry. Bios Scientific Publishers Ltd, Oxford, UK.

Provot, S. and Schipani, E. 2007. Fetal growth plate: A developmental model of cellular adaptation to hypoxia. Ann. N. Y. Acad. Sci. 1117:26-39. doi: 10.1196/annals.1402.076.

Provot, S., Zinyk, D., Gunes, Y., Kathri, R., Le, Q., Kronenberg, H.M., Johnson, R.S., Longaker, M.T., Giaccia, A.J., and Schipani, E. 2007. Hif1alpha regulates differentiation of limb bud mesenchyme and joint development. J. Cell Biol. 177:451-464. doi: 10.1083/jcb.200612023.

Ramos-Vara, J.A. and Miller, M.A. 2014. When tissue antigens and antibodies get along: Revisiting the technical aspects of immunohistochemistrythe red, brown, and blue technique. Vet. Pathol. 51:42-87. doi: 10.1177/0300985813505879.

Salic, A. and Mitchison, T.J. 2008. A chemical method for fast and sensitive detection of DNA synthesis in vivo. Proc. Natl. Acad. Sci. U.S.A. 105:2415-2420. doi: 10.1073/pnas.0712168105.

Schenk, E. 1981. Notes on Technic: Note from the Biological Stain Commission a Newly Certified Dye-Alcian Blue 8GX. Biotech Histochem 56:129-131. doi: 10.3109/10520298109067298.

Schipani, E., Ryan, H.E., Didrickson, S., Kobayashi, T., Knight, M., and Johnson, R.S. 2001. Hypoxia in cartilage: HIF-1alpha is essential for chondrocyte growth arrest and survival. Genes Dev. 15:2865-2876.

Schipani, E. 2002. Conditional gene inactivation using cre recombinase. Calcif Tissue Int. Aug;71(2):100-102. Review.

Schmitz, N., Laverty, S., Kraus, V.B., and Aigner, T. 2010. Basic methods in histopathology of joint tissues. Osteoarthr. Cartil. 18(Suppl 3):S113116. doi: 10.1016/j.joca.2010.05.026.
Schultze, O. 1897. Ueber herstellung und conservirung durchsicichtiger embryonen zum stadium der skeletbildung. Anat. Anz. 13: 3-5.

Taylor, C.R., Shi, S.-R., and Barr, N.J., et al. 2002. Techniques of immunohistochemistry: Principles, pitfalls, and standardization. In Diagnostic Immunohistochemistry (D. DJ, ed.) pp. 3-43. Churchill Livingstone, New York, NY.

Titford, M. 2005. The long history of hematoxylin. Biotech Histochem 80:73-78. doi: 10.1080/10520290500138372.

Wang, Y., et al. 1996. Targeted DNA recombination in vivo using an adenovirus carrying the cre recombinase gene. Proc. Natl. Acad. Sci. U. S. A. 93:3932-3936. doi: 10.1073/pnas.93.9.3932.

Wilkinson, D.G. 1995. RNA detection using non-radioactive in situ hybridization. Curr. Opin. Biotechnol. 6:20-23. doi: 10.1016/0958-1669(95)80004-2.

Wilkinson, D.G. and Nieto, M.A. 1993. Detection of messenger RNA by in situ hybridization to tissue sections and whole mounts. Methods Enzymol. 225:361-373. doi: 10.1016/0076-6879(93)25025-W.

Wissowzky, A. 1877. Ueber das eosin als reagenz auf hämoglobin und die Bildung von Blutgefässen und Blutkörperchen bei säugetier und hühnerembryonen. Archiv für mikrosk. Anat. 13:479-496.

Yu, C.C., Woods, A.L., and Levison, D.A. 1992. The assessment of cellular proliferation by immunohistochemistry: A review of currently available methods and their applications. Histochem. J. 24:121-131. doi: 10.1007/BF01047461.

Zelzer, E. and Olsen, B.R. 2003. The genetic basis for skeletal diseases. Nature 423:343-348. doi: 10.1038/nature01659.

Zelzer, E., Mamluk, R., Ferrara, N., Johnson, R.S., Schipani, E., and Olsen, B.R. 2004. VEGFA is necessary for chondrocyte survival during bone development. Development 131:21612171. doi: 10.1242/dev.01053.
Mouse Growth Plate Development 